University of Louisville

ThinkIR: The University of Louisville's Institutional Repository

$5-2013$

\title{
The relationship between early attachment and adolescent risky behaviors with changes in loneliness in a mediating role.
}

Sze Sze Tong

University of Louisville

Follow this and additional works at: https://ir.library.louisville.edu/etd

\section{Recommended Citation}

Tong, Sze Sze, "The relationship between early attachment and adolescent risky behaviors with changes in loneliness in a mediating role." (2013). Electronic Theses and Dissertations. Paper 1449.

https://doi.org/10.18297/etd/1449

This Doctoral Dissertation is brought to you for free and open access by ThinkIR: The University of Louisville's Institutional Repository. It has been accepted for inclusion in Electronic Theses and Dissertations by an authorized administrator of ThinkIR: The University of Louisville's Institutional Repository. This title appears here courtesy of the author, who has retained all other copyrights. For more information, please contact thinkir@louisville.edu. 
THE RELATIONSHIP BETWEEN EARLY ATTACHMENT AND ADOLESCENT RISKY BEHAVIORS WITH CHANGES IN LONELINESS IN A MEDIATING ROLE

\author{
By \\ Sze Sze Tong \\ B.A., Baylor University, 1996 \\ B.A., University of Texas at Austin, 1997 \\ M.A., Texas Woman’s University, 2002

\begin{abstract}
A Dissertation
Submitted to the Faculty of the

College of Education and Human Development of the University of Louisville in Partial Fulfillment of the Requirements

for the Degree of
\end{abstract}

Doctor of Philosophy

Department of Educational and Counseling Psychology

University of Louisville

Louisville, KY

May 2013 
Copyright 2013 by Sze Sze Tong

All right reserved 



\section{THE RELATIONSHIP BETWEEN EARLY ATTACHMENT AND ADOLESCENT RISKY BEHAVIORS WITH CHANGES IN LONELINESS IN A MEDIATING ROLE By \\ Sze Sze Tong \\ B.A., Baylor University, 1996 \\ B.A., University of Texas at Austin, 1997 \\ M.A., Texas Woman’s University, 2002 \\ A Dissertation Approved on}

April 12, 2013

by the following Dissertation Committee:

Patrick Hardesty, Ph.D. (Dissertation Chair)

Jeffrey C. Valentine, Ph.D.

Thomas R. Tretter, Ph.D.

Mark M. Leach, Ph.D. 


\section{DEDICATION}

This dissertation is dedicated to my family

for all the love and support that they have given me. 


\section{ACKNOWLEDGEMENTS}

I would like to thank my dissertation chair, Dr. Patrick Hardesty, and all of the committee members, Dr. Tom Tretter, Dr. Jeff Valentine, and Dr. Mark Leach, for the support and guidance through this long journey. I want to thank my parents for their endless support through my many years of education. I want to thank my husband for his patience and support even through some of the toughest times of this process. I finally want to thank my children, without whom I may not have found reason to continue with the process. They are truly the light in my life that brightens even the darkest days. 


\begin{abstract}
THE RELATIONSHIP BETWEEN EARLY ATTACHMENT AND ADOLESCENT RISKY BEHAVIORS WITH CHANGES IN LONELINESS IN A MEDIATING ROLE Sze Sze Tong
\end{abstract}

April 12, 2013

The premise that attachment in the early stages of development is influential on future development has been extensively researched. Though research denotes that attachment in early development does influence behavioral outcomes in later stages of development, the path of influence is an indirect one, often involving more temporally proximal mediating variables (i.e. mediating variables that occur in the time between the assessment of attachment in the early stages and the measurement of behavioral outcome variables in the later stages of development). Previous research in this area has identified various mediating variables: relationship variables, individual child characteristics, environmental variables, and behavioral constructs. Of these constructs, internalizing behaviors is not as extensively researched. Also, these mediating variables are generally measured at one time point between the predictor variable and the outcome variable which does not adequately represent the dynamic nature of these constructs. This dissertation extends current research by examining the impact of temporal changes in an often neglected construct within the umbrella of internalizing behaviors, childhood loneliness, on the relationship between attachment in the early stages of development and risk behaviors in the later stages of adolescence. 
This study used data of 825 participants who participated in three of the four phases of data collection for NICHD Study of Early Child Care and Youth Development that occurred from 1991 to 2007. Data were collected from the child/adolescent in the lab using questionnaires on loneliness (during three different time points of data collection) and risky behaviors (at age 15) and behavioral observations for attachment (at 36 months) as well as the demographic variable of child/adolescent gender. Latent growth curve modeling and structural equation modeling were used to examine the proposed model illustrating the hypothesized relationships. Results from this dissertation indicated that a good model fit for the overall structural model; however, upon closer examination, the relationships between early attachment and loneliness as well as early attachment and adolescent risk behaviors produced nonsignificant path coefficients. The significant relationship within the structural model was between changes in loneliness throughout childhood and adolescent risk behaviors. This significance indicates that participants who reported experiencing greater loneliness through childhood would also report higher levels of engagement in risky behaviors in adolescence with observed gender effects for engagement in risky behaviors (i.e. males were more likely to engage in externalizing risk behaviors). The dissertation concludes with implications of the findings and study limitations. 
TABLE OF CONTENTS

PAGE

ACKNOWLEDGMENTS............................................................

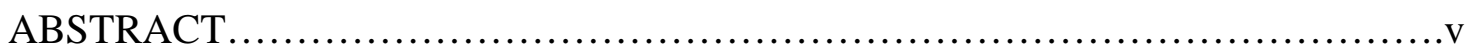

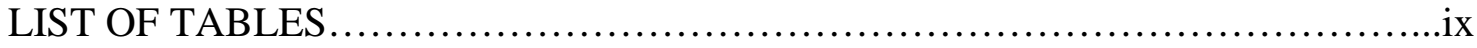

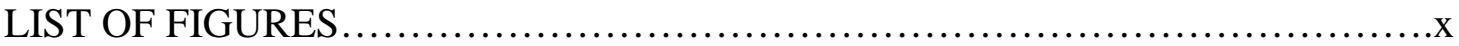

CHAPTER ONE: INTRODUCTION.........................................

Development and Attachment..............................................

Early Attachment and Maladaptive Outcomes................................5

Risky Behaviors as an Outcome Variable..................................

Progression of Loneliness as a Mediating Variable............................12

Purpose of the Study and Proposed Model....................................16

CHAPTER TWO: LITERATURE REVIEW .....................................19

Introduction........................................................... 19

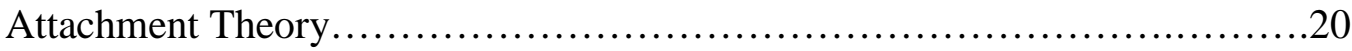

Research on Attachment and Outcomes......................................25

Adolescent Risk Behaviors..............................................32

Attachment Security and Risk Behaviors...................................36

Loneliness................................................................. 48

Integration of Research for the Proposed Model...............................59

Research Questions and Hypotheses.......................................60 
CHAPTER THREE: METHODOLOGY .......................................62

NICHD SECCYD Longitudinal Data Set................................62

Participants........................................................64

Data Collection......................................................65

Measures..........................................................66

Data Analyses...................................................73

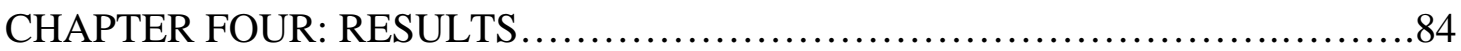

Descriptive Analyses................................................84

Model Development...............................................86

Implications for Hypotheses.......................................92

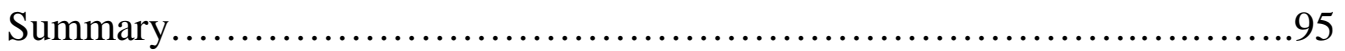

CHAPTER FIVE: DISCUSSION AND CONCLUSIONS........................97

Introduction..................................................97

Implications of the Results and Suggestions for Future Research.............97

Limitations of the Study......................................... 104

REFERENCES......................................................... 107

TABLES............................................................. 138

FIGURES ............................................................. 152

CURRICULUM VITAE ..................................................... 165 


\section{LIST OF TABLES}

TABLE

PAGE

1. Item Parceling Summary for Risky Behavior Indicators in CFA Model.

2. Descriptive Statistics of Variables for Participants.

3. Correlations of Observed Variables

4. Number of Estimated Parameters for Each Model

5. Sample Sizes, Means, and Standard Deviations for Group with Complete Data and Group with Missing Data

6. Data Analysis for Effects of Attrition: Comparison of Group with Complete

Data and Group with Missing Data

7. Means, Variances, and Covariance for LGC Model of Loneliness without Gender.

8. Means, Variances, and Covariance for LGC Model of Loneliness with Gender.

9. Modification Indices for Initial CFA Model for Risky Behavior.

10. Standardized and Unstandardized Coefficients for CFA Model of Risky Behaviors without Gender.

11. Standardized and Unstandardized Coefficients for CFA Model of Risky Behaviors with Gender.

12. Standardized and Unstandardized Coefficients for the Structural Paths of the Full Model without the Covariate Gender.

13. Standardized and Unstandardized Coefficients for the Structural Paths of the Full Model with the Covariate Gender.

14. Fit Indices for Models 


\section{LIST OF FIGURES}

FIGURES

PAGE

1. Proposed Structural Model.

152

2. Hypothesized Latent Growth Curve (LGC) Model for Loneliness over Three Time Points.............................................................

3. Hypothesized Confirmatory Factor Analysis (CFA) Measurement Model for Adolescent Risky Behavior

4. Hypothesized Full Structural Model.........................................155

5. CFA Measurement Model for Adolescent Risky Behavior with Gender as TimeInvariant Covariate...................................................156

6. LGC Model with Child Gender as a Time-Invariant Covariate................157

7. Full Model with Gender as a Time-Invariant Covariate.......................158

8. LGC Model of Loneliness with Means, Variances, and Covariance.............159

9. LGC Model of Loneliness with Gender as a Covariate and Factor Loadings, Means, Variances, and Covariance...........................................160

10. Final CFA Measurement Model of Risky Behavior with Factor Loadings and Error Covariances between E5-E8 and E6-E8 Freely Estimated...............161

11. CFA Model of Risky Behavior with Gender as a Covariate and Factor Loadings, Variances, and Covariances.....................................162

12. Full Model with Factor Loadings, Means, Variances, and Covariances.........163

13. Full Model with Gender as a Covariate and Factor Loadings, Variances and Error Covariances........................................................ 164 


\section{CHAPTER ONE}

\section{INTRODUCTION}

The impact of early development on outcomes in later developmental stages has been extensively studied in developmental research topics. The research includes a

diverse range of predictor, mediating, moderating, and outcome variables. The purpose of this dissertation is to further contribute to this body of literature by examining the impact of early attachment styles on later behavioral outcomes (i.e. risky behaviors) through an affect-based mediating variable, childhood loneliness. This chapter will briefly review each variable of interest, beginning with significance of the construct of attachment on developmental theory. The chapter will then discuss the link between attachment styles to maladaptive outcomes. The focus shifts to the outcome variable, risky behaviors in adolescence and then to the mediating variable, changes in loneliness over time. The chapter will conclude with a statement of the specific purpose of the research and the proposed model to be examined.

\section{Development and Attachment}

Development is a series of transitions through which one progresses over the course of life. Oftentimes, the course of development is influenced by what has happened in the past in conjunction with what is currently happening. For many years, researchers in psychology have been attempting to answer the questions related to the impact of the early years of development as an individual matures through childhood, adolescence, and 
adulthood (see Fraley, 2002). Some of the questions that have been posed are: what are the factors in development that continue to impact development at a later period? What factors are associated with the development of risk behaviors or maladaptive outcomes? What are the protective factors that lead to more adaptive outcomes? What are the intervening variables? If they are present, what variables mediate? What variables moderate? The research is rich in diversity as it relates to the variables chosen (e.g. attachment, temperament, parent-related variables, and environment). The research also reflects contrasts in findings. However, the unifying premise in the research, regardless of the outcome, is that the early stages of development are influential to future development, providing the foundation on which one's life is built, influencing the developmental trajectory of the individual. Therefore, especially with differing outcomes in research indicating the need for further clarity on this topic, it is important that the connection between the early and later stages of development continue to be explored, particularly as it relates to informing intervention and prevention efforts for maladaptive, unhealthy, and/or life threatening outcomes.

Multiple psychological theories have posited their perspectives on the connections between early and later years of development. From psychoanalysis to social learning, the mechanisms of influence of early development on later years have been a focus of theoretical and empirical interest. Attachment theory was formed from this foundation of interest and is an integration of aspects of psychoanalysis and learning theory with ethology to account for behaviors that start in infancy and continue to exert influence through the later years in life (Ainsworth, 1969). 
Attachment refers to a bond or a "pattern of organized behavior" (Sroufe, Carlson, Levy, \& Egeland, 1999, p. 1) between one person and another specific individual within a relationship. In the context of developmental research, attachment is initially based on assessments of the nature of parent-child relationships within families. Attachment behavior is viewed to be any behavior that allows the person to maintain accessibility to the attachment object. Within the context of the parent-child relationship, the accessibility of the attachment object determines the level of security of the emotional bond within the relationship for the infant or child. According to Bowlby (1969) and Ainsworth (1969), these bonds have the potential for continuity, which has implications for later development. The bonds within primary relationships reflect either healthy attachment behaviors or disturbed attachment behaviors depending on the circumstances.

The classification of attachment behaviors was further developed by Mary Ainsworth and colleagues (Ainsworth, Blehar, Waters, \& Wall, 1978), who described secure and insecure attachment strategies specifically within the mother-infant relationships. The description of the attachment behaviors within a classification system further stimulated research, giving structure to general behaviors within parent-child relationships. Attachment theory and classifications offer researchers ways to examine questions regarding "some of the most compelling, longstanding issues of developmental psychology” (Thompson, 2000, p. 145) as it relates to early socioemotional and personality development.

With the introduction of attachment theory, research was provided with an integrative framework that combined psychological and biological perspectives of development. Much of the initial research into the link between early attachment and 
later development focused on direct “input-output designs” (Belsky \& Pasco Fearon, 2002a, p. 364) that do not consider the potential impact of concurrent or subsequent mediator and/or moderator variables that may occur during development (e.g. Fagot \& Kavanaugh, 1990; Lewis, Feiring, McGuffog, \& Jaskir, 1984).

According to Sroufe, Egeland, Carlson, and Collins (2005a), those interested in understanding how development works need to remember that "Development is not linear; it is characterized by both continuity and change” (p.11). From the perspective of attachment theory, Bowlby (1969) asserted that the continuity of attachment is stable through one's life span; however, given certain contextual factors, the internal working models related to attachment are responsive to change. This is in accord with the perspective that development is a complicated exchange between the individual and environmental contexts (Belsky \& Pasco Fearon, 2002a; Greenberg, Speltz, \& DeKlyen, 1993; Lamb, Thompson, Gardner, \& Charnov, 1986; Raikes \& Thompson, 2008; Sroufe, 2005; Sroufe, Egeland, \& Kreutzer, 1990; Sroufe, et al., 1999; Sroufe et al., 2005a; Sroufe, Egeland, Carlson, \& Collins, 2005b). Some of the current research responds to this potential to changes in developmental pathways by focusing on proximal and distal variables that are temporally concurrent for the individual and environment leading to outcomes related to pro-social behaviors (Turner, 1991), social competence (Cohn, 1990), and social problem solving (Raikes \& Thompson, 2008). This shift to focusing on more temporally concurrent outcomes may seem contrary to the assertion that early development is influential in later developmental outcomes. However, research acknowledging that these changes in developmental trajectory do not automatically negate the impact of early development is also present in the literature (Sroufe, 2005; 
Sroufe, et al., 1990; Sroufe, et al., 2005a, 2005b); it is the path of influence that has potentially changed (Belsky \& Pasco Fearon, 2002a, 2002b; Sroufe, 2005).

For research to truly capture an understanding of development, the field as a whole needs to go beyond sole focus of demonstrating either the direct causal links between early experience and later development or causal links between concurrent experience with current and later development. Movement in the field to build knowledge about the intricacies of the various paths showing how early experiences continue to influence development as well as accounting for the impact of concurrent situations that occur throughout development is necessary (Bowlby, 1980; Sroufe et al., 1999; Sroufe et al., 2005a, 2005b).

\section{Early Attachment and Maladaptive Outcomes}

One of the pathways examined through research has been the relationship between early experiences and risky, pathological behaviors later in development. Bowlby (1969) hypothesized that disruption during the formation of attachment bonds is often a primary reason for the development of psychopathology. The overall research that has investigated this general hypothesis has presented with mixed results. On the one hand, there is a significant amount of research that shows that early attachment is a variable with significant influence on maladaptive development. Research has shown that attachment insecurity assessed at infancy is linked with behavior problems in later childhood (Erickson, Sroufe, \& Egeland, 1985; Greenberg et al., 1993; Greenberg, Speltz, DeKylen, \& Jones, 2001; Lewis et al., 1984; Sroufe et al., 1990; Sroufe et al., 1999). Lewis et al. (1984) found support that infant attachment leads to later psychopathology at the age of 6 for males. In a meta-analysis, Fraley (2002) examined 
this central tenet of attachment stability by testing mathematical models for attachment theory. His findings indicate that early attachment behaviors remain relatively stable throughout one's lifespan which has implications for the relationship between early attachment and developmental outcomes, particularly for outcomes that occur in later developmental stages. Warren, Huston, Egeland, and Sroufe (1997) revealed that anxious attachment determined during infancy was a significant predictor of psychopathology in later teen years over other variables measured in infancy (e.g. temperament, maternal anxiety). According to Sroufe et al. (1999), the general literature suggests that the experiences of adolescence, particularly as it relates to the development of self, tap into early attachment experiences in a unique and influential way. These research findings support that early development does have an influence on outcomes that occur in the later years of development.

However, as is often present in research, there have been studies that indicate that infant attachment is not a good predictor for certain at risk behaviors. Fagot and Kavanaugh (1990) found that infant attachment was not a strong predictor for externalizing behaviors, recommending caution in using infant attachment as the sole predictor for identification and intervention of problem behaviors. In a review of multiple studies, Friedman and Boyle (2008) reported modest findings with fairly small effect sizes for the direct relationship between early attachment and later developmental outcomes. With regard to attachment continuity, attachment stability from infancy to young adulthood was not observed in samples of high risk individuals (Van Ryzin, Carlson, \& Sroufe, 2011; Weinfield, Sroufe, \& Egeland, 2000). On the basis of similar findings, a trend developed in which early experiences were seemingly dismissed as a 
potential variable with significant influence on later development (Clarke \& Clarke, 1976), with the focus shifting to examining the impact of temporally concurrent attachment with a variety of variables (Lewis, Feiring, \& Rosenthal, 2000).

Others have opted for a more integrated approach with studies that reflects the contributions of both early and concurrent contexts on overall development, normal and pathological (Belsky \& Pasco Fearon, 2002a; Robins, 1991). In keeping with this integration, support for a multifactor model in identifying developmental pathways is being explored in the research (Belsky \& Pasco Fearon, 2002a; Carlson, Sroufe, \& Egeland, 2004; Greenberg et al., 1993; McElwain, Wu, \& Booth-LaForce, 2011; Stupica, Sherman, \& Cassidy, 2011). According to Sroufe et al. (1999), the importance of early experiences and the later context cannot be ignored, particularly as it relates to the development of psychopathology. According to Bowlby (1969) and as summarized by Sroufe et al. (1999), psychopathology results from a collection of factors and continued progression down a pathological path, taking an individual further away from a healthier path. Individual experiences of these different factors such as having negative life events occur during infancy (see Greenberg et al., 1993) or following infancy (see Waters, Merrick, Treboux, Crowell, and Albersheim, 2000) leading to attachment insecurity contribute to vulnerability or increased risk for the development of psychopathology in children and adolescents such as indiscriminant sexual behavior, alcohol/drug use, and delinquency to cope during times of distress (Cooper, Shaver, \& Collins, 1998) as well as demonstrating unhealthy internalizing or externalizing behaviors (see Marsh, McFarland, Allen, McElhaney, and Land, 2003). In contrast, attachment security has shown an impact as a protective factor, buffering the impact of high-risk contexts, to foster 
continued healthy development (Dallaire \& Weinraub, 2007; Sroufe, et al., 1990).

Overall, attachment security is an important contributor to the overall development of an individual; however, attachment security/insecurity alone is not sufficient to determine the course of development. Other contextual factors also need to be considered, particularly in the development of psychopathology in later stages of life (Friedman \& Boyle, 2008; Rutter \& Sroufe, 2000).

When addressing maladaptive outcomes, research still needs to continue efforts in constructing the developmental pathways from infancy to middle childhood to adolescence (see Robins, 1991). However, even with continued efforts in this area, much of the current research offers only an incomplete picture of the development of problem behaviors because variables are examined starting with middle to late childhood, without accounting for the impact of early childhood and infant development. As a result, understanding of both normal and pathological pathways is incomplete and unrefined which has significant implications for the development of effective early intervention or prevention efforts.

Healthy and pathological development involves multiple possible pathways with variations in context; as a result, the link between early experiences and later development is not generally a direct path. In studies that considered early and concurrent contextual variables, the support for an indirect path of influence of early attachment on variables measured in later stages of development has been supported through use of models (see Carlson et al.,2004) and path analysis (see Wood, Emmerson, \& Cowan, 2004). It is vitally important for future research to account for various concurrent contextual variables in combination with early experiences when evaluating the course of 
healthy and pathological relational, emotional, and individual development (Steinberg \& Avenevoli, 2000; Thompson, 2008a).

\section{Risky Behaviors as an Outcome Variable}

Risky behaviors can be broadly defined as behaviors that lead to increased risk of a harmful outcome. However, not all risk behaviors are maladaptive. Throughout development, we are constantly taking adaptive risks. If certain risks are not taken, then development is stunted. For example, infants are exhibiting risky behavior when they learn to walk. With children entering school for the first time, an adaptive risky behavior relates to social risks, making new friends and developing their peer social support system. Continuing through adolescence into adulthood, adaptive risks encompass social, emotional, and educational activities (e.g. choice of friends, applying to college, dating, and choice of occupation). Given that risky behaviors have an adaptive component, the question that research has attempted to answer is when does adaptive risk taking become maladaptive and harmful?

Because maladaptive risk behaviors often do lead to harmful outcomes, it is important for research to address the developmental sequelae that lead to these maladaptive behaviors to inform and advance treatment and prevention efforts. With respect to youth, early maladaptive risky behaviors often lead to poor prognosis (Sroufe, 1997). According to Sroufe, the pathway to psychopathology is "repeated failure of adaptation" to "normative developmental issues" (p.253). Sroufe maintains that those who continue with repeated deviations from healthy adaptation have an increased chance of developing further problems. For individuals who have been on the maladaptive path across multiple developmental phases, the likelihood of successful redirection to an 
adaptive direction of development is lowered. This highlights the importance of increasing the understanding of the development of risky, maladaptive behaviors throughout the life span for the purposes of effective prevention and intervention. Research reflects the importance for the need to understand given the increased interest in reporting the effectiveness of prevention efforts in decreasing risk behaviors, particularly in youth through early intervention (e.g. Hooven, Herting, \& Snedker, 2010; Massey, Boroughs, \& Armstrong, 2007; Pollard \& Austin, 1990; Soper, Wolchik, Tein, \& Sandler, 2010; Zapata, et al., 2004). If one can understand the antecedents that contribute to the development of risky behaviors in children and adolescents as well as the protective factors that contribute to healthier outcomes, then treatment/prevention efforts can be more targeted and effective in achieving the goal of lowering the prevalence of risky behaviors of youth (see Hawkins, Catalano, \& Arthur, 2002).

Developmentally, adolescence is a time in which engagement in general risk behaviors is expected. Experimentation is not a shocking development given that this developmental transition period is primarily focused on an emerging sense of identity. The question in which developmental researchers are interested is when does engagement in risk behaviors go beyond typical experimentation into the realm of pathological involvement? What factors contribute to the likelihood of increased and/or continued engagement in risk behaviors? In the efforts to address these questions, researchers have focused on ways to categorize the behaviors (Ackerson, 1942; Hewitt \& Jenkins, 1946; Achenbach \& Edelbrook, 1978), construct developmental pathways to specific psychopathology (Loeber, et al., 1993; Zahn--Wexler, Klimes-Dougan, \& Slattery, 2000) 
or maladaptive outcomes (Jessor, 1991), and determine the continuity of certain behaviors (Greenberg, et al., 1993; Loeber, 1982).

The research that has focused on identifying the factors related to increased risk behavior engagement for adolescents have identified multiple factors: exposure through mass media (e.g. radio, television, print media, internet, video games; Escobar-Chaves \& Anderson, 2008; Klein et al., 1993), insecure early attachment (Fraley, 2002; Sroufe et al., 1999), genetic predisposition (Rose, 1998), negative peer influence (Gardner \& Steinberg, 2005), externalizing behaviors (Caminis, Henrich, Ruchkin, Schwab-Stone, \& Martin, 2007; Schofield, Bierman, Heinrichs, Nix, \& Conduct Problems Prevention Research Group, 2008; Thompson, et al., 2011), and various affective variables such as loneliness, depression, and anxiety (Askénazy, et al., 2003; Guertin, Lloyd-Richardson, Spirito, Donaldson, \& Coergers, 2001; Lezine, 2006; Mijuskovic, 1988). This brief list is by no means an exhaustive summary of the factors that research has potentially identified. The two factors that are of interest for this proposed study are early attachment styles and perceived loneliness.

According to Thompson (2008b), early attachment is connected to outcomes in later stages of development; however, the 'how' of that connection continues to be explored in the most current of attachment research (e.g. Belsky, Houts, \& Pasco Fearon, 2010; Booth-LaForce \& Oxford, 2008; McElwain, et al., 2011; Pasco Fearon \& Belsky, 2011; Stupica, et al., 2011). What seems to be the consensus of much of the research looking specifically at the relationship between early insecure attachment and maladaptive outcomes is that there are mediating variables to consider (Greenberg et al., 1993; Sroufe et al., 2005a, 2005b; Thompson, 2008a). Thompson (2008b) and DeKlyen 
and Greenberg (2008) reviewed several potential mediating variables that have been investigated in the research such as parent-child relationship variables following infancy, peer relationship variables, child characteristics/variables, and family ecosystemic variables. When considering affective variables as potential mediators of early attachment and later risk behaviors, research seems to have been focused on the continuum of internalizing and externalizing behaviors. Externalizing behaviors such as aggression, anger, and defiance have shown remarkable stability in the relationship with the development of risk behaviors (Galéra, Bouvard, Encrenaz, Messiah, \& Frombonne, 2008; Loeber, 1990; Thompson et al., 2011) and psychopathology (Loeber 1990). Internalizing behaviors related to emotions such as sadness, worry, and fear have not been as strongly researched. According to Zahn-Waxler et al. (2000), developmental research is lacking such that the stability of internalizing problems related to depression and anxiety in children and adolescents are not well known. Subsequently, when looking at a specific affective variable which is considered to be subsumed under the umbrella of internalizing emotions, loneliness as a potential mediating variable between early attachment and later risk behaviors has not been well studied. One line of focus for research on loneliness in childhood and adolescence has been towards establishing loneliness as a potential risk factor for risk behaviors, predominantly in adolescence (e.g. Rokach \& Orzeck, 2003; Shapiro, Siegel, Scovill, \& Hays, 1998).

\section{Progression of Loneliness as a Mediating Variable}

As a construct, loneliness has various definitions. According to Weiss (1973), loneliness has various descriptions: "gnawing rather than ennobling, a chronic distress without redeeming features," "unwanted individuation: being separated off," equating it 
to depression and grief reactions, or as something more than a simple "desire for company” (pp. 13-15). According to Peplau and Perlman (1982), loneliness is characterized by poor or lacking social relationships, viewed as a subjective experience, and experienced as painful and unwanted. Weiss also offers that "ordinary loneliness," though distressing, is qualitatively different than loneliness associated with clinical disorders and more commonly experienced than documented. This type of loneliness is more than just the absence of a relationship, but the absence of something considered to be meaningful in relationships (Weiss). Individuals can be surrounded by people with whom they interact regularly and still report feeling lonely. Reports of perceived loneliness tap into an internal experience of self in relation to others that may not always be readily observed. According to Weiss, loneliness is often characterized by a desire to seek what is missing as a remedy to the distress.

Loneliness is an often under-appreciated construct in the world of psychological research that has been well researched with adults (see Bogaerts, Vanheule, \& Desmet, 2006; Larose, Guay, \& Boivin, 2002; Levin \& Stokes, 1986) and somewhat researched with adolescents (see Lasgaard, Goossens, Bramsen, Trillingsgaard, \& Elklit, 2011; Wiseman, Mayseless, \& Sharabany, 2006; Witvliet, Brendgen, van Lier, Koot, \& Vitaro, 2010). With loneliness in children, the research is not as extensive. Previous research on children's experience of loneliness was typically based on reports by third parties (i.e. teachers, parents, and other adult observers). It was believed at one point that developmentally, children did not have the capacity to report on loneliness which research did not support (Asher, Hymel \& Renshaw, 1984). The initial development of 
the Loneliness and Social Dissatisfaction Questionnaire (Asher et al., 1984) allowed a way to measure children's internal experience of loneliness and social isolation.

The experience of loneliness does vary. Some may experience feelings of loneliness transiently. However, others may experience feelings of loneliness as a pervasive presence in their lives; whereas, others may initially experience low levels of loneliness that increase in intensity over time. This progressive experience of loneliness has relational implications that can carry forward into future interactions. According to Weiss (1973), loneliness is a response to the absence of a "close, indeed intimate, attachment” (p. 17). For an infant in which the development of an intimate relationship with the primary caregiver at an early stage led to insecurity, this internal working model of relationships is carried forward in the child's perspective of social interactions with others (Bowlby, 1980). Research studies show that insecure attachment assessed in early development leads to loneliness in later childhood (Berlin, Cassidy, \& Belsky, 1995; Raikes \& Thompson, 2008). Retrospective assessments of early attachment (see Hecht \& Baum, 1984) and current attachment (Goossens, Marcoen, van Hees, \& van de Woestijne, 1998; Larose et al., 2002; Wiseman et al., 2006) are related to self-reported experiences of loneliness. According to Rubin, Hymel, Mills, and Rose-Krasnor (1991), children who are insecure may withdraw, fail to develop necessary social skills to engage with peers effectively, and continue to be isolated from peers, falling into a vicious cycle. Although the authors did not discuss loneliness explicitly, they do implicate internal (e.g. internal working model, attribution style, attitude) as well as external processes (e.g. peer rejection, deficient social networks) that would support the development, maintenance, 
and escalation of loneliness as has been explored in loneliness research with adults (Levin \& Stokes, 1986; Marangoni \& Ickes, 1989).

Loneliness is a common symptom experienced throughout development with peak intensity during adolescence, a major developmental transition period (Brennan, 1982; Rubenstein \& Shaver, 1982). Moore and Schultz (1983) described lonely adolescents as being in a "social limbo" (p.100) that is characterized by "emptiness, isolation, and boredom” (p. 100). This emotional and social experience leads to increased risk for psychopathology and maladaptive outcomes. With respect to psychopathology, studies have indicated that symptoms of depression also increase sharply during adolescence (Birmaher, et al., 1996; Hankin, et al., 1998). Oftentimes, adolescents with symptoms of depression such as loneliness, that have proven stable through adolescence (Orvaschel, Lewinsohn, \& Seely, 1995), are at risk for more serious psychopathology such as major depressive disorder later in development (Pine, Cohen, Cohen, \& Brook, 1999). With younger children, research has shown that children who report high rates of loneliness are more inclined to be viewed as less prosocial, more aggressive, and more disruptive by others (Cassidy \& Asher, 1992). In adolescence, research has demonstrated that loneliness during this period of life has been linked to increasing vulnerability to various risk behaviors (e.g. self-mutilating behaviors, see Guertin et al., 2001; sexual behavior in adolescent females, see Mendez, Hulsey, \& Archer, 2001; alcohol use, see Mijuskovic, 1988; alcohol use in adolescent females, see Page \& Cole, 1991). Overall, the research on loneliness, particularly the progression of loneliness into adolescence, would indicate that it is an influential variable that merits further study. 


\section{Purpose of the Study and Proposed Model}

Given the research discussed previously, there seems to be a continued need to understand the connections between early stages of development to outcomes at later developmental stages. The direct path between early attachment and later risk behaviors is not particularly strong given the conflicting research findings as previously discussed (Erickson et al., 1985; Fraley, 2002; Friedman \& Boyle, 2008; Greenberg et al., 1993; Greenberg, et al., 2001; Weinfield, et al., 2000). However, developmental studies that do not consider the influence of early development would be in opposition to the basic definition of development. As various developmental theories posit (e.g. Bowlby’s attachment theory, Erickson's stages of psychosocial development, Piaget's stages of cognitive development, Bronfenbrenner's ecological systems theory), the stages of development are interconnected, generally where previous stages exert influence on subsequent stages. How the influence is exerted is where the theories tend to differ. Overall, the research supports that the relationship between early development and outcomes in later years are often influenced by variables that intercede following the early years. This perspective is supported by a growing trend in more current developmental research of exploring the influence of mediating and/or moderating variables as researchers continue to explore the 'how' of developmental outcomes.

The proposed model of this study will continue to explore the 'how' of developmental outcomes through examination of the mediating effect of progressive changes in perceived loneliness in the stages of development between early attachment and adolescent risk behaviors. Baron and Kenny (1986) defined four characteristics of mediation models: 1) a significant relationship is demonstrated between the predictor and 
outcome variables, 2) a relationship between predictor and mediator variables is established, 3) the mediator variable exerts an effect on the outcome variable, and 4) the remaining effect between the predictor and outcome variables is noted. The research indicates that the early attachment (predictor variable) and adolescent risk behaviors (outcome variable) are significantly associated. There is also support in the literature to confirm the relationship between early insecure attachment and loneliness in later stages of childhood into adolescence. In addition, the literature notes that the effect of loneliness in childhood and adolescence generally increases the potential risk of engaging in various risk behaviors. Given the framework of mediation established by Baron and Kenny, perceived loneliness could be a potential mediating variable for the relationship between early attachment and adolescent risk behaviors. Testing a model in which loneliness is a mediator of the effects of early insecure attachment on adolescent risk behaviors has not yet been examined. Given the risks that are associated with the presence of perceived loneliness, this seems to represent a possible missing link in the quest to understand potential precursors to adolescent risk behaviors.

Loneliness is not experienced as a static construct. When the element of time is considered, loneliness can wax and wane depending on different variables that are internal (e.g. perception of self in relation to others) and external (e.g. social network) to the individual. As a result, the proposed model of this study is not just to look at mediating effects of loneliness measured at one specific time, but to look at the mediating effects of both the initial level of perceived loneliness when it is first measured and the growth of perceived loneliness over a specified period of time, through growth curve analysis. In summary, the proposed model for this study will examine the connection 
between early attachment as measured as a toddler and risk behaviors in adolescence as mediated by initial levels of perceived loneliness and changes in levels of perceived loneliness experienced through middle childhood into adolescence.

The variables for this model will be collected from existing data set of longitudinally collected data. The National Institute of Child Health \& Human Development (NICHD) Study of Early Child Care and Youth Development (SECCYD) collected data on diverse variables over a period of approximately 16 years on a fairly large sample of children and families. With respect to size and variables, the NICHD SECCYD data set is ideal for the hypotheses, this particular model, and proposed analyses. The analysis of the hypotheses will undergo model fit testing using structural equation modeling (SEM) and latent growth curve (LGC) modeling using the framework of SEM. The proposed model is illustrated in Figure 1. 


\section{CHAPTER TWO}

\section{LITERATURE REVIEW}

\section{Introduction}

The purpose of this study is to examine the connection between early attachment as measured as a toddler and risk behaviors in adolescence as mediated by initial levels of perceived loneliness and changes in levels of perceived loneliness experienced through middle childhood into adolescence. This chapter will review the relevant research related to this purpose through discussion of attachment, risk behaviors, and loneliness as independent and related constructs.

The chapter will begin with a brief review of literature related to attachment theory leading to a discussion of the research supporting the relationship between early attachment security and outcomes in later developmental stages with an emphasis on mediating contextual variables. The focus of the discussion will narrow to a discussion of adolescent risk behaviors as the outcome variable and the mediating variables associated in the relationship between early attachment security and adolescent risk behaviors. A review of the research on loneliness, with a focus on the relationships between loneliness and attachment as well as loneliness and adolescent risk behaviors, will follow. The chapter will conclude with an integration of the research in support of the proposed model. 


\section{Attachment Theory}

Many psychological theories have defined and refined understanding of the influence of early development on psychological functioning in later years. From psychoanalytic theory, Freud and other analysts (e.g. Anna Freud, Melanie Klein, Karen Horney, and Erik Erickson) that followed him emphasized early experiences on development through psychosexual stages, instinct, and structural concepts such as the developing ego and superego that are integral in personality formation. Erikson elaborates from psychoanalytic theory as posited by Freud using stages that emphasized psychosexual development as well as cultural and social factors (Miller, 2002). Erikson’s stage model theorized that individuals would build upon previous stages as they progressed in their own development where the previous stage would impact the subsequent stage (Miller, 2002). Object relations theory also emphasized early experiences as central to later development beginning with infancy, focusing on internalizations of good and bad objects that served as representations of various fundamental relationships (Ainsworth, 1969; Miller, 2002).

Social learning theorists (e.g. Bandura) included both behavioral and cognitive components when discussing behavioral development. Modern social learning theory encompassed not only ideas about the behavior of individual learning but also the social context of learning (Miller, 2002). Within the context of learning, particularly with respect to behaviors that start in infancy and early childhood, theorists posited the importance of observational learning, conditioning, and reinforcement in the development of behaviors (Miller, 2002). 
The bioecological model of development integrated individual genetic components with the social and cultural components that influence overall human development. The model posits that the development of an individual is best understood through interactions of that individual with his/her surrounding context or environment, or proximal processes (Bronfenbrenner, 1979; Bronfenbrenner \& Ceci, 1994; Miller, 2002). Bronfenbrenner has continued to modify the specific model of human development and respective processes (for brief summary see Bronfenbrenner \& Evans, 2000). The model illustrates the interactions between individual biology and the surrounding context through various levels of environmental subsystems (i.e. microsystem, mesosystem, exosystem, and macrosystem). This theory brought forward the idea that human development is not an isolated process by placing a measure of importance on the impact of environment and the reciprocal interactive processes with individuals in context.

Ethology, a discipline traditionally anchored in biological sciences, has influenced perspectives on behavioral development. The most notable contributor to this discipline was a zoologist and one of the founding fathers of modern ethology, Konrad Lorenz. His behavioral observations involving baby geese and imprinting in animals (Lorenz, 1970) was related to instinctual behaviors in the relationship between mother and child in humans (Bowlby, 1969). Ethological perspective emphasizes the importance of evolution and biology by connecting the presence of innate reflexes in animals that are designed to enhance survival of the individual and the species (Miller, 2002). This biological emphasis on the instinctual nature of bonding behaviors appealed to psychoanalytic 
perspectives of behavioral instinct, particularly in early development, with the most notable connection to John Bowlby and attachment theory.

Attachment theory was influenced by ethology; however, as attachment theory was developed, instinct was not as highly emphasized as with traditional psychoanalysis. Attachment theory takes the perspective that development starts with “a class of event...[with] attempts thence to trace the psychological and psychopathological processes that commonly result” (Bowlby, 1969, p. 4). According to Ainsworth (1969), attachment theory was developed to maintain “...the many psychoanalytic contributions to understanding human experience and behavior...” (p. 25) but alter the aspects of an outdated emphasis on instinct to reflect a perspective that is better suited to present-day emphasis on empiricism.

Developed by Bowlby in his seminal trilogy (1969, 1972, 1980), attachment theory has played a crucial role in the research of the development of emotional bonds within relationships. Bowlby (1969) believed the foundations of an individual's ability to establish emotional bonds were initiated by the infant-caregiver bond. The nature of this bond in the early years of human development has the potential to impact the formation of future bonds in other relationships. According to Bowlby (1969), these bonds are formed as a result of a collection of behaviors that is organized by the infant based on experiences in multiple contexts with the primary caregiver. Attachment behaviors are viewed to be any behavior that allows the person to maintain accessibility to the attachment object. Within the context of the parent-child relationship, the accessibility and response of the attachment object determines the level of security in the relationship for the infant or child as well as the attachment behaviors exhibited by the infant or child. 
Attachment behaviors are most notably observed during periods of emotional arousal. It is during these periods of heightened emotion that establishes the patterns of attachment behaviors with the caregiver as well as in relationships outside of the primary caregiver. When a secure base is established, the infant is more likely to explore the unfamiliar and to adapt effectively to changes, reflecting secure attachment behaviors. When insecure attachment behavior patterns are established, the infant is less likely to be effective with exploration and adaptation.

In his development of attachment theory, Bowlby (1969) developed the key concept of internal working models that are important in understanding how attachment behavior patterns extend beyond the infant-caregiver relationship. For example, in a study that looked at friendship development over time, current patterns of interacting with peers was a reflection of early attachment security (Shulman, Elicker, \& Sroufe, 1994). Internal working models are internalized representations of experiences with the world and others, particularly experiences with significant caregivers; these internalized models of the self in relation to the world influence the ways that the infant and/or child engage with their environment (Bowlby, 1969). The internal working models initiated during infancy are dynamic, potentially influenced by environmental and emotional contexts (Bretherton \& Munholland, 2008). They are "working” models that develop along with the individual (Bowlby, 1969). These models influence the individual's perception of self and others and what to expect within relationships based on the initial infant-caregiver relationship (Bowlby, 1969). Internal working models help guide the child in determining what to expect from interpersonal situations; how the child will behave in a given situation, how the child expects others to behave, and how those 
expectations interface with each other (Bowlby, 1969). According to Carlson and Sroufe (1995), attachment organization through the formation of internal working models "regulates the processing of emotional information and provides direction in interpersonal relationships” (p. 598).

Ainsworth et al. (1978) further developed attachment theory through research that led to the development of a way to measure attachment, the Strange Situation. The Strange Situation is a series of separation and reunification episodes between caregiver and infant in which attachment behaviors are observed and classified accordingly (Ainsworth et al.). Through the development of the measure, the authors identified three attachment classifications that described secure and insecure attachment behaviors within the parent-child dyad, with a particular focus on mother-infant relationships. In general, attachment behaviors reflect the infant's balance between proximity seeking of the secure base and exploration of the unfamiliar. Secure infants actively seek the attachment figure but are also able to explore once the secure base is established. Avoidant or anxiousavoidant infants exhibit minimal demonstrated distress at separation from the attachment figure and lack proximity seeking behaviors. Upon entering early childhood, children with avoidant attachment histories are frequently hostile and aggressive or distancing with peers resulting in a cycle of rejection and social isolation that can carry forward into middle childhood and adolescence (Carlson \& Sroufe, 1995). Ambivalent or anxiousresistant infants demonstrate persistent proximity seeking behaviors for the attachment figure; however, once reunited with the attachment figure, the infant displays angry resistance. These infants carry into childhood difficulties in sustaining appropriate boundaries in close relationships which can lead to either having no friends or many 
superficial friendships through middle childhood and adolescence. The fourth classification was developed later by Main and Solomon (1990) for the infants that exhibited insecure attachment strategies but did not fit into either the avoidant or ambivalent classifications. Disorganized infants express inconsistent behaviors related to the attachment figure. According to Main and Solomon, these infants display various responses in the Strange Situation (Ainsworth et al.) that are bizarre and disoriented. Oftentimes, the attachment figure is the source of desired closeness for the purpose of security but is also a source of fear such as in the case of child abuse (Main \& Hesse, 1990). In these instances, the authors maintain that the caregiver behavior initiating a fear response interferes with the development of an organized attachment strategy. These categories offered researchers a way to organize the distinctive differences in attachment behaviors.

\section{Research on Attachment and Outcomes}

The initial research on attachment focused on refinement of measurement and classification, which continues within the current literature. However, another line of research emerged, focusing on the impact of attachment on temporally proximal and distal outcomes. Research has shown that at the time that early attachment is formed, behavioral and representational processes influenced by internal working models are developing the most rapidly (Raikes \& Thompson, 2008). These internal working models are carried forward, influencing formations of emotional bonds in current and future relationships. Attachment behaviors formed during early childhood do influence outcomes at various developmental stages (Bowlby, 1969). It is important to keep in mind that insecure attachment is not viewed as psychopathology itself; however, it does 
lay a foundation for pathways leading to vulnerability for further maladaptation (Sroufe, et al., 1999). These possible maladaptive outcomes have behavioral and socio-emotional implications in accordance to the principles of attachment theory.

Behavioral outcomes. Research on early attachment and behavioral outcomes is abundant, generally with a focus on attachment insecurity that are associated with problem behaviors as the child develops. In research that examines the relationship between specific types of attachment with behavioral outcomes, findings generally support the development of problem behaviors that potentially lead to clinically significant psychopathology. For example, Warren et al. (1997) presented support that an ambivalent or anxious-resistant infant attachment style was predictive of later child and adolescent anxiety disorders after accounting for other variables that have been shown to be predictive of the development of anxiety disorders. Carlson (1998) found that disorganized attachment assessed at infancy was predictive of behavioral problems throughout childhood and adolescence as well as psychopathology assessed at age 17 related to conduct and dissociation. Munson, McMahon, and Spieker (2001) reported that infants with avoidant and disorganized attachment histories are at greater risk for externalizing behavior problems at the age of 9. Overall, specific attachment styles assessed in early development does show association with problematic behaviors that could lead to psychopathology at later developmental stages.

In studies that examined insecure attachment as opposed to the specific types, research also indicates association with difficulties in later stages of development. Dallaire and Weinraub (2005) studied the relationship between early attachment security and later separation anxiety in school-aged children. The authors found that insecurity 
during infancy did predict higher levels of separation anxiety for school-aged children even when accounting for subsequent maternal sensitivity and maternal levels of separation anxiety. Campbell, Shaw, and Gilliom (2000) reviewed several studies focused on the developmental progression of risk for behavior problems from early development to psychopathology in later childhood. In their review of the studies, the authors indicated that early parent-child relationships have lasting influences on the developmental trajectory of the individual child. The emergence of certain problem behaviors early in development related to poor interpersonal relationships with caregivers can lead to significant psychopathology such as attention deficit hyperactivity disorder (ADHD), conduct disorder (CD), and oppositional defiant disorder (ODD). Erickson et al. (1985) studied the relationship between early attachment and behavior problems in a high risk sample of preschool children in which insecure attachment was associated with less effective problem solving and greater problem behaviors such as acting out, attention issues, and social withdrawal. Overall, the results of currently existing attachment research would indicate that insecure attachment results in increased risk for poor behavioral outcomes.

Social development implications. Research on early attachment and social development implications is also important, especially when considering the principle of attachment theory regarding relationship formation. Attachment security relates to the ability to explore surroundings, socially and emotionally, promoting adaptability to novel circumstances, greater sense of competence, and autonomous functioning (Erickson et al., 1985). For example, Sroufe et al. (2005b) reported that attachment security is related to friendship competence in middle childhood, with other significant links to peer 
functioning at various ages from preschool to adolescence. Shulman et al. (1994) also asserted that attachment security from infancy is significantly related to social competence in preadolescents, with those who were securely attached having more effective social skills when compared to children with insecure attachment histories. Matas, Arend, and Sroufe (1978) also reported that attachment security is related to social competence in later stages of development when they found a relationship between infant attachment and competence in play and problem solving at age 2. The authors also discussed that social competence with peers is the ability to demonstrate flexibility which is supported through attachment security. Secure attachment leads to the ability to separate from the secure base caregiver while also being able to return to the secure base for assistance without over-reliance on that person to address different social situations, encouraging healthy social skills development. Cohn (1990) found the early attachment is associated with social competence in school aged boys, reporting that insecurity was associated with higher levels of aggression and greater incidents of behavior problems. Waters, Wippman, and Sroufe (1979) reported a significant relationship between infant attachment security and later social competence. Toddlers who were securely attached as infants demonstrated social competence with peers when assessed at age $31 \frac{122}{2}$. According to the authors, the "ability to generate and coordinate flexible adaptive responses to demands and to generate and capitalize on opportunities for interaction and learning” (p. 828) is important in social development. In examining structural models, Bost, Vaughn, Washington, Cielinski, and Bradbard (1998) reported that attachment security does contribute to the development of social competence with peers. According to Masten and Curtis (2000), lower levels of social competence can be linked to psychopathology in 
children (i.e. depression, externalizing behaviors, and conduct problems). For example, Bosquet and Egeland (2006) reported that insecure attachment leads to a poor sense of competence in childhood and preadolescence which leads to the development of anxiety symptoms in adolescence. Social development, particularly as it relates to social competence, is influenced by early attachment security.

Overall outcomes to later stages of development. The research for behavioral outcomes and social development implications does support the need to continue examining the relationship of early attachment to various outcome variables. Current research reflects the continued pursuit in understanding the implications of early development on outcomes at later developmental stages. The general trend in the research as it continues to grow reflect that contextual variables that occur subsequent to attachment security assessment as an infant and/or toddler can be highly influential and play a mediating or moderating role in the relationship between early attachment and later outcomes. For example, in examining the relationship between early attachment security and adolescent social competence, Weinfield, Ogawa, and Sroufe (1997) found that secure attachment did not predict social competence as expected without consideration of other intervening contextual variables such as the presence of high interest and knowledge of social relationships. The authors reported that when this intervening variable was examined, those with insecure attachment histories were considered to be socially competent by others. Booth-LaForce and Oxford (2008) found that attachment security assessed at 24 months was strongly related to parental sensitivity which was strongly related to social withdrawal trajectories. Using a cross-lagged structural model, Carlson et al. (2004) showed that the influence of early attachment on 
adolescent social functioning is indirect through various developmental periods in which relationship and behavioral factors were considered. Longitudinal data were used to study the direct and indirect impact of infant attachment to adolescent social functioning and relationship expectations. Given the structural model that was developed, the impact of early experience is present but generally indirect, with influence from more proximally temporal variables as well as the concurrent context of the individual as it related to social functioning being significant (Carlson et al.). Wood et al. (2004) explored the continuity of early attachment through path analysis, revealing significance in an indirect path of influence of early attachment on peer social status through externalizing behaviors. Cassidy, Kirsh, Scolton, and Parke (1996) looked at attachment security and peer-related representations as a reflection of peer relationships, in which representations mediated the relationship between attachment security and subsequent peer relationships. Dallaire and Weinraub (2005) found that the effect of insecure infant attachment and childhood separation anxiety is moderated by maternal sensitivity subsequent to infant attachment classification (i.e. insecurely attached infants who experience separation anxiety as a child will be more anxious if mother sensitivity levels are low following infant attachment classification). Erickson et al. (1985) reported that changes in parental sensitivity subsequent to infant attachment formation can result in later developmental outcomes, particularly problem behaviors, which are not expected given the attachment classification established in early development due to intervening contextual variables. Sroufe, et al. (1990) found that environmental context can change or fade out previously established attachment styles. Belsky and Pasco Fearon (2002a) also found that changes in environmental context throughout development can influence later outcomes such that 
the outcomes are counter to what would have been predicted by the determined early attachment style. Other researchers have also found that infant attachment is susceptible to change when difficult life events are experienced later in development (Waters, et al., 2000; Weinfield, et al., 2000). These research findings support the need for the field to continue examination of mediating variables to build understanding of the developmental sequence involving early and later stages of development.

Overall, developmental research of attachment agrees that infant-mother attachment in the early years of development forms the foundation upon which other aspects of the developing individual are built (Sroufe, et al., 1999; Sroufe, 2005; Sroufe, et al., 2005a, 2005b). Although mediating models may seem contrary to attachment theory, this growth of research towards mediating models is in actually in accordance with the original hypothesis developed by Bowlby $(1973,1980)$ that emphasized the importance of both early experiences or history and current contextual variables throughout development on attachment behaviors. On the whole, early experience is multifunctional and never lost (Sroufe et al., 1990; Sroufe, 2005), with the relationship between early experiences and later development following a more indirect pattern (Belsky \& Pasco Fearon, 2002a, 2002b; Sroufe, 2005). Models that reflect patterns formed from early experiences may be reactivated during times of stress (Bowlby, 1973, 1980), indicating that these patterns do not disappear but are possibly incorporated into the working models (Sroufe, et al., 1990). Even when early attachment is no longer a direct predictor of a specified outcome, it does provide information and context that enriches overall findings (Sroufe, et al., 2005a, 2005b). 
In accordance with a mediation model of early attachment and later outcomes that is of interest in this particular study, various experiences, both external and internal, can lead to various risk behaviors at later stages of development such as adolescence.

\section{Adolescent Risk Behaviors}

Risk behaviors are often operationalized differently with respect to the particular behaviors of interest as well as the specific developmental stage of interest. In research focused on early childhood, risk behaviors are generally defined within the context of aggressive and disruptive behaviors. As the individual progresses through adolescence, these aggressive and disruptive risk behaviors can also be carried through development. However, the qualitative and quantitative nature of risk behaviors can also change with the overlay of developmental variables (i.e. as children mature, the specific types of risky behaviors in which they are engaged can also change). In early childhood, risk behaviors are often defined as physical aggression, noncompliance (e.g. skipping school, destroying property), cheating, lying, and stealing (Achenbach \& Edelbrock, 1978; Ackerson, 1942;

Greenberg, et al., 1993; Hewitt \& Jenkins, 1946; Schofield, et al., 2008). With adolescence, childhood risk behaviors may continue with the addition of or possibly evolution into substance use (CDC, 2010; Klein, et al., 1993), promiscuous and unsafe sexual behaviors (Klein et al., 1993; Mendez, et al., 2001), suicide attempts (CDC, 2010), poor nutritional practices (CDC, 2010), gang affiliation (Pollard \& Austin, 1990), having carried a weapon (CDC, 2010), and transportation risks (e.g. speeding excessively, driving while intoxicated, traveling with an intoxicated driver; see CDC, 2010; Shapiro et al., 1998). 
Oftentimes, research targets specific risk behavior with the results being more focused on the outcomes of engagement in risk behaviors for different age groups such as antisocial behaviors (adolescents - Aguilar, Sroufe, Egeland, \& Carlson, 2000; early childhood - Fagot \& Kavanagh, 1990), conduct problems in preschoolers (Greenberg, et al., 2001), substance use in adolescents (Parker \& Benson, 2004; Shapiro, et al., 1998), and poor social competence (Cohn, 1990; Dykas, Ziv, \& Cassidy, 2008; LaFreniere \& Sroufe, 1985; Pastor, 1981; Weinfield, et al., 1997). Other research has approached operationalizing risk behavior outcomes more generally such as disruptive behaviors (Egeland, Kalkoske, Gottesman, \& Erickson, 1990; Erickson, et al., 1985; Greenberg, et al., 1993; Waters, Posada, Crowell, \& Lay, 1993) or psychopathology meeting diagnostic criteria (Carlson \& Sroufe, 1995; DeKlyen \& Greenberg, 2008; Egeland, Pianta, \& Ogawa, 1996; Greenberg, et al., 1993; Lewis, et al., 1984; Sroufe, 1997). These differences in definitions and target outcomes highlight the broad scope that is activated when examining engagement in risk behaviors with the underlying common premise that increased engagement can lead to problematic outcomes.

Adolescence is a developmental period that is often associated with some measure of risk taking that leads to risk behaviors. In a monograph focused on examining the research available about unhealthy risk taking by adolescents, Reyna and Farley (2006) summarized findings related to decision making leading to risk taking during adolescence. According to the authors, the overall research indicates that children and adolescents are less able to delay gratification, inhibit behaviors, learn from negative outcomes, and consider consequences for chosen action. Reyna and Farley also indicate that adolescents have difficulty in adequately gauging harmful consequences for risk 
behaviors, expressing an optimistic bias that they are at less risk than others for the consequences of certain risk behaviors. With these factors in place, adolescence is a period in which the likelihood for escalation of risk behaviors substantially increases. During this period of development, youth are also more often influenced by peers, leading to greater instances of taking risks (Gardner \& Steinberg, 2005). In addition, Gardner and Steinberg reported that youth are more likely to focus on the potential benefits as opposed to the possible costs of risk behaviors leading to an increased likelihood of engagement in risk behaviors. When in the presence of peers, engagement in risk behaviors can increase even further. Peer socialization in adolescence is "fraught with tension, ambiguity, and strain” (Allen, Porter, McFarland, Marsh, \& McElhaney, 2005, p. 747). Even popularity among peers, once thought to be a reflection of healthy social adaptation, is a potential risk factor for engaging in risk behaviors during adolescence (Allen, Porter, et al.). As youth enter adolescence, they experience a number of transitions that include physical changes, both internal (i.e. puberty) and external (i.e. school environment changes). Youth also encounter a number of more subtle changes related to various cognitive shifts (i.e. future orientation, greater autonomy, abstract thinking, and preference for peer groups). Navigation through these multiple transitions within a transitional period is challenging for all, but particularly for those who struggled emotionally and behaviorally during earlier stages of development. The questions posed by many developmental researchers are related to determining who engages in a typical level of risk from those who engage in a maladaptive level of risk during adolescence. One prominent area of research is to examine the possible factors that contribute to the likelihood of increased and/or continued engagement in risk behaviors. 
Research has identified different trajectories for the development of risk behavior engagement of adolescents. One trajectory is the onset of engagement in risk behaviors starting during adolescence. Another trajectory involves an earlier onset such that the risk behaviors observed in adolescence are a continuation or culmination of behaviors observed at earlier stages of development. An earlier onset of risk behaviors increases the chances of experiencing lasting harmful consequences associated with extended engagement of risk behaviors (Thompson, et al., 2011). In looking specifically at early childhood factors that are predictive of adolescent risk behaviors, Thompson et al. found that children who demonstrated moderate and increasing levels of externalizing behavior problems are at risk for violent and delinquent behaviors in adolescence. Schofield et al. (2008) developed a structural model that indicates that early behavior problems upon school entry leads to increased problem behaviors in middle school which promotes early engagement in sexual activity in early adolescence. Caminis et al. (2007) conducted a longitudinal study over 2 years with incoming sixth grade students. The authors indicate that prior externalizing problems such as violent behaviors and substance use are a strong predictor of engagement in sexual risk in early adolescence. Research further indicates that those who report earlier engagement in sexual behaviors are at greater risk for engaging in a continued pattern of risky sexual behaviors such as irregular use of contraceptives, multiple partners, and engaging in sex when intoxicated or high (O’Donnell, O’Donnell, \& Stueve, 2001). These behaviors fostered from childhood through adolescence can be continued through adulthood, with implications for the general overall functioning as adults. O'Donnell et al. (2001) indicate that adolescents who continue to engage in risky sexual behaviors put themselves at further risk for 
adverse outcomes such as unplanned pregnancy and sexually transmitted diseases which have implications for functioning into adulthood. Clark, Lynch, Donovan, and Block (2001) found that adolescents with alcohol use disorders are at higher risk for clinical levels of liver injury (with indications of subclinical liver injury already present) and other physical and psychological health problems. For example, the authors noted that symptoms of depression and anxiety that are more often reported in the form of somatic complaints are significantly associated with adolescents who are in treatment for alcohol use disorders. Research also indicates that poor health outcomes that start in adolescence as a result of substance abuse or dependence can continue into adulthood (Mertens, Flisher, Fleming, \& Weisner, 2007). Georgiades and Boyle (2007) reported that data from a longitudinal health study resulted in findings that tobacco and cannabis use starting in adolescence does persist into adulthood with links to poorer functioning in areas such as physical health, emotional well-being, personal income/SES, and education. Given these possible and lasting outcomes for adolescents engaging in risk behaviors, the importance of continued examination of possible precursors to risk behaviors, particularly those in the early stages of development, is highlighted.

\section{Attachment Security and Risk Behaviors}

Attachment insecurity is a possible precursor to the development of risk behaviors at later stages of development. At this point, the discussion has reviewed research indicating that risk behaviors are more pervasive given an earlier onset. The discussion has also reviewed the research on the relationship between early attachment insecurity and later maladaptive outcomes. As a result, the next step in the discussion is to review the research delineating the current understanding of how attachment and risk behaviors 
are linked. The current research involves examination of outcome variables concurrent to attachment assessment and examination of outcome variables that are predicted by attachment security from the earlier stages of development. It is important for research to take both concurrent and early developmental measures into consideration when looking at predicting outcomes. Raikes and Thompson (2008) point out that any significant influence of concurrent measures does not negate the importance of early measures. The authors postulate that the significance of the influence of concurrent measures is potentially a reflection of explaining a unique aspect of the variance or a reflection of being in closer temporal proximity to the outcome of interest. Regardless of the reason, it is important for research to continue to consider early attachment in addition to mediating concurrent variables when studying developmental outcomes.

Research with concurrent measures and outcomes. Overall, the research on concurrent parent child relationships and problematic child behaviors does indicate that there is a strong relationship between the two constructs. In a report using longitudinal data, Doyle, Moretti, Brendgen, and Bukowski (2003) indicated that concurrent parent child relationships and adolescent risk behaviors (i.e. substance use, physical risks, violence against property, affiliation with deviant peers) do merit continued research. The authors of the report state that parent child relationships marked with frequent rejection, low warmth, and low support are more likely to result in maladaptive adolescent outcomes (i.e. internalizing and externalizing behaviors, psychopathology). Although Doyle et al. (2003) did not measure attachment directly, they did discuss that their findings do support the principles of attachment. In support of the findings by Doyle et al., Parker and Benson (2004) reported that lack of parental support during adolescence is 
a risk factor for the development of problem behaviors in adolescence (Parker \& Benson, 2004).

When focused specifically on attachment as a measure of the parent child relationship, concurrent assessment of insecure attachment and problematic behaviors is also fairly strong. For example, Turner (1991) reported findings that in a group of four year olds, insecure attachment leads to problem behaviors for boys who were more likely to exhibit fighting, increased aggression, and attention seeking behaviors. This is in contrast to girls in the same group of four year olds who were more likely to be engaged with peers in a more submissive, dependent, and passively compliant way. With respect to research in concurrent attachment evaluations in adolescents, studies indicate that attachment security does impact social and behavioral domains of functioning. Allen, Moore, Kuperminc, and Bell (1998) reported that attachment security assessed in adolescence seems to function as a protective factor, resulting in fewer internalizing and externalizing behaviors and increased social competence. In another example of concurrent attachment assessment in adolescence, Allen, Marsh, et al. (2002) indicated that insecure attachment, particularly preoccupied type, was a risk factor for increasing delinquent behaviors from age 16 to 18 . In summary, the research continues to highlight the importance of concurrent variables on outcomes.

\section{Research with early measures and outcomes at later stages of development.}

However, in accordance with the proposed model of this study, the research that has focused on the impact of early attachment security assessed during infancy or toddler years on behavioral outcomes at later stages of development is of primary interest. The importance of early attachment security is highlighted by Rutter (1979) who reported that 
attachment security was related to exhibition of problem behaviors. In his study, children who had at least one relationship with a parent or another caregiver (e.g. grandparent) in which the child was securely attached would exhibit fewer behavior problems. Rutter points out that attachment security can change later in life due to changing environmental circumstances; however, these changes in security may not generalize beyond the specific change to later stages of development, supporting the importance of the formation of secure attachment during the early stages of development. This highlights the importance of continued examination of the impact of early of attachment on development as will be further emphasized in the following paragraphs.

Carlson and Sroufe (1995) summarized findings that support the importance of secure early attachment as a vital protective factor to the development of later risk behaviors. In their review of the literature, Carlson and Sroufe indicate that the research links early attachment to later functioning in social relationships. The authors summarize that children who are evaluated later in development demonstrate noticeable patterns of behaviors and emotional regulation that are linked to early attachment. For example, they summarized multiple findings in which insecure toddlers were observed to be less flexible and willing to engage in effective problem solving with lower levels of autonomous functioning. They also summarized research findings for children through preschool in which attachment security was linked to emerging personality factors (i.e. emotional regulation, flexibility in novel situations, emotional responsiveness towards others, social competence, increasing levels of autonomy). The research supports the perspective that early attachment behaviors and emotions are activated to cope with stressors. With insecure attachment, the strategies are effective in controlling emotional 
conflict; however, the result is behavior that is not particularly adaptive. This leads to increased vulnerability to further risk behaviors or psychopathology.

Internalizing behaviors as outcomes. Early attachment security has been linked to the development of internalizing behaviors that have the potential to lead to the development of internalizing psychopathology (e.g. anxiety and depression). ZahnWaxler et al. (2000) conducted a review of the research related specifically to the development of internalizing problems related to symptoms of anxiety and depression. In their discussions of the relationship between attachment security and the development of internalizing problems, the authors stated that children in the early stages of development who develop insecure attachment are at higher risk of developing further internalizing problems in later stages of development. For example, Warren et al. (1997) found that children with anxious-resistant or ambivalent attachment styles were more likely to develop an anxiety disorder in adolescence. Bates, Maslin, and Frankel (1985) reported that infants who failed to seek proximity to the mother during the Strange Situation, a hallmark of insecure attachment, were found to have more anxiety problems at the age of 3. Bosquet and Egeland (2006) found that insecure infant attachment predicted negative peer relationship representations in preadolescence which then predicted anxiety symptoms in adolescence. The authors assert that insecure attachment results in maladaptive emotion regulation strategies due to internal working models of others as unreliable sources of support and comfort which generalizes beyond immediate caregivers to peer relationships, leading to increased vulnerability to anxiety symptoms into later childhood and adolescence. In examining secure attachment, Dallaire and Weinraub (2007) demonstrated with their findings that infant-mother attachment is a 
strong protective factor to the development of anxiety symptoms into first grade, even with the occurrence of negative life events following infant attachment classification. In researching the emergence of depressive symptoms, Carlson and Sroufe (1995) reported there are strong indicators defined in the research that when early caregiver relationships are disrupted impacting adaptive affect regulation then children are at greater risk for the development of depressive symptoms through adolescence (see also Shaw \& Dallos, 2005) which can lead to problematic risk behaviors. However, the current research examining the link between early development and internalizing problems and/or disorders continues to be explored.

Externalizing behaviors as outcomes. In the area of early attachment and externalizing behaviors, the research is more plentiful, probably due to how disrupting the behaviors can be in various settings. The research has examined early attachment and the onset of problem behaviors from early childhood to adolescence.

Being the most temporally proximal to attachment assessment, early childhood problem behaviors are often reported to have a strong relationship with early attachment styles. For example, Betherton and Waters (1985) asserted that insecure children do exhibit more behavior problems in preschool and insecure attachment does predict low social competency with peers. The authors asserted that the predictive link of infant attachment classification and defined problem groups in preschool is generally strong. When researching the impact of specific insecure attachment styles, research has shown that there is a difference in the specific behaviors manifested; however, the overall result is maladaptive problem behaviors. For example, Erickson et al. (1985) presented findings on three different types of problem behaviors (i.e. acting out, withdrawal, and attention 
problems) for preschool age children in which the specific problems manifested were different depending on the behavior classification. In looking at attachment security, children who were classified as avoidant were most notably different from the securely attached children. They were described as being hostile, impulsive, and noncompliant with very poor social skills. The children who were classified as ambivalent or anxiousresistant were lacking in confidence and assertiveness which has implications for social interaction with peers. This group was not as notably different from secure peers for some variables; however, they still presented with poor overall functioning. McElwain, Cox, Burchinal, and Macfie (2003) also reported that avoidant attachment resulted in more aggressive behaviors; whereas, resistant attachment resulted in a lack of assertiveness and control at the age of 3. Greenberg and Speltz (1988) indicated that preschoolers who have a history of insecure attachment are more likely to show behavioral problems than preschoolers with secure attachment histories due to "maladaptive patterns of emotional control and interpersonal communication” (p.206). In summary, researchers have found that the quality of infant attachment is a strong predictor of behavior during preschool years.

The relationship between early attachment and younger school age children also demonstrates strong relationships. In a study that examined the continuity of the influence of attachment beyond preschool years, Munson et al. (2001) reported a relationship between avoidant and disorganized attachment to externalizing behaviors where the effects of insecure attachment were noted at age four and continued further through age nine. The findings support that the influence of early attachment continues into school age years. In another example, Shaw, Owens, Vondra, Keenan, and Winslow 
(1996) linked disorganized infant attachment to later disruptive and aggressive behaviors at the age of 5. For males, Lewis et al. (1984) also found that both avoidant and ambivalent infant attachment was related to later psychopathology marked with aggressive, externalizing behaviors at the age of 6 .

Overall, the research relating early attachment and behavioral outcomes that occur at later stages of development does indicate relationships that are worth continued investigation, particularly into the middle and late childhood and adolescence. As the child ages and progresses through various stages of development, the impact of early attachment becomes less direct in light of intervening variables (Sroufe et al., 1990; Sroufe et al., 1999; Thompson, 2008a).

Overall influence of early attachment to risk behaviors. DeKlyen and Greenberg (2008) summarized research which strongly indicates the importance of attachment theory as a critical piece of the developmental puzzle that will lead to greater understanding of how early caregiving relationships can influence processes related to the later stages of development, particularly maladaptive development (see also Sroufe et al., 1990 and Sroufe et al., 1999). However, as it relates to attachment research and later risk behaviors, the research continually references the potential mediating variables in that relationship that needs to be further explored. Researchers in the area of attachment have continually advocated for the inclusion of potential mediating influences into the sequalae following early attachment (Carlson \& Sroufe, 1995; Greenberg et al., 1993; Thompson, 2008a).

In the research that examines mediating influences between early attachment and later risk behaviors, the focus seems to have been on parental variables such as maternal 
sensitivity, maternal depression, and sensitive parenting. For example, Raikes and Thompson (2008) examined outcomes of early attachment relationships related to thoughts about peers at 54 months and upon entering first grade. The authors discussed the mediating impact of concurrent parenting quality, maternal depression, and maternal sensitivity. Their findings indicate that some variables exert a stronger mediating influence in the relationship between early attachment and later outcomes than the others depending on the particular outcome variable of interest. In summary, maternal sensitivity mediated the relationship between early attachment insecurity and social problem-solving, such as the use of aggression as a response. Maternal depression mediated the relationship between early attachment insecurity and negative attribution style (i.e. perception of the intentions of others negatively) of the child. Sensitive parenting following initial attachment assessment mediated the relationship between early attachment insecurity and children's expressed thoughts and feelings about peers. With a focus on behavioral outcomes, Erickson et al. (1985) reported that the relationship between infant attachment and later behavioral outcomes was influenced by subsequent parental sensitivity. The authors reported that sensitive parenting mediated the relationship between insecure attachment and the manifestation of behavior problems in later developmental stages. As a result, children who experienced subsequent sensitive parenting following infant attachment insecurity did not manifest behavior problems later in development as would be expected. However, in the absence of the mediating factor, infant insecurity was carried forward increasing the vulnerability to future behavior problems. In a study conducted by the NICHD Early Child Care Research Network (2006), the authors focused on the mediating role of parenting sensitivity in the 
relationship between infant attachment security and later behavior outcomes. The findings reflected that subsequent parenting behavior mediated the effects of infant attachment on externalizing and internalizing behaviors. With a focus specifically on the outcome variable of externalizing behaviors, Pasco Fearon and Belsky (2011) conducted further analyses using the NICHD SECCYD data through grade 6. The authors reported that maternal sensitivity mediated the effect of infant attachment on externalizing behaviors for the avoidant attachment group. Shaw et al. (1996) found that maternal perception of the child at age 2 mediated the relationship between disorganized attachment at 12 months and aggression at age 5. Munson et al. (2001) found similar mediating effects for maternal depression on the relationship of avoidant and disorganized infant attachment and externalizing behaviors at the age of 9. For internalizing behaviors, Booth-LaForce and Oxford (2008) studied various developmental trajectories for social withdrawal from Grades 1 to 6 based on early developmental history. In the model developed by the authors, subsequent parenting sensitivity mediated the impact of attachment history on the trajectory of social withdrawal. The overall general findings support the importance for the consideration of roles of various mediating variables when examining the influence of early development to later outcome variables.

Much of the research that has been previously reviewed has focused on outcomes in preschool years and early school ages. In a longitudinal study, Sroufe et al. (2005a) summarized their findings for outcomes that extend into adolescence and adulthood. Overall, attachment styles were noted to impact social behavior patterns throughout development with a specific emphasis on the influence of subsequent experience in the 
context of this developmental history. For example, the authors described a subgroup of preschool aged children who were classified as insecurely attached as infants who did not demonstrate significant behavior problems during preschool years. It was noted that in that group, the children experienced environmental or contextual changes (i.e. mother in stable relationships, mothers more supportive of autonomy and exploration) such that the expected developmental trajectory shifted. For middle childhood, children with secure attachment histories in infancy and subsequent emotional guidance and support were noted to be more socially competent within peer groups, exhibiting self-confidence and appropriate emotional regulation (Sroufe, et al., 2005a). For adolescence, the authors further note that early developmental history was associated with adolescent risky behaviors (i.e. risky sexual behaviors, substance use, and association with deviant crowds); however, as with the other developmental stages, the development of such problem behaviors had foundations in both the past and concurrent context of an individual teen. For each developmental stage, the authors note that development is influenced and organized around both historical and concurrent circumstances, with each stage building upon the previous stages. In this broad and in-depth analysis, Sroufe et al. (2005a) illustrate the importance of considering both early antecedents of behaviors in conjunction with current context for a full developmental picture at all stages of development.

Sroufe et al. (2005b) point out that "early attachment experiences are not (and should not be) related to any and all outcomes” (p. 51). The influence of attachment on outcome variables is better viewed and presented in probabilistic terms in accordance with both Bowlby's view of attachment and current research findings (Sroufe, et al., 
2005b). In a review of the findings from Sroufe et al. (2005a), Sroufe (2005) concluded that developmental attachment research has transformed from direct predictions of later outcomes to questions about how links in the developmental process occurs. Such a shift in perspective highlights the overall complexity of developmental research. This is not to say that research related to predicting outcomes is not valuable, but that it is an initial step in understanding the more complex overview of development from cradle to grave.

Overall, efforts to study the impact of early attachment on later behaviors have strong support in the literature. In the context of developmental research, omitting early history in favor of current context would result in an incomplete picture of development. Allen, Moore, et al. (1998) assert that attachment security is reflective of the adolescent's capacity to internally organize affect and cognition around external attachment related experiences which has potentially broad applications to outcome variables reflective of functioning. Raikes and Thompson (2008) theorize that attachment relationships could be important for the development of peer related representations as young children transition into representational thought thereby increasing their level of insight into the behaviors of others. Future research needs to continue the examination of the impact of early antecedents to later behaviors, such as early attachment leading adolescent behaviors with an emphasis on the development of the roles of mediating influences.

Much of the research on potential mediating variables in the relationship between early attachment and outcomes at later stages of development has focused on variables external to the child such as maternal depression, maternal sensitivity, and parental sensitivity. Mediating variables reflecting the internal experience of the child has not been as well explored. Behavioral outcomes are a reflection of both external and internal 
influences; however, the internal influences can be more difficult to access and measure than external influences. However, internal influences are a key construct in attachment theory, reflecting an individual's internal working model (Thompson, 2008a). Individuals with an insecure attachment history often have an internal model of relationships with others as unreliable sources of support leading to an inability to form meaningful relationships. According to Weiss (1973), loneliness is a reflection of an internal experience that is generally related to the lack of meaningful relationships in an individual's life. As a result, loneliness can be a potential mediating variable in the relationship between early attachment and behavioral outcomes.

\section{Loneliness}

Rokach (2011) equated loneliness to a void that is felt when there is a discrepancy between the need to belong and degree to which that need is fulfilled. Peplau and Perlman (1982) describe loneliness as subjective and painful, resulting in relationship deficits as proposed by Weiss (1973) or due to changes in social needs that have not been met. Loneliness is commonly experienced throughout all stages of development in some form. For some individuals, the experience is fleeting and occasional. For others, the experience of loneliness is pervasive and steady. For another group, loneliness is experienced as steadily increasing, reaching levels that make it difficult to tolerate. Although the experience and complexity of loneliness varies with each individual, it is a “universal phenomenon which is fundamental to being human” (Rokach, 2004, p. 25).

Research on loneliness. As a psychological construct, loneliness has been examined more extensively in recent years, with a notable surge during the 1980s. However, the research in this area is still very much in the nascent stages of development. 
Historically, the research has been focused on loneliness in adult samples, ranging from early college years to the elderly, generally using self-perception questions (i.e. Do you often feel lonely?) in survey form or established questionnaires such as the UCLA Loneliness Scale (Russell, Peplau, \& Cutrona, 1980). With children, the research on loneliness has been less prominent, generally using reports from other sources (i.e. teachers, parents, or other adult observers) until the development of the original version of the Loneliness and Social Dissatisfaction Questionnaire (Asher et al., 1984) for older children and adolescents. For younger childhood, research with this population was even less prominent until the revision of the Loneliness and Social Dissatisfaction Questionnaire (Cassidy \& Asher, 1992) for younger age children. Having the added dimension of self-report for children is helpful into accessing their internal experience, a reflection of their internal working model of relationships. Given that childhood loneliness has predominantly been determined exclusively by observations, having the child report their internal experience is an invaluable source of information. This is particularly important given that individuals, both children and adults, may report an internal experience that is contrary to what is observed by others. This expansion of the research in this area has offered insight into the experience of loneliness across the life span.

Loneliness research with adults. Early loneliness research started with adult populations. Some of the research focused on specific transition periods of adult development. For example, Wiseman et al. (2006) studied the development of loneliness in students in their first year at a university. The authors looked at variables reflective of personality and parental relationships that would predict greater vulnerability to the 
development of loneliness, particularly during this transitional period. They reported that students who indicated higher levels of self-criticism and reports of poor relationships with parents were more likely to report higher levels of loneliness. In another study using university students, loneliness and social competence was linked in which those who reported greater levels of social competence expressed less loneliness and better adjustment socially and emotionally (DiTommaso, Brannen-McNulty, Ross, \& Burgess, 2003). Using gender as the grouping variable, Borys and Perlman (1985) reported that there may be gender differences with loneliness for adults. The authors reviewed different data sets to examine gender differences. Overall, the results seem to indicate that there are possible gender differences to consider with adults depending on the type of measure administered. When using direct questions that would self-label the individual as lonely, females tended to report higher rates of loneliness. When using measures that assessed loneliness indirectly (i.e. not asking if the individual is lonely per se but assessing loneliness based on other variables) such as the UCLA Loneliness scale (Russell et al., 1980), males report greater loneliness. However, Borys and Perlman also highlight the need for continued research for gender differences. The research using specific adult groups, whether divided by age, experience, gender, or other variables, seems to be focused on understanding the development of loneliness.

Much of the current research has focused on the possible mechanisms, predictors, and antecedents of loneliness in adults through various stages of development. Levin and Stokes (1986) conducted a study using adults who, though enrolled in college, were generally older than the typical college-age student. The authors investigated the relationship between specific personality variables and loneliness by testing models of 
social network and cognitive bias. Overall, the authors found that adults who reported higher levels of loneliness also reported smaller social network size and lower sense of connection. With respect to individual personality variables, Levin and Stokes reported that lonely adults often reported more negative views of self and others, higher levels of depression, lower levels of self-esteem, greater introversion, and lower levels of acceptance of others. The authors further noted that reported levels of self-esteem were a stronger predictor of loneliness than the other variables examined. Larose et al. (2002) also examined the same two models of loneliness as Levin and Stokes but with different predictor variables, specifically looking at attachment and social support. In this study, the authors found that both models with the identified predictor variables are predictive of loneliness. Insecure attachment and low levels of social support, both perceived and observed, jointly predict higher levels of loneliness, resulting in a combined model for loneliness. In a qualitative exam of antecedents to loneliness, Rokach (1989) developed a model through cluster analysis of survey data in which she delineated three clusters: relational deficits, traumatic events, and characterological and developmental variables. Relational deficits reflect either missing or less than fulfilling current relationships. Traumatic events refer to significant disturbance in an individual's life. Characterological and developmental variables include a number of individual factors that increases vulnerability to loneliness such as disturbances in early relationships. This research focus has resulted in the formulation of various models that predict the development of loneliness in adults.

Still other research has further developed the specificity of the construct through the exploration of subtypes of loneliness. For example, Bogaerts et al. (2006) specifically 
looked at emotional loneliness as opposed to social loneliness in adults. The authors maintain that the experience can be qualitatively different such that a distinction in the research needs to be further studied. This point was also highlighted by Larose et al. (2002). The authors noted that their findings support the need to distinguish the difference between the social and emotional component of support in order to effectively address what lonely adults bring into treatment or intervention settings. Overall, in accordance to the review by Marangoni and Ickes (1989), loneliness research needs to continue to refine specificity in definition and conceptualization as well as measurement. Given the diversity of research available, loneliness research with adults reflects the growth of understanding of the construct in later stages of development.

Loneliness research with children and adolescents. The research with the younger stages of development has only recently gained momentum with the development of self-report measures to be used in conjunction with observation measures. As previously stated, prior studies on younger children have been confined in measurement, dependent on behavioral observations by adults (e.g. parents, child care workers, and teachers). Previously, it was once thought that loneliness could not be experienced until adolescence when the importance of social relationships increased (see Weiss, 1973). However, in more recent literature, it has been empirically demonstrated that children and adolescents are capable of experiencing and expressing feelings of loneliness (Coplan, Closson, \& Arbeau, 2007). For example, Asher et al. (1984) demonstrated that dissatisfaction in peer relationships and lower social status in schoolage children would result in higher reports of loneliness on the Loneliness and Social Dissatisfaction Scale that was developed for older children and adolescents. When 
combined with perceptions and reports of peer rejection, older children who were observed to rarely interact with others or were observed to be aggressive with others would report higher levels of loneliness (Hymel, Bowker, \& Woody, 1993; Qualter \& Munn, 2002). When persistent, childhood loneliness can lead to further psychopathology in later stages of development, such as adolescent depression (Qualter, Brown, Munn, \& Rotenberg, 2010), which has further implications for emotional, social, and behavioral functioning in adulthood. In examining gender differences in the development and impact of loneliness, Heinrich and Gullone (2006) reported that gender differences in loneliness for children and adolescents has been shown to be inconsistent as with the adult population (see Borys \& Perlman, 1985). According to their review, Heinrich and Gullone indicate that childhood loneliness does not reflect gender differences until adolescence which is inconsistent with some of the existing research that examines gender differences (for younger children see Coplan et al., 2007). As with adult populations, gender differences in loneliness during the younger stages of development also needs further study prior to drawing further conclusions. The existing research highlights the importance of the need to further examine the role of loneliness in development, particularly as it relates to behavioral outcomes as well as an understanding of the early antecedents leading to the persistence of loneliness.

Attachment security and loneliness. In refining possible early antecedents to the development and persistence of loneliness, early attachment is a construct that has been examined to some extent in the literature. According to attachment theory, attachment is a construct that is based in relationships, forming internal models of self and others from the earliest relationships with significant caregivers and carrying these internal working 
models into future relationships. With secure attachment, the internal working model reflects a perception of self as being relationally competent and others as trustworthy in relationships which facilitates fulfilling social bonds; whereas, with insecure attachment, the internal working model is marked by wariness of others in relationships and relational incompetence. When that model leads to maladaptive and ineffective ways of relating to others, the child or adolescent can experience a lower sense of belonging. Insecure attachment leads to difficulties in forming meaningful relationships throughout development (Bogaerts et al., 2006; Hecht \& Baum, 1984). The internal working models of insecurely attached children are based on their experiences with inconsistent or nonexistent responses from caregivers to overtures for connection. The response of the insecure child (either the ambivalent or avoidant type) with peers or other adults reflects this experience. This internalized response to others often results in neglect or rejection by others, not connection and acceptance, leading to possible loneliness and isolation (Asher \& Wheeler, 1985). In a review of the research on loneliness, Rokach (2004) points out that loneliness stems from not being able to fully attain our desires for human connection and acceptance. Although Rokach does not specifically discuss attachment, her summary has implications for individuals who started life with insecure attachment.

When examining the research, a connection between early attachment and the development of loneliness through the younger stages of development (i.e. childhood and adolescence) does emerge, particularly as a reflection of social competence. For example, . Raikes and Thompson (2008) report that children who were classified as insecure expressed higher levels of loneliness at 54 months. Berlin et al., (1995) report that school age children who have a history of early secure attachment are viewed as being more 
outgoing and socially competent than their insecure peers. According to Elicker, Englund, and Sroufe (1992), early attachment should be considered as a predictor for social competence because of the foundation of learning relationship reciprocity and developing self-worth to encourage further social exploration that is inherent in the formation of attachment security. The authors indicate that the competence of a child is built through successful resolution of progressive developmental stages from infancy through middle childhood. Without successful resolution of these progressive stages, Elicker et al. maintain that loneliness develops and can become persistent through the future stages of development. As a result, social competence and connection are important components to development. An inability to navigate relationships effectively can impact feelings of confidence in one's ability to address challenging social situations. Without the components for social confidence in relationships, children and adolescents are at greater risk for the development of persistent loneliness (Chipuer, 2001). This is particularly prominent in times of developmental transition, such as the transition into adolescence, especially when the ability to negotiate within relationships to satisfy one's own needs has been consistently ineffective. Adolescence is a period in which the experience of loneliness can be particularly marked without a history of inadequate social interaction (Heinrich \& Gullone, 2006; Weiss, 1973). However, when the transition period follows a history of ineffective negotiation within relationships to satisfy one’s own social needs, the experience of loneliness does increase (see Galanaki and KalantziAzizi (1999). According to Cassidy, Ziv, Mehta, \& Feeney (2003), loneliness is a feedback cycle in which one has an internal working model of self as unlovable and 
ineffective. The authors assert that insecure individuals with this internal working model tend to seek confirmatory feedback from external sources, leading to a feedback loop.

Overall, the cascading influence of the early years to later development is important to understand because early experiences do contribute to the ability to think effectively about social interactions. Marangoni and Ickes (1989) maintain that one of the major similarities in the various definitions of loneliness is insufficient fulfillment of social relationships. When children and adolescents have experienced consistent peer exclusion leading to increased social withdrawal (see Booth-LaForce \& Oxford, 2008), the choices to relieve emotional and social isolation are seemingly narrowed, leading to poor decisions and maladjustment in later life (Parker \& Asher, 1987). Weiss (1973) concluded that the pressure of emotional and social isolation leading to loneliness can result in a broadening of who and/or what is considered acceptable in relationships, leading to possible inappropriate choices that results in engagement of risk behaviors.

Risk behaviors and loneliness. The stress of loneliness has been shown to have a significant impact on both emotional and physical health (Lynch \& Convey, 1979). For example, in researching the impact of loneliness on behavioral outcomes, Crick and Ladd (1993) reported that loneliness in middle to late childhood can lead to internalizing behaviors such as anxiety and a negative sense of self; whereas, Boivin, Poulin, and Vitaro (1994) reported that loneliness can lead to externalizing behaviors such as aggressive behaviors. Cassidy and Asher (1992) reported that younger children who reported greater loneliness were either more aggressive and disruptive in class or more shy and withdrawn from peers. For children in kindergarten, Coplan et al. (2007) reported that reports of loneliness were associated with anxiety and aggression putting them at risk 
for later psychopathology or further risk behaviors. With older school age children, Efrati-Virtzer and Margalit (2009) indicated that increased loneliness was related to higher levels of aggression and an inability to effectively manage stressful situations. The research findings, though focused on behavioral outcomes have implications for overall emotional health.

With adolescents, the questions and findings have been focused on problematic outcomes that have both physical and emotional health implications, such as substance use, sexual risk behaviors, and suicide. Mijuskovic (1988) researched the connection between feelings related to loneliness and adolescent use (and abuse) of alcohol. The author describes loneliness as a source of anxiety leading to resentment of others for the isolation and possible hostility towards others, either overtly or covertly. Mijuskovic indicates that, apart from infancy, the need to belong is exceptionally strong and intense during adolescence. Adolescence is generally the time in which self-identity is being reformed from family/parents to others, increasing autonomy with no guarantee of a sense of belonging being immediately formed. In fact, the development of autonomy, acceptance of changing roles, formation of realistic expectations, and formation of a more solid self-concept takes time to grow. For the adolescent whose experience during this stage is prolonged or unusually painful, alcohol as a way of coping with and escaping the painful feelings of separateness and alienation is seen as a viable option (Mijuskovic). With increased use of mood altering substances, the chances of engaging in further risky behaviors is increased such as risky sexual behavior (see Caminis et al., 2007).

Adolescents who experience loneliness are also at risk to develop later symptoms of psychological disorders such as depressive and/or anxious symptoms which has 
implications for further risk behaviors. Fontaine et al. (2009) found that peer rejection, loneliness, and symptoms of depression and/or anxiety are interrelated in adolescents. Their findings showed that loneliness in childhood has a partial mediating effect on early peer difficulties and adolescent symptoms of depression and anxiety. Qualter et al. (2010) found that childhood reports of loneliness predict depressive symptoms in adolescence. The presence of depressive symptoms can lead to further risk behaviors and harmful consequences such as risky sexual behaviors in adolescents that lead to contracting a sexually transmitted disease (Shrier, Harris, Sternberg, \& Beardslee, 2001). In a study of self-mutilating behavior, adolescents with a history of suicidality who reported higher levels of loneliness also were six times more likely to engage in self-mutilating behavior (Guertin, et al., 2001). Other research has shown that adolescents who report loneliness in the context of family relationships are possibly at risk for self-harming behaviors and eating disorders (Lasgaard et al., 2011). Loneliness has also been demonstrated in the research to be associated with increased risk for suicidal behaviors (Kidd, 2006; Laederach, Rischer, Bowen, \& Ladame, 1999). These findings seem to indicate that reports of loneliness are to be considered seriously as an indicator for more serious risk behaviors that result in possible emotional and physical harm.

Overall, the research on loneliness as an independent construct was more prolific in the 1980s and has since waned, possibly due to the inclusion of loneliness as a feature in other related constructs such as depression and anxiety (Heinrich \& Gullone, 2006). However, in the research that is available, loneliness is a construct that is "worthy of attention in its own right” (Heinrich \& Gullone, 2006, p. 712) for all stages of development, particularly given the implications for the development of risk behaviors. 


\section{Integration of Research for the Proposed Model}

In general, the importance of understanding the impact of early development on later development cannot be disputed. However, what is often discussed in the research is the 'how' of that impact. The proposed model of this paper focuses on understanding the impact of early attachment security on later developmental outcomes in childhood and adolescence, in particular the roles of the development of loneliness from childhood into adolescence and risky behaviors during adolescence. The research that has been reviewed previously highlights the continued need to understand how early developmental variables impact later outcomes. The research of looking at early attachment and adolescent risk behaviors indicate that there are many possibilities in the examination of potential mediating variables in that relationship that is ongoing.

In considering mediating variables in the relationship between early attachment and later risk behaviors, loneliness, particularly the development of loneliness through childhood leading into adolescence, is a viable possibility. The development of loneliness through a key transition period of development (childhood into adolescence) could mediate the effects of early attachment on adolescent risk behaviors. An insecure attachment history results in isolation from and possible rejection by peers due to ineffective behaviors in maintaining relationships as the child enters a period of development where the exposure and emphasis on peer relationships increases in importance. This pattern of isolation and rejection by peers leads to feelings of loneliness and inadequacy through development. If this pattern is not changed or resolved, then the possibility of developing chronic feelings of loneliness through childhood increases. This 
developmental sequence can result to feelings of desperation such that the individual considers doing anything to belong resulting in poor choices leading to risky behaviors.

The purpose of this research proposal is to establish this base relationship between the variables of early attachment, developing loneliness over time, and later risky behaviors. If those relationships are established, further analysis can be conducted to further the discussion of mediating variables in the developmental sequence of early developmental variables to later outcome variables.

\section{Research Questions and Hypotheses}

The research questions and hypotheses related to the proposed model are as follows:

1) To what extent does early attachment style established as a toddler relate to the establishment and growth or changes in perceived loneliness through childhood and adolescence and risk behaviors in adolescence? The hypothesis is that the relationship between early attachment style and adolescent risk behaviors will be mediated by the establishment and growth or changes in perceived loneliness from childhood through adolescence.

2) To what extent do the initial levels of perceived loneliness in childhood mediate the relationship between early attachment and adolescent risk behaviors in a sample of individuals who have been followed from birth to age 15 ? The hypothesis is that the initial levels of perceived loneliness will mediate the relationship of early attachment style and adolescent risk behaviors. In other words, associations between early attachment style and risky behaviors will be explained in part by the initial levels of perceived loneliness. In sum, those who 
have insecure attachment styles as toddlers will have higher initial levels of loneliness in childhood which will predict greater risky behaviors in adolescence.

3) To what extent do the changes in levels of perceived loneliness mediate the relationship between early attachment and adolescent risk behaviors in a sample of individuals who have been followed from birth to age 15? The hypothesis is that the changes in levels of perceived loneliness will mediate the relationship of early attachment style and adolescent risk behaviors. In other words, associations between early attachment style and risky behaviors will also be explained in part by increasing levels of perceived loneliness. In sum, those who have insecure attachment styles as toddlers will report increased levels of loneliness from childhood into adolescence which will predict greater risky behaviors in adolescence.

4) What is the role of gender in the proposed mediating model? Does the mediating role of changes in loneliness differ for males and females? The hypothesis is that gender will play a role in the overall structural mediation model, particularly as it relates to the relationship between loneliness and adolescent risk behavior. Gender could also play a role in the growth of loneliness, with females reporting higher levels of loneliness both initially and over time. 


\section{CHAPTER THREE}

\section{METHODOLOGY}

\section{NICHD SECCYD longitudinal data set}

Researching developmental sequelae in psychology presents with many different challenges (e.g. data collection, time invested by researchers and participants, and funding over an extended period of time). However, the information obtained from such experimental designs is invaluable to the field. According to Jessor and Jessor (1977), longitudinal designs strengthen the ability to make causal inferences with the results obtained through "temporal antecedence, the prospective forecasting of new events such as behavioral onset, and the observation of temporal co-variation” (p. 9).

The original purpose of the longitudinal data set developed by the National Institute of Child Health \& Human Development (NICHD) Study of Early Child Care and Youth Development (SECCYD) was to study the impact of various child care experiences and children’s development in different areas (i.e. social, emotional, intellectual, physical, language, and health) in various contexts collected from participants in four separate phases across multiple settings using multiple measures of multiple constructs starting from early infancy to $9^{\text {th }}$ grade (for more information, refer to http://www.nichd.nih.gov/research/supported/seccyd/overview.cfm). Numerous studies have been fostered by this data set in support of the original goal of the project (e.g. NICHD Early Child Care Research Network, 1996, 1997, 1998, 1999, 2000, 2003). Other 
studies that have been generated by the NICHD SECCYD data set performed secondary analysis of the data (e.g. Belsky \& Pasco Fearon, 2002b; Booth-LaForce \& Oxford, 2008; Konold, Hamre, \& Pianta, 2003; Rudasill, Reio, Stipanovic, \& Taylor, 2010).

The NICHD SECCYD data set is well suited for secondary analysis due to the depth and breadth of information collected over an impressive amount of time. There are distinctive advantages in using this particular data set for the research question proposed. First, it provides a well-conceived longitudinal data set. Second, the data set contains raw data collected that have been made available for secondary analysis. Secondary data analysis allows for different perspectives for taking the raw data and applying it to hypotheses that are different from the ideas of the original researchers (i.e. different theoretical perspectives), possible expansion of ideas with the same variables, and further analysis using different methodologies (Burstein, 1978). Most importantly, the data set offers access to the specific variables of interest in this study that used reliable and valid measures.

However, with concerns related to data security, the NICHD SECCYD data set is classified as a restricted use data set. As is common with the majority of data sets available for secondary data analysis, the NICHD SECCYD data set is de-identified. However, the design of the original research project, the duration of the study (over a period of 16-17 years), and the detailed demographics collected jointly increase the sensitivity of this data set to possible deductive disclosure. As a result, a comprehensive data protection plan is required to detail how the sensitive data will be used and protected to ensure ethical protection of the human subject data, protecting the confidentiality of the participants and their families which will be reviewed by the Inter-University 
Consortium for Political and Social Research (ICPSR) at the University of Michigan, who currently distributes the data to various qualified parties.

\section{Participants}

Participants for the NICHD SECCYD were recruited from hospitals in or near 10 different sites around the United States in 1991: Little Rock, AK; Irvine, CA; Lawrence, KS; Boston, MA; Philadelphia, PA; Pittsburgh, PA; Charlottesville, VA; Morganton, NC; Seattle, WA; and Madison, WI. Within certain 24 hour sampling periods, 8986 women who were giving birth were visited to determine eligibility. From that number, prospective participants were excluded from the study using the following criteria: 1) the mother was under 18 years of age, 2) the mother was not fluent in English, 3) the family planned to move from the study area, 4) multiple births were involved, 5) the child born was hospitalized for more than 7 days or had obvious disabilities, 6) the mother had a known or acknowledged substance abuse problem, or 7) the family lived far from the site or that the location was unsafe for home visitors. This resulted in sample pool of 5,265 women who met criteria and agreed to be contacted after returning home from the hospital. From the pool, a subset of participants, 3,015 prospective participants, were selected using conditional random sampling that was implemented to ensure adequate demographic diversity within the catchment area of each research site, even though the overall sample was not designed to be nationally representative. Upon contact, 1,526 families agreed to be interviewed and of those, 1,364 families completed the home interview when the infant was 1 month old and were enrolled in the study.

This longitudinal study was divided into four separate phases of data collection.

Phase I was conducted from 1991 to 1994 when the children were from ages 0 to 3 years. 
Phase II was conducted from 1995 to 1999 for participants through the $1^{\text {st }}$ grade. Phase III data were collected from 2000-2004 for participants through the $6^{\text {th }}$ grade. The final phase, Phase IV, was conducted from 2005-2007 for participants through the $9^{\text {th }}$ grade or age 15 .

Sample numbers will vary due to attrition rates. Depending on the variables of interest, sample size is inevitably less than the 1364 participants that originally enrolled. This variability is a reflection of families who were not able to complete all assessments of all phases for various reasons. For this particular study, the sample includes cases in which only completed data for all variables of interest are present. Participants who did not complete any or part of the measures selected for this study are not included in the analyses. As a result, the overall sample size for this study is 825 (males $=403$, females $=$ 422).

\section{Data Collection}

The data were collected for the NICHD SECCYD occurred from 1991 to 2007 at multiple sites across the United States. Data collection occurred when participants were $1,6,15,24,36$, and 54 months old, during $1^{\text {st }}, 2^{\text {nd }}, 3^{\text {rd }}, 4^{\text {th }}, 5^{\text {th }}$, and $6^{\text {th }}$ grades, and at the age of 15 (approximately $9^{\text {th }}$ grade). These data collection times were also supplemented with phone calls that occurred every 3 to 6 months, with frequency waning as the child aged. Depending on the particular measure, assessments were conducted either in the home environment, school setting, or in a lab setting from a variety of different sources (e.g. parents, teachers, caregivers, principals) through various methods (e.g. observations, written questionnaires, formal assessments, interview questionnaires). For the variables of interest in this study, the data were collected within a lab setting. 


\section{Measures}

Attachment at 36 months. NICHD collected attachment data at three separate time points of early development, at 15 months, 24 months, and 36 months. Each collection was performed using different measures or modifications of previous measures; however, the outcome was a measurement of the level of attachment security for the participant. In this study, the measurement taken at 36 months will be used in the proposed analyses.

Internal working models, a reflection of a child's internal experience of the relationship with the primary caregiver, are the construct into which attachment security measure tap. As infants, internal working models are malleable constructs that are shaped during interactions with primary caregivers starting in the first year of life. According to Bowlby (1969), the development of internal working models begins in the early stages of life:

Starting, we may suppose, towards the end of his first year, and probably especially actively during his second and third when he acquires the powerful and extraordinary gift of language, a child is busy constructing working models of how the physical world may be expected to behave, how his mother and other significant persons may be expected to behave, how he himself may be expected to behave, and how each interacts with all the others. (p. 354)

It is within this framework that a child forms an attachment style. According to Thompson (2000), infants do not have a well formed internal working model, more vulnerable to environmental changes (see Vaughn, Egeland, Sroufe, \& Waters, 1979), until the emergence of more formative ideas of self and emotions enables more stable 
internal working models of self and others that are possibly more influential on later development (Ainsworth, 1989; Marvin \& Britner, 2008; Thompson, 2000).

Given that the purpose of this study is to examine potential effects into adolescent behaviors, the attachment classification determined at 36 months was selected for this model due to a greater likelihood of stabilization in attachment style at this point of development.

Strange situation. The Strange Situation is the most widely used assessment tool of infant attachment security. The Strange Situation (Ainsworth et al., 1978) is a series of episodes of separation and reunification, each for 3 minute intervals. These episodes involved both the primary caregiver/mother and a stranger being present in the room with the infant. The episodes are designed to activate the attachment system by inducing a stressful situation through separation that result in attachment behaviors that are observed upon reunification of the infant and the caregiver. The episodes are recorded to be coded by observers looking for specific criteria (see Friedman \& Boyle, 2008 for details on coding). The coding types reflect secure attachment (Type B) or insecure attachment avoidant (Type A) and ambivalent or resistant (Type C). Disorganized attachment (Type D) was later added for those infants who demonstrated insecure attachment that did not conform to either existing insecure attachment coding (Main \& Solomon, 1990).

However, the Strange Situation is designed to assess attachment for infants ranging in age from 12 to 18 months. In order to measure attachment styles in older children, modifications and other procedures (see Waters and Deane, 1985 for information on the Attachment Q-sort) have been developed to remedy this discrepancy. In the NICHD SECCYD study, the investigators opted to use a modification of the 
Strange Situation for preschoolers, ages 3 to 5, developed by Cassidy and Marvin with the MacArthur Working Group on Attachment (1992). The investigators of the NICHD SECCYD used this with their participants at 36 months. In this modification, the assessment has fewer sessions of separation and reunification. The child and mother were placed in an unfamiliar room in the lab. The mother stayed in the room for three minutes and then signaled to leave. The first separation was for 3 minutes or until the child expressed distress, followed by a 3 minute reunion. The mother was then signaled to leave again, with the second separation being for 5 minutes or until the child expressed distress before a second reunification. After 3 minutes of the second reunion, the assessment was terminated and subsequently coded using the MacArthur coding system. According to the NICHD SECCYD documentation, the coding system classified the 36 month-old participants as either secure or insecure. The system is similar to that described for the infant Strange Situation (see above); the difference being noted with the D classification in which the classification indicates controlling behaviors, which is demonstrated in some form of role reversal in the child-caregiver relationship or punitive behavior towards the caregiver, or a combination of insecure strategies.

The video recordings of the sessions were sent to a central location in which a team of three coders, trained by Cassidy, used the MacArthur coding system to classify the participants' attachment behaviors. The agreement of the four-category classification between coders before conferencing for disagreements was 75.7\%. Disagreements between coders were discussed as a group and a consensus code was provided.

Variable to be used in the proposed model. For attachment as measured at 36 months, the NICHD SECCYD provides data for the attachment rating (A, B, C, D 
classifications) as well as an attachment security rating (scale of 1 to 9 , where $1=$ very insecure and $9=$ very secure). For the purposes of this study, the attachment security rating from 1 to 9 will be used in this study as the measurement of attachment security for the model. This particular scale was selected because it best satisfies the recommendation for interval data in SEM analysis without sacrificing the intent of the measurement, level of attachment security.

Loneliness. Loneliness and Social Dissatisfaction Questionnaire was developed by Asher et al., (1984). Prior to the development of this questionnaire, reports of children's experience related to difficulties with peers were from external sources such as parents, teachers, and other external observers of behaviors. The purpose of developing this particular measure was to assess children's experiences directly from the particular child through self-report (Asher et al., 1984).

The questionnaire was originally used on 506 children (243 females, 263 males) from third to sixth grade from 20 classrooms in a Midwestern city of the United States. The instrument consists of 24 total items using a 5 point Likert scale ( 1 = "Not at all true" to 5 = "Always true”), 16 of which are focused on perceived feelings of loneliness and 8 filler items on hobbies or preferred activities. Through factor analysis, the authors confirmed that the 16 loneliness items loaded on one factor where none of the 8 filler items loaded significantly on this factor. The overall results in the development of the questionnaire are that the measure is internally consistent (Cronbach’s alpha $=.90$ ) and internally reliable $($ split-half correlation $=.83$; Spearman-Brown reliability coefficient $=$ .91 ; Guttman split-half reliability coefficient $=.91$ ). In the administration of this measure to the sample, the raw items continued to evidence high internal reliability (Cronbach's 
alpha $=.87$ for $3^{\text {rd }}$ grade/age 9 and .91 for $5^{\text {th }}$ grade/age 11 and age 15$)$. Overall, the Loneliness and Social Dissatisfaction Questionnaire is a reliable and valid measure of children’s perceptions of loneliness.

NICHD made a couple of minor modifications to the original questionnaire. In the version administered to $5^{\text {th }}$ graders (at age 11 ) and those at age 15 , one filler item was added to the items. For all ages, the order of responses was reversed from the original version for the NICHD study. However, all other aspects of the questionnaire remained unchanged.

Variables to be used in the proposed model. Loneliness is measured at three different time points: age 9 (grade 3), age 11 (grade 5), and age 15 (grade 9). Although the total number of items for the measure differs from age 9 (grade 3 ) to age 11 (grade 5) and age 15 (grade 9), the items used to calculate the construct of interest (i.e. loneliness) is unchanged in each administration. The sum of those items at each time point will be used for this model, with higher scores indicating greater felt/perceived loneliness.

Adolescent risky behaviors. The Risky Behaviors Questionnaire was especially developed for administration for the NICHD study. The items of the measure is influenced by Conger and Elder (1994), the Fast Track project, and the New Hope project. Fast Track is a prevention and intervention project that began in 4 different areas across the United States. It is a program designed for early intervention of youth identified as being at risk for certain behaviors. The design of the intervention was universal, targeting individual competencies as well as building protective contextual factors through family and community (Pinderhughes, et al., 2010). The New Hope project was also conceived along a similar vein in that the design was to target at risk 
families with children to lower risk of maladaptive behaviors to foster positive growth at the individual, family and community levels. Conger and Elder (1994) detailed in their work the ongoing efforts in the Iowa Youth and Families project, focusing on intervention and prevention for rural families that faced economically difficult times.

The risk behaviors identified in the questionnaire were influenced by these projects with at risk youth and families. The Risky Behaviors Questionnaire is a 61 item measure that asks how often within the past year has the adolescent engaged in 55 identified risky behaviors on a 3 point scale $(0=$ "not at all”, 1 = "once or twice", 2 = "more than twice"). The measure administered to participants at age 15 included additional items including vaginal sexual behavior, oral sexual behavior, tobacco use, safety behaviors, and violent behaviors. These additional items were influenced by research in those specific areas (see Halpern-Felsher, Biehl, Kropp, \& Rubinstein, 2004; Halpern-Felsher, Cornell, Kropp, \& Tschann, 2005). There are also questions related to number of partners over lifetime and in more recent history (within the past 30 days). The overall score indicates any risk taking which has a high internal reliability (Cronbach's alpha $=.89$ ). The measure also offers scoring focused on sexual risk taking for which the internal reliability (Cronbach's alpha $=.73$ ) is moderate.

Variable to be used in the proposed model. For Risky Behaviors at age 15, scores for indicators selected based on the research of adolescent risky behaviors previously reviewed. Originally, the measure only provides a single total score for items 1 through 55 based on the recoding of the scoring on a $0 / 1$ scale with $0=$ Never and $1=$ Once or twice and more than twice (the original scale was from 0 to 2 , so the researchers converted it to what is essentially a binary scale). However, as indicated in the research, 
risky behaviors at any age are varied, such that one composite score is not an adequate indicator of the entire construct.

According to Byrne (2001), the measurement model must be developed with an optimal number of indicators (i.e. too many indicators per factor would be problematic for SEM) followed by a determination of the specific items that will formulate each indicator. Each indicator can be composed of a single item or total score of several items (i.e. parcel). According to Byrne, the determination of item parceling to form indicators for the measurement model can occur in several ways: 1) random assignment, 2) exploratory factor analysis, or 3) theoretical or conceptual base.

For this project, the formulation of indicators was based on the research reviewed related to adolescent risky behaviors. The indicators are formed through parceling and summation of multiple items from the measure, Risky Behavior Questionnaire. The items were divided into different indicators consolidating different items guided by the existing research of adolescent risky behaviors (Centers for Disease Control, 2010; Thompson et al., 2011). The indicators for the latent variable risky behaviors are sexual risk, violence (including violent behavior and gang involvement), substance use, and noncompliance/conduct problems (i.e. behavior problems that generally do not involve violence). Table 1 illustrates the specific items from the Risky Behavior Questionnaire that were selected to measure the specific indicators of adolescent risky behaviors.

Gender. Parents of the participants were queried during the initial phone contact conducted when the participants were approximately 1 month old. A number of detailed demographic variables were collected including participant gender, a time invariant variable, to gain basic information such that the participant and the family were officially 
enrolled into the SECCYD study. Gender is coded on a nominal scale in which $0=$ Male and $1=$ Female .

\section{Data Analyses}

For the proposed model in this study (see Figure 7), the overall structural model is composed of the latent constructs of attachment, loneliness, and risky behaviors and a time-invariant variable, gender. Both attachment and risky behaviors are measured at one set time point, attachment as measured at 36 months and risky behaviors as measured at age 15. Loneliness is measured at three different time points, age 9 (grade 3), age 11 (grade 5), and at age 15 (grade 9). The overall purpose of the analyses is to generate a parsimonious model that can be meaningfully interpreted using latent growth curve (LGC) modeling and structural equation modeling (SEM).

LGC modeling. As part of the growth of modeling used in research, various methods for analyzing longitudinal data are more readily available, particularly the tools such as latent growth curves for describing developmental patterns or trajectories and identifying potential predictors of aspects of development. Originally developed in the early work of Tucker (1958) and Rao (1958), latent growth curves were subsequently associated with SEM by other researchers (e.g. Meredith and Tisak, 1990). LGC modeling refers to the combination of this early work of latent growth models with SEM.

LGC modeling is a tool that provides information about patterns of change over a specified period of time, generally a key interest in most longitudinal studies, and provides a way to identify variables of interest as possible predictors of the patterns of change. With LGC modeling, investigation of both within-person and between-person models of growth within the same structural framework becomes possible, something that 
cannot be done with traditional longitudinal methods (Byrne \& Crombie, 2003). Byrne (2010) indicates that using LGC within the framework of structural equation modeling has the advantage of separating group effects from individual effects. The SEM framework also allows for the difference to be made between observed and latent variables through model specification. Another distinctive advantage of LGC models using an SEM framework is the function to account for errors in predictors and the flexibility to be used in testing mediation hypotheses (Burchinal, Nelson, \& Poe, 2006). These advantages are well suited to the proposed model.

Model specification and identification. The LGC model within the proposed structural model for this project examines the changes in loneliness of children into adolescence. The changes in loneliness for the participants will be based on a measure that was administered at three different time points: age 9 (grade 3), age 11 (grade 5), and age 15 (grade 9). The assumption of this hypothesized model is that the change over time will reflect a linear pattern. As a result, the model includes an intercept parameter, the participant's score on the loneliness measure at age 9 (grade 3), and a slope parameter, the participant's rate of loneliness over the period from age 9 (grade 3) to age 15 (grade 9). The intercept parameter paths are constrained to a constant since the intercept value does not change over time. The slope parameter paths can reflect the unequal time spacing by setting the slope parameters to reflect the spacing intervals. Since LGC modeling will be using the SEM framework, it is important to consider whether the model is under-, just-, or over-identified as calculated by the parameters of the hypothesized model. The goal is to develop a model that is over-identified such that the parameters can be estimated. 
In order to use LGC modeling, other conditions also need to be met. The first condition is that the measure used for loneliness, the mediator variable in this model, be on a continuous scale. When examining social science research, true continuous data are difficult to assess given that many of the measures used in the field involve the use of categorical Likert scales. According to Byrne (2010), the use of Likert scaled values "has been the norm for many years now and applies to traditional statistical techniques (e.g. ANOVA, MANOVA) as well as SEM analyses” (p. 143).Also, the practice of using scores based on Likert scaled items has been noted in research for over a decade. The measure used to assess loneliness in this study uses Likert scale items to calculate an overall score, both of which are accepted in practice to use for the proposed analyses. The second condition is that the spacing of the assessment of loneliness is the same for all participants, which was collected during the same waves for all participants in the original NICHD SECCYD study. The third condition is that there needs to be at least three different time points of assessment of loneliness, which is satisfied by the three time points for loneliness data discussed previously. The last condition is that the sample size be large enough to detect individual changes (Willett \& Sayer, 1994), which according to Byrne (2010) needs to be at least 200 for each data collection wave. The sample size for each collection wave of loneliness data is 825 . Since all of the conditions are satisfied, the loneliness NICHD SECCYD data set selected is suitable for the proposed analyses.

SEM. The use of SEM and LGC modeling has distinct advantages in data analysis, particularly with longitudinal data. The advantages of SEM over other statistical methodologies have contributed to the growing popularity of this approach in social sciences research. A distinct advantage of SEM over traditional multivariate approaches 
is that SEM accounts for error through estimates of error variances within the measurement model (Byrne). Also according to Byrne and Hopwood (2007), a final advantage of SEM is the specification of the relationship between observed and unobserved (or latent) variables, which is distinctive because many variables of interest, particularly in the social sciences, are not directly observable (e.g. self-concept, verbal ability, depression, anxiety, loneliness, attachment) but can be inferred from observed variables (e.g. scores on measures reflecting number of times a specific behavior is observed, reflecting intensity of specific depression or anxiety symptoms, reflecting perceived isolation, reflecting vocabulary knowledge). Also, a latent variable offers a more reliable estimate of the effect because the measurement error that is associated with observed variables will not have an effect on the latent variable because measurement error unique to one observed variable is generally not shared with other observed variables (Hopwood, 2007).

Model specification and identification. The overall structural model proposed incorporates the previously discussed LGC model as a mediator in the relationship between attachment at 36 months (exogenous variable) and risk behaviors in adolescence measured at age 15 (endogenous variable). In SEM, the analysis of specification and identification is initiated at the level of the measurement models embedded within the structural model.

For the proposed model, the measurement model is for risk behaviors in adolescence. The measurement model needs to be examined to determine if it meets criteria such that when it is incorporated into the overall structural model, the structural model also meets established criteria for SEM models. 
SEM involves both the use of a series of structural equations and use of diagrams to illustrate the structural relations for the variables of interest (Byrne, 2001, 2010). SEM is typically a confirmatory approach to data analysis, which involves establishing a model based on theory and testing how well the data fit the hypothesized model, allowing for more effective methods of hypothesis testing. As previously mentioned when discussing LGC models, the goal is to develop a model that is over-identified such that the parameters can be estimated (i.e. more known values than parameters that are to be estimated).

The data that are used to define the latent variables of the model are theoretically to be continuous data; however, in social science research, the most common scale in measures is either ordinal or interval in scale. As previously discussed, the practice of using scores based on Likert scaled items has been noted in research for over a decade (Byrne, 2010). The measurement data to be used for the proposed model of this project consist of measures using Likert scales. Attachment at 36 months are measured on an interval scale from 1 to 9; risky behaviors at age 15 is measured using a total score from items using a Likert scale; and loneliness at age 9 (grade 3), age 11 (grade 5), and age 15 (grade 9) are measured using a total score from items using a Likert scale. In terms of what is considered acceptable given limitations of social science research, the measures chosen for the proposed analyses satisfy the criteria as is currently accepted.

Model fit and testing for SEM and LGC modeling. In establishing model fit within an SEM framework, it is important to select an estimation method for model fit that meets an important assumption of SEM, multivariate normality of the observed variables. Maximum likelihood estimation was chosen as the fitting process for this 
project because it can tolerate an acceptable distribution of non-normality to assess model fit (Meyers, Gamst, \& Guarine, 2006). Maximum likelihood estimation of parameters is typically used with continuous data; however, it is an acceptable practice to use Likert scaled data as previously discussed (see Byrne, 2010).

Once the data have been prepared and the fitting process selected, model testing is the next step in which fit indices are selected. Unlike other multivariate models in which a single fit index is used, SEM has multiple fit indices from which to select to best compensate for the range of strengths and weaknesses that each individual fit index offers. The indices to be examined in this project include the chi-square statistic, comparative fit index (CFI), and root mean square error of approximation (RMSEA). The chi-square statistic will be used primarily to evaluate the statistical significance of chisquare differences from one model to the next. Due to known limitations of the chisquare statistic in evaluating models, it is essential that other indexes are also used to assess a model's fit.

The CFI is an incremental index which ranges from zero to one with larger values indicating a better fit of the model to the data. Initially, the cutoff for CFI was .90 (Hu \& Bentler, 1995); however, in further analyses, it was determined that the .90 cutoff was too low, resulting in an inability to reject mis-specified models. As a result, values equal to or larger than .95 have been established to indicate an acceptable model fit (Hu \& Bentler, 1999). However, studies do continue to use the more conservative and traditional cutoff of .90 (Browne \& Cudeck, 1992; Bollen \& Long, 1993). An incremental index uses a restricted baseline model to which the target model is being compared (Hu \& Bentler, 1995). According to Bentler (1990), the CFI is a good incremental index because of the 
range, yielding small sampling variability. This index was chosen because the size for each sample met the criteria to avoid overestimated and erratic CFI values. Sample size also eliminated an inflation of Type II error for the CFI.

The RMSEA, a residual based absolute fit index, uses the average residuals for the sample data, relative to the size of variances and covariances of the sample. RMSEA normalizes by sample size and thus is not sensitive to sample size but is affected by nonnormality and model complexity. According to Steiger (2000), the RMSEA looks at how well the sample data will fit the population by examining the covariance matrix. In other words, RMSEA values indicate how well the sample represents the population from which it is drawn. Values of RMSEA less than or equal to .05 indicate a close fit, between .05 and .08 indicate a reasonable fit, and values larger than .08 signify a poor fit. In addition to the RMSEA value, it is important to report confidence intervals (MacCallum, Browne, \& Sugawara, 1996) because the range of the confidence interval could be used to argue adequate fit of the model if the range is inclusive of scores that support good to adequate model fit in addition to values indicating poor fit (Raykov \& Marcoulides, 2006). The confidence interval also reflects the precision of the RMSEA value on how well the model fits for the population.

If the fit of the model is determined to be inadequate, then further analysis is warranted. For poor fitting models, adjustments to the model are made based on modification indices that are consistent with theory. If the changes that are suggested by modification indices are supported by theory, then the modification indices provide guidelines to re-specification for the parameters of the model to achieve a more 
parsimonious fit to the data. This process occurs simultaneously for both the measurement model and overall structural model.

Model fit considerations specific to LGC modeling. According to Willett and Sayer (1994), there are two levels of model fit testing for LGC modeling, levels 1 and 2. Level 1 is the portion of model fit testing that represents the individual changes for each person on loneliness over the specified time period. At the level of intra-individual change, the portion of the LGC model that examines the links between the observed variables, the 3 different waves of loneliness scores, and the unobserved variables, intercept and slope. In this level of determining model fit, the analysis is based on modification indices for the covariance between slope and intercept. Once the model that best fits the data are established, then further analyses are conducted.

Level 2 is the portion of model fit testing that represents the between-person differences in loneliness. In this level of determining model fit, an examination of the parameter estimates for the means, covariances, and variances for the slope and intercept of the model is needed. If the examination of these estimates reveals strong interindividual differences, further investigation into this variability of growth trajectories is warranted, such as incorporation of predictors into the LGC model or incorporation of the LGC model into the overall proposed model of this project (Byrne, 2010; Willett \& Sayer, 1994).

Software to be used. The software programs to be used for data analysis are SPSS Version 20.0 and AMOS Version 20.0 (Arbuckle, 2011). SPSS is used to prepare the specific variables of interest, identify missing values in the data, and perform possible bootstrapping on the data if needed. SPSS is needed to prepare the raw data or convert 
into variance-covariance matrices. AMOS requires a complete data set in order to run the analyses. The structural equation model that will be tested using this data will be constructed using AMOS and then the prepared data file will be uploaded to test the model.

Missing data for SEM and LGC modeling. Missing data occur for a number of reasons. In a longitudinal study, missing data can be associated with attrition of participants over time or for participants who were unable to complete certain parts of assessment due to scheduling conflicts or omissions. In the NICHD SECCYD data set, there are a number of cases in which data for specific measures are missing resulting in incomplete records (i.e. missing data for a single measure or missing data for multiple measures) for data analysis. Different approaches for addressing the presence of missing data are available. The more conservative approach involved deletion of data (i.e. listwise deletion and pairwise deletion) whereas the other approach involved methods of imputation (i.e. mean imputation, regression imputation, expectation maximization, and full information maximum likelihood). There was no indication that any other approach would offer a greater advantage to data analysis at this time. As a result, the more conservative and conventional method of listwise deletion was selected. When these incomplete records are removed from the data set, the final number of cases is still a substantial number $(\mathrm{N}=825)$.

There are several concerns with this approach to addressing missing data. One concern is the potential loss of statistical power with a reduced sample size. Small sample sizes are problematic with SEM. Fortunately, even with the deletion of cases with incomplete data, the remaining data subset is still adequately large for SEM 
considerations. Another concern involves the potential for selection bias. Although there are no known systematic reasons to account for incomplete data for certain individuals, descriptive data from a subset of 825 cases with completed data will be compared to the data for the subset of 539 cases with missing data using appropriate bivariate analyses and calculated standardized mean difference effect sizes to screen for potential selection bias.

Overview of data analysis plan. Using a confirmatory factor analysis approach, the hypothesized latent growth curve model for loneliness, the measurement model for risk behaviors, and the overall structural model will be tested using a subset of complete NICHD SECCYD data for model fit to test the established hypotheses. The first step is to examine the model at the measurement model level. Since attachment at 36 months is being measured at one time point with only a single score, data analysis will begin with the remaining latent variables, risk behaviors and loneliness.

An independent analysis of a basic LGC model for fit to the loneliness data over three waves of data collection without independent variables will be conducted. As shown in Figure 2, the factor loadings for the three indicators of loneliness on the latent intercept are fixed to one, representing the initial point of loneliness. The factor loadings for the three measurements of loneliness on the latent slope were fixed to zero, two, and six indicating the time spacing between measurements (e.g. number of years).

The fit of the measurement model for risky behaviors will also need to be assessed. According to Byrne (2001), developing a measurement model of a full structural model requires selection of indicators that comprise the latent construct, risky behaviors, and identification of the specific items that comprise each indicator. For risky 
behaviors, the indicators that are selected are based on the research on specific risk behaviors in adolescents. The items comprising the indicators of adolescent risk behaviors were selected and judiciously combined (as recommended by Byrne, 2001). Figure 3 illustrates this measurement model. Once the items and indicators are selected, model fit is tested to determine the adequacy of fit to the data.

Once the best fitting model to the data is determined for each model independently, the analysis of the structural model will follow (see Figure 4). According to Byrne (2001), establishing confidence in the building blocks leads to increased confidence in the findings for the fit of the structural model.

Each model will be re-evaluated for adequate fit when a time-invariant covariate, child gender, is added to determine the impact of gender on the model. The covariate method of examining the impact of gender on the latent variables was selected. Gender is added as a time invariant covariate to the CFA model for risky behaviors, the basic LGC model for loneliness, and to the overall structural model (see Figures 5-7). Again, the same format of testing the measurement model prior to addressing the structural model will continue. With this analysis, the focus is on determining the effect of gender on the specific latent constructs as well as the impact on the overall structural model. 


\section{CHAPTER FOUR}

\section{RESULTS}

\section{Descriptive Analyses}

Data from the NICHD SECCYD used in the analyses was selected based on completion for the specific measures being used for the variables of interest. Listwise deletion is a conservative approach of addressing incomplete data, so it is important that the data selected do not reflect a significant difference from the total sample. Table 2 summarizes the means and standard deviations of each observed variable for each group. The sample of completed cases $(\mathrm{N}=825)$ is comprised of $48.8 \%$ males and $51.2 \%$ females. Table 3 illustrates the correlations between observed variables for the sample of participant data utilized in this project. The correlations between observed variables, though significant, range from weak to moderate.

Missing data analyses. Listwise deletion was the selected method for addressing missing data. There are concerns with this particular approach related to possible loss of information and statistical power due to a smaller sample size. However, given that the rule of thumb for SEM is to have at least 10 participants for each estimated parameter of the model, the sample size of 825 completed cases from the NICHD SECCYD data set exceeds the suggested minimum (see Table 4).

Approximately $60 \%$ of the participants completed all measures across all time points. As a result of listwise deletion, $40 \%$ of the sample is not being used in the present 
analyses. With such a substantial number of participants with incomplete data, it is important that analyses are conducted to determine whether the participants who had missing data were different from those who remained in the study with completed data on the variables of interest (see Table 5). Chi-square and t-tests were conducted to compare those with complete data from those with missing data on gender, loneliness, attachment, and risky behaviors (i.e. violence, noncompliance, substance use, and sexual risk). In comparing the two groups, the analyses indicate that differences between gender and noncompliant/conduct problems met criteria for statistical significance (i.e. $p<.05$, see Table 6). However, examination of the effect sizes for determination of practical significance for attachment, loneliness, and risky behaviors (i.e. standardizd mean difference effect size, see Table 6) may be more appropriate. Cohen's d is used as the standardized mean difference measure for effect size. ). All of the calculated effect sizes are small (i.e. $\mathrm{d}<.2$, see Cohen, 1988). This indicates that the differences in the mean scores for the variables of interest between the group with complete data and the group with missing data is small, thereby not practically significant.

For this data set, the missing data most likely do not meet the assumption of missing completely at random due to differences noted between groups for gender with males more likely to have missing data (see Allison, 2003). However, there was no indication that the missing data does not meet the assumption of missing at random.

The lack of significance in the standardized mean differences and assumption of data missing at random does allow for continued analysis using the group with complete data for model analyses. 


\section{Model Development}

In developing the overall structural model, analyses will progress methodically through examination of smaller parts of the structural model prior to conducting analysis on the full structural model. According to Byrne (2001), it is important to ensure fit of the overall model by first examining the fit of the smaller components. This section will begin with individual analyses of the LGC model of loneliness and the CFA model of risky behavior. Once the best fitting model at that level is determined, exploration of the next level can occur, progressing to the final analysis of the overall structural model.

LGC model of loneliness. To address the question of changes in loneliness over time, a base model of loneliness was developed and analyzed through LGC modeling (see Figure 2). This basic model of change includes 3 time points, testing for a linear pattern of growth.

The specified base model for loneliness includes two latent factors, three waves of the indicator variable, and no predictors. As indicated in Table 7, the model exhibits significant effects for both latent factors. All of the estimates for the means, variances, and covariance in this model are significant (see also Figure 8). The factor for the intercept reflects an average score on the loneliness measure of $27.529(p<.001)$ during the $3^{\text {rd }}$ grade (age 9 ). The mean of the slope factor indicates that loneliness score decreased by .248 per year $(p<.001)$ with each measure. The covariance between the slope and intercept factors predict the degree to which the initial levels of loneliness predict rates of linear change in perceived loneliness by the participant. The covariance is negative $(-4.585, p<.001)$ which indicates that over time, perceived loneliness declines from the initial level at age 9 (grade 3) up through age 15 (grade 9) with the children who 
reported being more lonely at age 9 (grade 3) were slower to experience changes in loneliness over time than those who reported lower levels of loneliness at age 9 (grade 3).

Unfortunately, the overall model fit was less than adequate, $\chi^{2}(1)=45.66, p<$ .001 , with a comparative fit index $(\mathrm{CFI})=.843$ and root mean square error of approximation $($ RMSEA $)=.233 .90 \%$ CI $[.178, .293]$. However, the variances for both factors are significant, indicating "strong interindividual differences in both the initial scores...” of loneliness and their change over time (Byrne, 2010, p. 320), supporting continued exploration into this variability related to growth trajectories of loneliness.

In response to the poor fit and as indicated by the significant variances, an iterative expansion of the base model to determine possible changes in model fit was conducted, expanding the model to include a time invariant covariate, gender (see Figure 9) to possibly account for the variability. The result of adding gender as a covariate is a model that continues to be less than adequate, $\chi^{2}(2)=49.97, p<.001$, with a comparative fit index $(\mathrm{CFI})=.833$ and root mean square error of approximation $($ RMSEA $)=.171 .90 \%$ CI [.132, .213].

The expanded model exhibits significant and nonsignificant effects as indicated in Table 8. The majority of the estimates for the means, variances, and covariance in this model are significant. The mean for the intercept reflects an average score of the initial levels of loneliness at $27.967(p<.001)$. The difference in this expanded model is reflected in the mean of the slope factor, which is no longer significant. The slope indicates that the loneliness score decreased by .110 per year $(p=.597)$ with each measure of loneliness. When controlling for gender, the participants as a group did not indicate statistically significant changes in loneliness. However, the variance of the slope 
factor is 1.687 and is statistically significant $(p<.001)$ indicating that there is a significant variability of changes between individuals within the entire group; however, when examined as a group after controlling for gender, the overall average gave the appearance of stability in the rate of loneliness over time. As with the previous LGC model version, the covariance between the slope and intercept factors is negative (-4.562, $p<.001$ ) which still indicates that those who report higher initial loneliness experience a slower rate of change than those who reported lower levels of initial loneliness.

With the addition of gender as a covariate, the factor loadings indicate that there is not a significant effect of gender on either the initial levels of perceived loneliness ( $\beta=$ -.022 ; S. E. $=.609 ; p=.633)$ or the change of loneliness over time $(\beta=-.035$; S. E. $=$ $.130 ; p=.481)$. As a result, gender differences related to perceived loneliness is not currently supported.

CFA model of adolescent risky behavior. In the initial analysis of the CFA model, the model fit indices indicated that $\chi^{2}(5)=66.765, p<.001$, with CFI $=.942$ and RMSEA $=.122,90 \% \mathrm{CI}=[.097, .149]$. The model is a fair fit when considering the CFI; however, the RMSEA indicates that the model is not likely to generalize to the population. As a result, the modification indices (MI) were examined for possible areas of model misfit.

Modification indices provide information related to the parameters that are fixed in the model. The modification indices indicate the expected parameter change if the parameter were allowed to be freely estimated as opposed to being fixed. Many of the changes suggested by the modification indices did not make substantive sense with the exception of the error covariances. In this particular model (see Figure 3), the 
modification indices recommended that the error covariance between violence (E6) and substance use (E8) as well as sexual risk behaviors (E5) and substance use (E8) be freely estimated in the model rather than fixed to zero (as modeled in the first iteration of the model by leaving those covariances absent) for a better model fit to the data (see Table 9).

Substantively, the relationship between these constructs is supported by research and theory, which could manifest itself in the model by having their errors covary. The engagement in substance use increases the likelihood of involvement in violence and sexual risk behaviors (Caminis et al., 2007; O’Donnell et al., 2001). As a result, the model was re-specified to allow for these changes (see Figure 10). Once the error covariances were allowed to be freely estimated, the overall model fit improved. The respecified model is a good fit to the data, $\chi^{2}(3)=8.3, p=.041$, with CFI $=.995$ and RMSEA $=.046,90 \%$ CI $[.008, .085]$. In addition, the unstandardized and standardized factor loadings for all of the observed variables in this model are statistically significant. As a general rule of thumb, it is recommended that standardized regression weights be at least .5 to be acceptable. These results indicate that the observed variables are significant predictors of the latent factor (see Table 10), further support of a good model fit.

In an examination of gender effects, child gender was added as an indicator within the model as a time-invariant constant. When gender is added as a covariate, the model fit indices present a mixed picture about the goodness of fit to the data, $\chi^{2}(6)=66.62, p<$ .001 , with a CFI $=.946$ and RMSEA $=.111,90 \%$ CI $[.088, .135]$. As with the initial CFA model analyzed, the CFI indicates a good fit of the model to the data; however, the 
RMSEA indicates that extending the model beyond the specific sample to the population could be problematic.

As with the previous iteration of the model, the factor loadings are statistically significant, indicating that the observed variables from the questionnaire are good indicators of the latent construct (see Table 11). The addition of gender as a predictor variable is also noteworthy as indicated by the significant path coefficient. The results indicate that adolescent males are more likely to report engaging in risk behaviors than adolescent females.

Full structural model. The full structural model (see Figure 12) involves combining all of the previous models into one cohesive whole, testing for the effects of the variables of interest: early attachment, childhood loneliness, and adolescent risky behaviors. The model fit indices, $\chi^{2}(18)=62.917, p<.001$, CFI $=.967$, RMSEA $=.055$, $90 \% \mathrm{CI}=[.041, .070]$, indicate an adequate to good fit to the data (see Table 12). Further modification of the parameters of the model might address the RMSEA such that a greater confidence in the model extending to the population is better supported (i.e. achieving a cutoff of less than .05). However, the modification indices that are suggested cannot be implemented due to lack of substantive reasoning for any of the suggested changes.

The regression coefficients for the pathways within the LGC and CFA models indicate statistically significant factor loadings between the observed variables and latent variables. When the focus is shifted to the regression coefficients for the structural paths of the model between loneliness and risky behaviors, they are statistically significant. However, the structural paths involving attachment reflect a different picture. The 
regression coefficients for attachment are not statistically significant for the initial levels of loneliness $(\beta=-.033$; S. E. $=.182 ; p=.473)$, changes of loneliness $(\beta=-.033$; S. E. $=$ $.039 ; p=502$.$) , and risky behaviors (\beta=-.051$; S. E. $=.011 ; p=.172)$.

With the final step in model identification, gender was added as time-invariant covariate to test for effects on the overall structural model (see Figure 13). To this point, the effects of gender have been examined with models at the level of the measurement model for loneliness and risky behaviors. The model fit indices, $\chi^{2}(22)=127.916, p<$ $.001, \mathrm{CFI}=.927, \mathrm{RMSEA}=.072,90 \% \mathrm{CI}=[.060, .085]$, indicate an adequate to moderate fit to the data (see Table 13). It would appear that the overall impact of adding the covariate of gender to the overall structural model leads to a decline in the fit of the data to the model. Because the paths involving loneliness were determined to be statistically insignificant with the LGC model alone, they are removed from the overall full model such that the examination of gender effects is on both attachment and risk behaviors. The regression path between gender and attachment is also statistically insignificant, $\beta=-.060$; S. E. $=.117 ; p=.082$. The regression path between gender and risk behaviors is the sole path showing statistical significance, $\beta=-.157$; S. E. $=.036 ; p<$ .001. The implications of these findings are that gender only plays a significant role in the direct relationship with risk behaviors, without the mediating influence of loneliness, in adolescence. The path coefficient suggests that adolescent males in the sample report higher levels of engagement in risk behaviors than females. 


\section{Implications for Hypotheses}

Hypothesis 1. The relationship between early attachment and adolescent risk behaviors will be mediated by the establishment and growth or changes in perceived loneliness from childhood through adolescence.

This hypothesis was not supported by the current analysis. In analyzing the structural model, the fit indices support a good fit to the data. However, upon further investigation, the regression coefficients indicate that the paths salient to the hypothesis do not completely support the mediating model proposed.

The lack of statistical significance between attachment and the other variables of interest (e.g. risky behaviors and loneliness) indicates weak to absent associations between variables with the current data set such that testing for mediational relationships is not indicated since it does not meet key specifications for mediating models. One of these specifications that the model does not meet is the demonstration of a relationship between the predictor and outcome variables (Baron \& Kenny, 1986).

Following the analysis of the overall structural model, the path coefficients within the model was examined. It was determined that the regression coefficient for attachment and risky behaviors was not statistically significant indicating a weak association between the two variables. As a result, it appears that the relationship of early attachment leading to later risky behaviors is not currently supported with this particular analysis.

Another criterion for a mediating model that was not met is reflected in the lack of a relationship between the predictor variable and the mediating variables. In analyzing the relationship between attachment and the mediation variables, the initial level of loneliness and the changes in loneliness, it was determined that the regression coefficient 
for both hypothesized relationships indicates no associations between those variables for the data set.

Only one criterion for mediating models was met; the relationship between the mediating variables and the outcome variable did demonstrate statistical significance indicating a strong relationship between the development of loneliness through childhood into adolescence and adolescent risk behaviors. For the initial levels of loneliness, the regression coefficient indicated a direct relationship with risky behaviors in adolescence. Higher initial levels of loneliness reported in childhood often leads to increased engagement of risky behaviors in adolescence. For the change in loneliness over time, the regression coefficient indicated a direct relationship as well. As a result, as loneliness decreases over time, the coefficient indicates lower levels of engagement in adolescent risky behaviors.

Therefore, given that the mediation model did not satisfy the majority of the criteria as defined, testing the hypothesis of mediation is problematic.

Hypothesis 2. The initial levels of perceived loneliness will mediate the relationship of early attachment style and adolescent risk behaviors.

This hypothesis was not supported by the current analysis. The variables of interest did not meet the criteria for a mediating model. According to Baron and Kenny (1986), in order to establish a viable mediating model, several criteria need to be met. In addition to the establishment of the relationship between the predictor and outcome variables, a relationship between the predictor and mediating variables also needs to be established. The relationship between attachment and the initial levels of loneliness was not statistically significant. 
Hypothesis 3. The changes in levels of perceived loneliness will mediate the relationship of early attachment style and adolescent risk behaviors.

The hypothesis was not supported by the current analysis. As with hypothesis 2 , the relationship between the predictor variable, attachment, and the mediator variable, changes in loneliness, was not statistically significant.

Hypothesis 4. Gender will play a role in the overall structural mediation model, particularly as it relates to the relationship between loneliness and adolescent risk behavior.

Gender does impact the overall structural model as well as the smaller component models, the LGC model of loneliness and the CFA model of risky behaviors. The impact of the time-invariant covariate was mixed for the variables within the structural model. Overall, when gender was added to a model as a covariate, the model fit indices reflect an overall decline in the goodness of fit to the data for each model. It would appear that gender does not offer further explanatory value for the models to which it was added.

In examining the specific structural pathways of the model, gender was most significantly related to risky behaviors in adolescence. The regression coefficient indicates that adolescent males are more likely to engage in more risky behaviors then adolescent females. The paths between gender and the mediating variables of loneliness intercept and loneliness slope are not at all significant with $p$-values of .602 and .457 respectively, indicating that gender is not a significant factor in the initial levels of loneliness or in changes in loneliness through childhood into adolescence. The path between gender and attachment is marginal, $p=.082$. It is possible that gender plays 
some role in attachment security; however, without evidence of statistical significance in the relationship, anything derived from this result would only be speculative at this time.

\section{Summary}

Overall, it appears that the results do not support all of the hypothesized relationships between attachment, loneliness, and risky behaviors as shown in the structural model (see Figure 13).

The full structural model appeared to be a good fit to the data according to the fit indices. However, it appears that the specific path coefficients between the variables of interest warrant a closer examination: attachment and risky behaviors, attachment and loneliness, and loneliness and risky behaviors. One of these defining characteristics is a relationship between the predictor (e.g. attachment) and outcome (e.g. risky behaviors) variables, which is lacking with the current data. Next is a relationship between the

predictor (e. g. attachment) and the mediating variables (e. g. initial levels of loneliness and loneliness changes). With the current data, this relationship is not statistically significant. The only relationship that demonstrates significant structural path coefficients is the one where each mediating variable (e. g. initial levels of loneliness and loneliness changes) exerts influence on the outcome variable (e. g. risky behaviors).

The impact of the time invariant covariate of gender for the structural model lowered the model fit indices resulting in a poorer fit of the model to the data (see Table 16). This was an unexpected impact on the hypothesized model. Upon further examination of the specific path coefficients, the relationship between gender and risk behaviors in adolescence was the only one that achieved statistical significance. There were no gender differences for initial levels of loneliness, loneliness changes over time, 
or early attachment. In conclusion, the overall results do not support any of the hypotheses for this project. 


\section{CHAPTER FIVE}

\section{DISCUSSION AND CONCLUSIONS}

\section{Introduction}

The purpose of this project was to determine the relationship among early attachment, loneliness throughout childhood, and risky behaviors in adolescence. In reviewing the literature, the research indicated that the potential of these relationships merit investigation. Based on the current research, a mediating model was developed for the purposes of this investigation. The statistical methods of SEM and LGC modeling were selected to test this model. A step-by-step approach to the analyses is detailed in the previous chapter. The approach was designed to analyze each individual construct and the individual impact of the covariate, gender, which was followed by an analysis of the full structural model, including detailed analysis of the structural pathways. The focus of this particular chapter is to discuss the implications of the results within the current context of the research while also discussing the future theoretical and practical implications. A review of the limitations of the study will conclude this chapter.

\section{Implications of the Results and Suggestions for Future Research}

Overall, the results of this project are mixed. The results reflect both convergence and divergence with existing research. The most noteworthy finding is the lack of support for the primary assertion of the hypothesized model, the impact of early attachment on 
behaviors in later developmental stages through a mediating affect-based variable, loneliness. As a result, the implications of the findings raise concerns related to theory, research design, and measurement selection and/or design.

Implications of non-significant findings. The theory on which the model is based has strong empirical support for the separate dimensions, or parts of the proposed model. The integration of these separate dimensions was an endeavor to determine how these dimensions related to each other. The hypothesized model using a mediating variable was a viable possibility that was supported by the existing research in the areas of attachment, childhood loneliness, and adolescent risk behaviors. The growth of loneliness over time is a viable construct as a mediator between the primary relationship between early attachment and later risky behaviors because it meets the established criteria as set by Baron and Kenny (1986). In addition, research supports a more indirect influence of early attachment on later developmental variables (see Carlson et al., 2004; Sroufe et al., 1990; Sroufe et al., 1999; Thompson, 2008a). In the spirit of this direction of research, the proposed mediating model was a theory-based attempt to reflect this indirect influence through an affect-based variable, changes in loneliness over time. Although theory supports the intent of the model, the implications of the non-significant path coefficients would seem to indicate that some adjustment to the model itself is needed.

This is not to say that the proposed model is without merit; however, the results seem to indicate the need to consider further specification of the identified constructs within the model. Currently, the results indicate that changes in loneliness over time do not provide significant mediating effects for the primary relationship. This finding is 
potentially a reflection that other contextual variables need to be considered. When examining the literature of loneliness in children, the focus of the construct is on the nature of peer relationships. According to Rubin et al. (1991), social withdrawal and social rejection are two separate constructs that can result in different outcomes. For example, children who self-isolate from peers are at risk for possible internalizing behaviors; whereas, children who are isolated due to rejection by peers are at risk for more externalizing behaviors that are carried forward into later developmental stages. In this particular proposed model, the specific risk behaviors that are identified are generally considered more externalizing than internalizing which have implications for the overall results. The theoretical underpinnings are essentially unchanged in that loneliness leads to later risk behaviors; however, it may be that the theoretical model needs to account for the specific origins of loneliness when considering the specific outcome variable.

Further examination of the constructs of the proposed model indicates that other adjustments to the specific constructs may be warranted. Previous research models have examined loneliness as a single affect event at a single point of time rather than the development of affect over time. The antecedents and development of loneliness over time have not been as well examined in the current literature. As a result, relatively little is known about the growth trajectory of loneliness. In the current model, loneliness is modeled as a growth model over three different time points, positing a linear growth trajectory. Existing literature does not contraindicate a linear model of growth over time for childhood loneliness. However, the less than adequate fit of the growth model for the development of childhood loneliness indicates that the linear model of change is not supported by the current data, so a nonlinear growth model may need to be considered. 
Perceived loneliness is an internal construct that can be impacted by environmental circumstances such as peer rejection or peer neglect (Corsano, Majorano, \& Champretavy, 2006; Boivin et al., 1994) or internal changes related to a developing sense of self. It is possible that at one point, the feelings of loneliness are more salient than at other points of development resulting in a nonlinear pattern of change over time. It is also possible that the growth trajectory of loneliness through childhood into adolescence truly does not mediate the relationship between early attachment and adolescent risk behaviors; however, it may be premature at this point to make that conclusion without further exploration of possible model modifications.

Another consideration for modification of the proposed model is that a stronger model may be more complex than what is currently proposed. As a result, additional variables may need to be considered within the model. For example, early attachment rating is often considered a reflection of the parent-child relationship providing a foundation on which future interactions within relationships are based. However, according to de Minzi (2006), the constructs of attachment and parent-child relationship styles are distinct constructs to be considered in various outcome variables such as behavior. This distinction in the related constructs is potentially a reflection of the changes that invariably occur throughout development. According to current research and theory, the influence of the early developmental years on later developmental stages can be constant but are more often adaptable to changing factors, such environment and affect. Model modifications could consider the development of parent-child relationships throughout childhood impacting child affect during that time and ultimately behavior outcomes in later stages of development. The growth trajectory of parent-child 
relationships over time is one possible consideration in model modification that is in accord with the theoretical underpinnings of the model.

Overall, because the research is fairly robust in the support of the general theory for this model, model modifications seem to be a more appropriate course of action for future endeavors at this point. This integration of the dimensions of the model has not been fully explored in the research and would seem to merit further investigation prior to modification of the overall theory, especially given that previous research in the areas of attachment, childhood loneliness, and adolescent risk behaviors support this line of inquiry. Theory modification might be premature until further studies are conducted.

Implications for significant findings. Even within the context of nonsignificance, the results reflected something worthwhile. The most significant finding is that the relationship between affect and behaviors in adolescence was upheld by the results. The current model and data indicated that loneliness does impact engagement in risky behaviors. The initial level of loneliness, as indicated by the intercept, and the changes in loneliness over time, as indicated by the slope, are both directly associated with engagement in risky behaviors. In other words, participants who reported experiencing greater loneliness through childhood would also report higher levels of engagement in risky behaviors in adolescence (see Boivin et al., 1994; Crick \& Ladd, 1993; Guertin et al., 2001; Kidd, 2006; Parker \& Asher, 1987). This finding has implications for practice such that identifying loneliness in children during middle childhood into early adolescence is a step in effective intervention and prevention of risk behavior engagement. 
In identifying gender differences, the current findings on the impact of gender on loneliness supported previous research. As reviewed in a previous section, gender effects on childhood loneliness has presented with variable and inconsistent results (Coplan, et al., 2007; Heinrich \& Gullone, 2006). The lack of significant impact of gender on both initial levels of loneliness and changes of loneliness over time indicates that gender does not play a significant role in perception of childhood loneliness.

The impact of gender on adolescent risky behaviors was also in line with previous research results. Overall, the current findings indicate that there is a gender difference as it relates to the engagement of externalizing risky behaviors. The gender effect for the hypothesized CFA model for risky behaviors indicated that males were more likely to engage in more risk behaviors than females. According to the existing research, gender differences vary with the type of risky behavior being considered (see Centers for Disease Control, 2010; Somers \& Gizzi, 2001). According to the Centers for Disease Control (2010), males are found to be more likely to engage in more externalizing risk behaviors related to violence or delinquent behaviors (see also Thompson, 2011), whereas females have been shown to be more likely to engage in more internalizing behaviors (see Zahn-Waxler et al., 2000) leading to risk behaviors such as those related to self-harm such as self-mutilating behavior (see Guertin et al., 2001). Other risk behaviors such as those related to engagement in sexual risk or substance use have mixed results on gender differences (see Centers for Disease Control, 2010). The observed gender effect in this study could be attributed to the item preference for the delinquent and violent behaviors in the selected questionnaire by male participants. 
Summary. Although the overall conclusions are not as anticipated, given the available research that connects the variables of early attachment, childhood loneliness, and adolescent risk behaviors, continued research is still warranted, addressing the limitations of this particular study in future model development and testing. Model refinement addressing the limitations of the study previously discussed could result in different outcomes. Ideally, the data set used in future studies would be ones developed with early attachment constructs in mind, specifically the impact of early attachment on later outcomes.

However, not all findings were disappointing. The findings that did reflect statistical significance have important theoretical and practical implications. The significance of the relationship between the latent variables reflecting the growth trajectory of childhood loneliness and adolescent risky behavior has practical implications for efforts of intervention and/or prevention of behaviors that potentially have long-term consequences. Children who report elevated levels of loneliness and/or demonstrate a progressive increase in loneliness over time could be identified as being at greater risk for higher levels of engagement in risky behaviors as they enter adolescence. The theoretical implication of the finding is the continued empirical support for the robust relationship between developing affect leading to risk behaviors in later stages of development.

The gender effects of risky behavior lends further support to the existing research that males are more prone to engage in more violent and disruptive behaviors than females. Future research could address the risk behaviors in which females are more prone to engage. This would require modifications to the indices of the current 
measurement model for the outcome of risky behaviors, resulting in qualitatively different definitions of risk behaviors. Gender effects may also have implications for the overall model pathways such that models reflect gender specific differences.

\section{Limitations of the Study}

When examining overall research design, the design of the study is appropriate for the research questions proposed. The archival data set selected for the research study was appropriate in that the measures selected reflected the constructs of interest. Each selected measure was found to be reliable and valid measures for the respective construct. The sample size was adequate for the statistical approach selected for this project. The longitudinal data collected were appropriate for the proposed growth model of the mediating variable. Overall, the design of the study is solid. However, as with any other study, this particular project has limitations. The major limitations for this study can be attributed to sample selection and measurement selection related to both the selected data set and the subsequent choices made specifically for this particular project.

Because of the breadth and depth of most longitudinal archival data sets, secondary data analysis has become fairly common and accepted method to address research questions that require longitudinal data while addressing the factors related to time, effort, and cost (Trzesniewski, Donnellan, \& Lucas, 2011). In this particular study, the selection of the NICHD SECCYD data set met the criteria for research question posed for this project. However, there were certain aspects of the data set that possibly influenced the overall results obtained through the analyses. 
When addressing sample selection, the investigators of NICHD SECCYD project are forthcoming with the limitations of the sample, including exclusionary criteria as part of the participant pool recruitment. The exclusionary criteria, applied during the initial stages of participant recruitment, eliminated individuals with certain high risk demographic characteristics. Potential participants were excluded from consideration if the mother was underage at the time of the child's birth, the family lived in an area deemed unsafe for home visitation, the mother had a known substance use history, the mother was not fluent in English, or the presence of greater risk of developmental disabilities. In considering the exclusionary criteria, it would seem that a portion of candidates from higher risk environments was not considered. The implications of these exclusionary criteria are that the higher risk subgroup for the overall sample is possibly underrepresented, limiting the number of children with insecure attachment, higher levels of loneliness, and greater engagement in risky behaviors from the sample pool.

In preparation for data analyses, adjustments made for missing data most likely further limited the study sample. Listwise deletion was the conservative method selected resulting in the deletion of approximately $40 \%$ of the original sample due to missing data. Although the results of the bivariate analyses indicated that any difference between the group with completed data and the group with missing data lacked practical significance due to very small effect sizes, the elimination of the group with missing data could have resulted in a subsample of participants representing a healthier subgroup with respect to attachment, reports of loneliness, and engagement in risky behaviors. The potential presence of this bias in the composition of the sample of completed data has implications for the assumption that data are missing at random. Given this information post-hoc, 
other methods such as imputation would need to be considered over listwise deletion for similar future studies.

With respect to measurement selection and design, the measures selected were found to be reliable and appropriate for the constructs being tested. However, others have argued for the limitations of self-report measures. It has been documented in the literature that self-report measures (see Furnham, 1986; Podsakoff, MacKenzie, Lee, \& Podsakoff, 2003), particularly when focused on sensitive topics, are impacted by possible response bias by participants. Social desirability could have influenced how participants reported levels of loneliness and frequency of risk behavior engagement. Fortunately, there does not appear to be reason to consider that the self-report of risk behaviors or perceived loneliness in this study are biased. For this particular study, the major salient limitation involving self-report instruments is the use of only a single measure for each construct of interest. Not having multiple sources of information for the latent constructs could have implications for the overall results of the study. 


\section{REFERENCES}

Achenbach, T. M., \& Edelbrook, C. S. (1978). The classification of child psychopathology: A review and analysis of empirical efforts. Psychological Bulletin, 85 (6), 1275-1301. doi: 10.1037//0033-2909.85.6.1275

Ackerson, L. L. (1942). Children's behavior problems, Vol. II: Relative importance and interrelations among traits. Oxford, England: University Chicago Press.

Aguilar, B., Sroufe, L. A., Egeland, B. \& Carlson, E. (2000). Distinguishing the earlyonset/persistent and adolescence-onset antisocial behavior types: From birth to 16 years. Development and Psychopathology, 12, 109-132. doi: $10.1017 / S 0954579400002017$

Ainsworth, M. D. (1969). Object relations, dependency, and attachment: A theoretical review of the infant-mother relationship. Child Development, 40, 969-1025. doi: $\underline{10.2307 / 1127008}$

Ainsworth, M. D. (1989). Attachments beyond infancy. American Psychologist, 44, 709716. doi: 10.1037/0003-066X.44.4.709

Ainsworth, M. D., Blehar, M. C., Waters, E., \& Wall, S. (1978). Patterns of attachment: A psychological study of the Strange Situation. Hillsdale, NJ: Lawrence Erlbaum Associates.

Allen, J. P., Marsh, P., McFarland, C., McElhaney, K. B., Land, D. J., Jodl, K. M., \& 
Peck, S. (2002). Attachment and autonomy as predictors of the development of social skills and deviance during midadolescence. Journal of Consulting and Clinical Psychology, 70, 56-66. doi: 10.1037//0022-006X.70.1.56

Allen, J. P., Moore, C., Kuperminc, G., \& Bell, K. (1998). Attachment and adolescent psychosocial functioning. Child Development, 69, 1406-1419. doi: 10.1111/j.1467-8624.1998.tb06220.x

Allen, J. P., Porter, M. R., McFarland, F. C., Marsh, P., \& McElhaney, K. B. (2005). The two faces of adolescents' success with peers: adolescent popularity, social adaptation, and deviant behavior. Child Development, 76(3), 747-760. doi: 10.1111/j.1467-8624.2005.00875.x

Allison, P. D. (2003). Missing data techniques for structural equation modeling. Journal of Abnormal Psychology, 112(4), 545-557. doi: 10.1037/0021-843X.112.4.545

Arbuckle, J. L. (2011). AMOS (Version 20.0) [Computer software]. Chicago: IBM SPSS. Asher, S. R., \& Wheeler, V. A. (1985). Children's loneliness: A comparison of rejected and neglected peer status. Journal of Consulting and Clinical Psychology, 53(4), 500-505. doi: $\underline{\text { 10.1037//0022-006X.53.4.500 }}$

Asher, S. R., Hymel, S., \& Renshaw, P. D. (1984). Loneliness in children. Child Development, 55,1456-1464. doi: $\underline{10.2307 / 1130015}$

Askénazy, F. L., Sorci, K., Benoit, M., Lestideau, K., Myquel, M., \& Lecrubier, Y. (2003). Anxiety and impulsivity levels identify relevant subtypes in adolescents with at-risk behavior. Journal of Affective Disorders, 74, 219-227. doi: $\underline{10.1016 / S 0165-0327(02) 00455-X}$

Baron, R. M., \& Kenny, D. A. (1986). The moderator-mediator variable distinction in 
social psychological research: Conceptual , strategic, and statistical considerations. Journal of Personality and Social Psychology, 51, 1173-1182. doi: 10.1037/0022-3514.51.6.1173

Bates, J. E., Maslin, C. A., \& Frankel, K. A. (1985). Attachment security, mother-child interaction, and temperament as predictors of behavior-problem ratings at age three years. Monographs of the Society for Research in Child Development, 50 (12), 167-193. doi: $10.2307 / 3333832$

Belsky, J., Houts, R. M., \& Pasco Fearon, R. M. (2010). Infant attachment security and the timing of puberty: Testing an evolutionary hypothesis. Psychological Science, 21(9), 1195-1201. doi: 10.1177/0956797610379867

Belsky, J., \& Pasco Fearon, R. M. (2002a). Early attachment security, subsequent maternal sensitivity, and later child development: Does continuity in development depend upon continuity of caregiving? Attachment \& Human Development, 4(3), 361-387. doi: 10.1080/14616730210167267

Belsky, J., \& Pasco Fearon, R. M. (2002b). Infant-mother attachment security, contextual risk and early development: A moderational analysis. Development and Psychopathology, 14, 293-310. doi: 10.1017/S0954579402002067

Bentler, P. M. (1990). Comparative fit indexes in structural models. Psychological Bulletin, 107(2), 238-246. doi: 10.1037/0033-2909.107.2.238

Berlin, L. J., Cassidy, J., \& Belsky, J. (1995). Loneliness in young children and infantmother attachment: A longitudinal study. Merrill-Palmer Quarterly, 41(1), 91103.

Birmaher, B., Ryan, N. D., Williamson, D. E., Brent, D.., Kaufman, J., Dahl, R. 
E.,...Nelson. B. (1996). Childhood and adolescent depression: A review of the past 10 years. Part I. Journal of the American Academy of Child and Adolescent Psychiatry, 35(11), 1427-1439. doi: 10.1097/00004583-199611000-00011

Bogaerts, S., Vanheule, S., \& Desmet, M. (2006). Feelings of subjective emotional loneliness: An exploration of attachment. Social behavior and personality, 34(7), 797-812. doi: $\underline{10.2224 / s b p .2006 .34 .7 .797}$

Boivin, M., Poulin, F., \& Vitaro, F. (1994). Depressed mood and peer rejection in childhood. Development and Psychopathology, 6, 483-498. doi: $\underline{10.1017 / S 0954579400006064}$

Bollen, K. A., \& Long, J. S. (1993). Tests for structural equation models: Introduction. Sociological Methods \& Research, 21(2), 122-131. doi: $10.1177 / 0049124192021002001$

Booth-LaForce, C. L., \& Oxford, M. L. (2008). Trajectories of social withdrawal from grades 1 to 6: Prediction from early parenting, attachment, and temperament. Developmental Psychology, 44(5), 1298-1313. doi: 10.1037/a0012954

Borys, S., \& Perlman, D. (1985). Gender differences in loneliness. Personality and Social Psychology Bulletin, 11(1), 63-74. doi: 10.1177/0146167285111006

Bosquet, M., \& Egeland, B. (2006). The development and maintenance of anxiety symptoms from infancy through adolescence in a longitudinal sample. Development and Psychopathology, 18, 517-550. doi: $\underline{10.1017 / S 0954579406060275}$

Bost, K. K., Vaughn, B. E., Washington, W. N., Cielinski, K. L., \& Bradbard, M. R. 
(1998). Social competence, social support, and attachment: Demarcation of construct domains, measurement, and paths of influence for preschool children attending head start. Child Development, 69(1), 192-218. doi: 10.1111/j.14678624.1998.tb06143.x

Bowlby, J. (1969). Attachment and loss: Vol. 1 Attachment. New York: Basic Books. Bowlby, J. (1972). Attachment and loss: Vol. 2 Separation. New York: Basic Books. Bowlby, J. (1980). Attachment and loss: Vol. 3 Loss. New York: Basic Books.

Brennan, T. (1982). Loneliness at Adolescence. In L. A. Peplau \& D. Perlman (Eds.), Loneliness: A sourcebook of current theory, research, and therapy (pp. 269-290). New York: John Wiley \& Sons, Inc..

Bretherton, I., \& Munholland, K. A. (2008). Internal working models in attachment relationships: Elaborating a central construct in attachment theory. In J. Cassidy, P. R. Shaver (Eds.), Handbook of attachment: Theory, research, and clinical applications (2nd ed.) (pp. 102-127). New York, NY US: Guilford Press.

Bretherton, I., \& Waters, E. (Eds.). (1985). Growing points of attachment theory and research. Monographs of the Society for Research in Child Development, 50, Serial No. 209 (1-2).

Bronfenbrenner, U. (1979). The ecology of human development: Experiments by nature and design. Cambridge, MA: Harvard University Press.

Bronfenbrenner, U., \& Ceci, S. J. (1994). Nature-nurture reconceptualized in developmental perspective: A bioecological model. Psychological Review, 101(4), 568-586.

Bronfenbrenner, U. \& Evans, G. W. (2000). Developmental science in the $21^{\text {st }}$ century: 
Emerging questions, theoretical models, research designs, and empirical findings. Social Development, 9(1), 115-125. doi: 10.1111/1467-9507.00114

Browne, M. W., \& Cudeck, R. (1992). Alternative ways of assessing model fit. Sociological Methods \& Research, 21(2), 230-258. doi: $\underline{10.1177 / 0049124192021002005}$

Burchinal, M., Nelson, L., \& Poe, M. (2006). Best practices in quantitative methods for developmentalists: IV. Growth curve analysis: An introduction to various methods for analyzing longitudinal data. Monographs of the Society for Research in Child Development, 71(3), 65-87.

Burstein, L. (1978). Secondary analysis: An important resource for educational research and evaluation. Educational Researcher, 7(5), 9-12. doi:

10.3102/0013189X007005009

Byrne, B. (2001). Structural equation modeling with AMOS: Basic concepts, applications, and programming. Mahwah, NJ: Lawrence Erlbaum.

Byrne, B. M. (2010). Structural equation modeling with AMOS: Basic concepts, applications, and programming. ( $2^{\text {nd }}$ ed.). New York: Routledge.

Byrne, B. M., \& Crombie, G. (2003). Modeling and Testing Change: An Introduction to the Latent Growth Curve Model. Understanding Statistics, 2(3), 177-203. doi: 10.1207/S15328031US0203_02

Caminis, A., Henrich, C., Ruchkin, V., Schwab-Stone, M., \& Martin, A. (2007). Psychosocial predictors of sexual initiation and high-risk sexual behavior in early adolescence. Child and Adolescent Psychiatry Mental Health, 1. doi:10.1186/1753-2000-1-14

Campbell, S. B., Shaw, D. S., \& Gilliom, M. (2000). Early externalizing behavior 
problems: Toddlers and preschoolers at risk for later maladjustment. Development and Psychopathology, 12, 467-488. doi: 10.1017/S0954579400003114

Carlson, E. A. (1998). A prospective longitudinal study of attachment disorganization/disorientation. Child Development, 69(4), 1107-1128. doi: 10.3102/0013189X007005009

Carlson, E. A., \& Sroufe, L. A. (1995). Contribution of attachment theory to developmental psychopathology. In D. Cicchetti, D. \& J. Cohen (Eds.), Developmental psychopathology, Vol. 1: Theory and methods (pp. 581-617). Oxford England: John Wiley \& Sons.

Carlson, E. A., Sroufe, L. A., \& Egeland, B. (2004). The construction of experience: a longitudinal study of representation and behavior. Child Development, 75(1), 6683. doi: $10.1111 / \mathrm{j} .1467-8624.2004 .00654 . x$

Cassidy, J., \& Asher, S. (1992). Loneliness and peer relations in young children. Child Development, 63(2), 350-365. doi: 10.1111/j.1467-8624.1992.tb01632.x

Cassidy, J., \& Marvin, R. S., with the MacArthur Working Group (1992). Attachment organization in preschool children: Procedures and coding manual (4th ed.). Unpublished manuscript, University of Virginia.

Cassidy, J., Kirsh, S. J., Scolton, K. L., \& Parke, R. D. (1996). Attachment and representations of peer relationships. Developmental Psychology, 32(5), 892-904. doi:10.1037/0012-1649.32.5.892

Cassidy, J., Ziv, Y., Mehta, T., \& Feeney, B. (2003). Feedback seeking in children and adolescents: associations with self-perceptions, attachment representations, and depression. Child Development, 74(2), 612-628. doi: 10.1111/1467-8624.7402019 
Centers for Disease Control and Prevention (CDC). (2010). Youth Risk Behavior Surveillance - United States, Surveillance Summaries, 2009. Morbidity and Mortality Weekly Reports, 59 (SS-5). Retrieved from http://www.cdc.gov/mmwr/pdf/ss/ss5905.pdf

Chipuer, H. M. (2001). Dyadic attachments and community connectedness: Links with youths' loneliness experiences. Journal of Community Psychology, 29(4), 429446. doi: 10.1002/jcop.1027.abs

Clark, D., Lynch, K., Donovan, J., \& Block, G. (2001). Health problems in adolescents with alcohol use disorders: Self-report, liver injury, and physical examination findings and correlates. Alcoholism, Clinical and Experimental Research, 25(9), 1350-1359. doi: 10.1111/j.1530-0277.2001.tb02358.x

Clarke, A. M., \& Clarke, A. D. B. (1976). The formative years? In Clarke, A. M. and Clarke, A. D. B., Early experience: Myth and evidence, (pp. 3-24). New York: The Free Press.

Cohen, J. (1988). Statistical power analysis for the behavioral sciences $\left(2^{\text {nd }}\right.$ ed.). Hillsdale, NJ: Lawrence Erlbaum.

Cohn, D. (1990). Child-mother attachment of six-year-olds and social competence at school. Child Development, 61(1), 152-162. doi: 10.1111/j.14678624.1990.tb02768.x

Conger, R. D., and Elder, G. H. (1994). Families in troubled times: Adapting to change in rural America. New York: Aldine de Gruyter.

Cooper, M., Shaver, P., \& Collins, N. (1998). Attachment styles, emotion regulation, and 
adjustment in adolescence. Journal of Personality and Social Psychology, 74(5), 1380-1397. doi: 10.1037//0022-3514.74.5.1380

Coplan, R., Closson, L., \& Arbeau, K. (2007). Gender differences in the behavioral associates of loneliness and social dissatisfaction in kindergarten. Journal of Child Psychology and Psychiatry and Allied Disciplines, 48(10), 988-995. doi: 10.1111/j.1469-7610.2007.01804.x

Corsano, P., Majorano, M., \& Champretavy, L. (2006). Psychological well-being in adolescence: The contribution of interpersonal relations and experience of being alone. Adolescence, 41(162), 341-353.

Crick, N. R., \& Ladd, G. W. (1993). Children's perceptions of their peer experiences: Attributions, loneliness, social anxiety. Developmental Psychology, 29(2), 244. doi: 10.1037//0012-1649.29.2.244

Dallaire, D., \& Weinraub, M. (2005). Predicting children's separation anxiety at age 6: The contributions of infant-mother attachment security, maternal sensitivity, and maternal separation anxiety. Attachment \& Human Development, 7(4), 393-408. doi: $10.1080 / 14616730500365894$

Dallaire, D. H., \& Weinraub, M. (2007). Infant-mother attachment security and children's anxiety and aggression at first grade. Journal of Applied Developmental Psychology, 28(5/6), 477-492. doi:10.1016/j.appdev.2007.06.005

DeKlyen, M., \& Greenberg, M. T. (2008). Attachment and psychopathology in childhood. In J. Cassidy \& P. R. Shaver (Eds.), Handbook of attachment: Theory, research, and clinical applications (2nd ed.) (pp. 637-665). New York, NY US: Guilford Press. 
de Minzi, M. (2006). Loneliness and depression in middle and late childhood: The relationship to attachment and parental styles. Journal of Genetic Psychology, 167(2), 189. doi: 10.3200/GNTP.167.2.189-210

DiTommaso, E., Brannen-McNulty, C., Ross, L., \& Burgess, M. (2003). Attachment styles, social skills and loneliness in young adults. Personality \& Individual Differences, 35(2), 303. doi:10.1016/S0191-8869(02)00190-3

Doyle, A. B., Moretti, M. M., Brendgen, M., \& Bukowski, W. (2003). Parent-child relationships and adjustment in adolescence: Findings from the HBSC Cycle 3 and NLSCY Cycle 2 studies - Technical report to Division of Childhood and Adolescence, Public Health Agency of Canada.

Dykas, M. J., Ziv, Y., \& Cassidy, J. (2008). Attachment and peer relations in adolescence. Attachment \& Human Development, 10(2), 123-141. doi:10.1080/14616730802113679

Efrati-Virtzer, M. M., \& Margalit, M. M. (2009). Students' behaviour difficulties, sense of coherence and adjustment at school: Risk and protective factors. European Journal of Special Needs Education, 24(1), 59-73. doi: $10.1080 / 08856250802596758$

Egeland, B., Kalkoske, M., Gottesman, N., \& Erickson, M. F. (1990). Preschool behavior problems: Stability and factors accounting for change. Journal of Child Psychology and Psychiatry, 31(6), 891-909. doi:10.1111/j.14697610.1990.tb00832.x

Egeland, B., Pianta, R., \& Ogawa, J. (1996). Early behavior problems: Pathways to 
mental disorders in adolescence. Development and Psychopathology, 8(4), 735749. doi:10.1017/S0954579400007392

Elicker, J., Englund, M., \& Sroufe, L. (1992). Predicting peer competence and peer relationships in childhood from early parent-child relationships. In R. D. Parke \& G. W. Ladd (Eds.), Family-peer relationships: Modes of linkage (pp. 77-106). Hillsdale, NJ: Lawrence Erlbaum Associates, Inc.

Erickson, M., Sroufe, L., \& Egeland, B. (1985). The relationship between quality of attachment and behavior problems in preschool in a high-risk sample. Monographs of the Society for Research in Child Development, 50(1/2), 147-166. doi:10.1111/1540-5834.ep11890039

Escobar-Chaves, S., \& Anderson, C. A. (2008). Media and risky behaviors. Future of Children, 18(1), 147-180.

Fagot, B. I., \& Kavanagh, K. (1990). The prediction of antisocial behavior from avoidant attachment classifications. Child Development, 61(3), 864. doi:10.1111/14678624.ep5858742

Fontaine, R., Yang, C., Burks, V., Dodge, K. A., Price, J. M., Pettit, G. S., \& Bates, J. E. (2009). Loneliness as a partial mediator of the relation between low social preference in childhood and anxious/depressed symptoms in adolescence. Development and Psychopathology, 21(2), 479-491. doi:10.1017/S0954579409000261

Fraley, R. (2002). Attachment stability from infancy to adulthood: Meta-analysis and dynamic modeling of developmental mechanisms. Personality \& Social Psychology Review, 6(2), 123-151. doi: 10.1207/S15327957PSPR0602_03 
Friedman, S. L., \& Boyle, D. (2008). Attachment in US children experiencing nonmaternal care in the early 1990s. Attachment \& Human Development, 10(3), 225-261. doi:10.1080/14616730802113570

Furnham, A. (1986). Response bias, social desirability and dissimulation. Personality and Individual Differences, 7(3), 385-400. doi:10.1016/0191-8869(86)90014-0

Galanaki, E. (1999). Loneliness and social dissatisfaction: Its relation with children's selfefficacy for peer interaction. Child Study Journal, 29(1). Retrieved from: MasterFILE Premier.

Galéra, C. C., Bouvard, M. P., Encrenaz, G. G., Messiah, A. A., \& Fombonne, E. E. (2008). Hyperactivity-inattention symptoms in childhood and suicidal behaviors in adolescence: The Youth Gazel Cohort. Acta Psychiatrica Scandinavica, 118(6), 480-489. doi:10.1111/j.1600-0447.2008.01262.x

Gardner, M., \& Steinberg, L. (2005). Peer influence on risk taking, risk preference, and risky decision making in adolescence and adulthood: An experimental study. Developmental Psychology, 41(4), 625-635. doi: 10.1037/0012-1649.41.4.625

Georgiades, K., \& Boyle, M. H. (2007). Adolescent tobacco and cannabis use: Young adult outcomes from the Ontario Child Health Study. Journal of Child Psychology \& Psychiatry, 48(7), 724-731. doi:10.1111/j.1469-7610.2007.01740.x

Goosens, L., Marcoen, A., van Hees, S., \& van de Woestijne, O. (1998). Attachment style and loneliness in adolescence. European Journal of Psychology of Education, 13(4), 529-542. doi:10.1007/BF03173103

Greenberg, M. T., \& Speltz, M. L. (1988). Attachment and the ontogeny of conduct 
problems. In J. Belsky \& T. Nezworski (Eds.), Clinical implications of attachment (pp. 177-218). Hillsdale, NJ England: Lawrence Erlbaum Associates, Inc.

Greenberg, M. T., Speltz, M. L., \& DeKlyen, M. (1993). The role of attachment in the early development of disruptive behavior problems. Development and Psychopathology, 5(1-2), 191-213. doi:10.1017/S095457940000434X

Greenberg, M. T., Speltz, M. L., DeKlyen, M., \& Jones, K. (2001). Correlates of clinic referral for early conduct problems: Variable- and person-oriented approaches. Development and Psychopathology, 13(2), 255-276. doi:10.1017/S0954579401002048

Guertin, T., Lloyd-Richardson, E., Spirito, A., Donaldson, D., \& Boergers, J. (2001). Self-mutilative behavior in adolescents who attempt suicide by overdose. Journal of the American Academy of Child \& Adolescent Psychiatry, 40(9), 1062-1069. doi: 10.1097/00004583-200109000-00015

Halpern-Felsher, B. L., Biehl, M., Kropp, R. Y., \& Rubinstein, M. L. (2004). Perceived risks and benefits of smoking: Differences among adolescents with different smoking experiences and intentions. Preventive Medicine, 39(3), 559-567. doi:10.1016/j.ypmed.2004.02.017

Halpern-Felsher, B. M. (2005). Oral versus vaginal sex among adolescents: Perceptions, attitudes, and behavior. Pediatrics, 115(4), 845-851. doi:10.1542/peds.2004-2108

Hankin, B. L., Abramson, L. Y., Moffitt, T. E., Silva, P. A., McGee, R., \& Angell, K. E. (1998). Development of depression from preadolescence to young adulthood: Emerging gender differences in a 10-year longitudinal study. Journal of Abnormal Psychology, 107(1), 128-140. doi: 10.1037/0021-843X.107.1.128 
Hawkins, J., Catalano, R. F., \& Arthur, M. W. (2002). Promoting science-based prevention in communities. Addictive Behaviors, 27(6), 951-976. doi: 10.1016/S0306-4603(02)00298-8

Hecht, D., \& Baum, S. K. (1984). Loneliness and attachment patterns in young adults. Journal of Clinical Psychology, 40(1), 193-197. doi: 10.1002/10974679(198401)40:1<193::AID-JCLP2270400136>3.0.CO;2-2

Heinrich, L. M., \& Gullone, E. (2006). The clinical significance of loneliness: A literature review. Clinical Psychology Review, 26(6), 695-718. doi:10.1016/j.cpr.2006.04.002

Hewitt, L. E., and Jenkins, R. L. (1946). Fundamental patterns of maladjustment; the dynamics of their origin; a statistical analysis based upon five hundred case records of children examined at the Michigan Child Guidance Institute. Oxford, England: State of Illinois.

Hooven, C., Herting, J. R., \& Snedker, K. A. (2010). Long-Term Outcomes for the Promoting CARE Suicide Prevention Program. American Journal of Health Behavior, 34(6), 721-736. doi: 10.5993/AJHB.34.6.8

Hopwood, C. J. (2007). Moderation and mediation in structural equation modeling: Applications for early intervention research. Journal of Early Intervention, 29(3), 262-272. doi: 10.1177/105381510702900305

Hu, L., \& Bentler, P. M. (1995). Evaluating model fit. In R. H. Hoyle (Ed.), Structural equation modeling: Concepts, issues, and applications (pp. 76-99). Thousand Oaks, CA US: Sage Publications, Inc.

Hu, L., \& Bentler, P. M. (1999). Cutoff criteria for fit indexes in covariance structure 
analysis: Conventional criteria versus new alternatives. Structural Equation Modeling, 6(1), 1-55. doi: 10.1080/10705519909540118

Hymel, S., Bowker, A., \& Woody, E. (1993). Aggressive versus withdrawn unpopular children: Variations in peer and self-perceptions in multiple domains. Child Development, 64(3), 879-896. doi:10.2307/1131224

Jessor, R. (1991). Risk behavior in adolescence: A psychosocial framework for understanding and action. Journal of Adolescent Health, 12(8), 597-605. doi:10.1016/1054-139X(91)90007-K

Jessor, R., \& Jessor, S. L. (1977). Problem behavior and psychosocial development: A longitudinal study of youth. New York: Academic Press.

Kidd, S. A. (2006). Factors precipitating suicidality among homeless youth: A quantitative follow-up. Youth \& Society, 37(4), 393-422. doi: 10.1177/0044118X05282763

Klein, J., Brown, J. D., Childers, K. W., Oliveri, J., Porter, C., \& Dykers, C. (1993). Adolescents' risky behavior and mass media use. Pediatrics, 92(1), 24-31.

Konold, T., Hamre, B., \& Pianta, R. (2003). Measuring problem behaviors in young children. Behavioral Disorders, 28, 111-123.

Laederach, J., Fischer, W., Bowen, P., and Ladame, F. (1999). Common risk factors in adolescence suicide attempts revisited. Crisis, 20, 15-22. doi: 10.1027//02275910.20 .1 .15

LaFreniere, P. J., \& Sroufe, L. (1985). Profiles of peer competence in the preschool: 
Interrelations between measures, influence of social ecology, and relation to attachment history. Developmental Psychology, 21(1), 56-69. doi: 10.1037//00121649.21.1.56

Lamb, M. E., Thompson, R. A., Gardner, W. P., \& Charnov, E. L. (1986). Convergent approaches to understanding strange situation behavior. Behavioral and Brain Sciences, 9(3), 559-561. doi:10.1017/S0140525X00047130

Larose, S., Guay, F., \& Boivin, M. (2002). Attachment, social support, and loneliness in young adulthood: A test of two models. Personality and Social Psychology Bulletin, 28(5), 684-693. doi:10.1177/0146167202288012

Lasgaard, M., Goossens, L., Bramsen, R. H., Trillingsgaard, T., and Elklit,A. (2011). Different sources of loneliness are associated with different forms of psychopathology in adolescence. Journal of Research in Personality, 45, 233237. doi:10.1016/j.jrp.2010.12.005

Levin, I., \& Stokes, J. P. (1986). An examination of the relation of individual difference variables to loneliness. Journal of Personality, 54(4), 717. doi:10.1111/14676494.ep8970527

Lewis, M., Feiring, C., McGuffog, C., \& Jaskir, J. (1984). Predicting psychopathology in six-year-olds from early social relations. Child Development, 55(1), 123. doi:10.1111/1467-8624.ep7405477

Lewis, M., Feiring, C., \& Rosenthal, S. (2000). Attachment over time. Child Development, 71(3), 707-20. doi: 10.1111/1467-8624.00180

Lezine, D. (2006). Psychological pain as a predictor of suicidality: A longitudinal, 
prospective study. Dissertation Abstracts International: Section B. Sciences and Engineering, 67(2-B), 1156.

Loeber, R. (1982). The stability of antisocial and delinquent child behavior: A review. Child Development, 53(6), 1431-46. doi: 10.1111/j.1467-8624.1982.tb03465.x

Loeber, R. (1990). Development and risk factors of juvenile antisocial behavior and delinquency. Clinical Psychology Review, 10(1), 1-41. doi:10.1016/02727358(90)90105-J

Loeber, R., Wung, P., Keenan, K., Giroux, B., Stouthamer-Loeber, M., Van Kammen, W. B., \& Maugham, B. (1993). Developmental pathways in disruptive child behavior. Development and Psychopathology, 5(1-2), 103-133.

doi:10.1017/S0954579400004296

Lorenz, K. (1970). Studies in animal and human behaviour: I. Trans. R. Martin. Oxford England: Harvard U. Press.

Lynch, J., \& Convey, W. (1979). Loneliness, disease, and death: Alternative approaches. Psychosomatics, 20(10), 702-708.

MacCallum, R. C., Browne, M. W., \& Sugawara, H. M. (1996). Power analysis and determination of sample size for covariance structure modeling. Psychological Methods, 1(2), 130-149. doi:10.1037/1082-989X.1.2.130

Main, M., \& Hesse, E. (1990). Parents' unresolved traumatic experiences are related to infant disorganized attachment status: Is frightened and/or frightening parental behavior the linking mechanism? In M. T. Greenberg, D. Cicchetti, \& E. Cummings (Eds.), Attachment in the preschool years: Theory, research, and intervention (pp. 161-182). Chicago, IL US: University of Chicago Press. 
Main, M., \& Solomon, J. (1990). Procedures for identifying infants as disorganized/disoriented during the Ainsworth Strange Situation. In M. T. Greenberg, D. Cicchetti, \& E. Cummings (Eds.), Attachment in the preschool years: Theory, research, and intervention (pp. 121-160). Chicago, IL US: University of Chicago Press.

Marangoni, C., \& Ickes, W. (1989). Loneliness: A theoretical review with implications for measurement. Journal of Social and Personal Relationships, 6(1), 93-128. doi:10.1177/026540758900600107

Marsh, P., McFarland, F., Allen, J., McElhaney, K., \& Land, D. (2003). Attachment, autonomy, and multifinality in adolescent internalizing and risky behavioral symptoms. Development and Psychopathology, 15(2), 451-467. doi: 10.1017/S0954579403000245

Marvin, R. S., \& Britner, P. A. (2008). Normative development: The ontogeny of attachment. In J. Cassidy \& P. R. Shaver (Eds.), Handbook of attachment: Theory, research, and clinical applications (2nd ed.) (pp. 269-294). New York, NY US: Guilford Press.

Massey, O. T., Boroughs, M., \& Armstrong, K. H. (2007). School violence interventions in the safe schools/healthy students initiative: Evaluation of two early intervention programs. Journal of School Violence, 6(2), 57-74. doi: 10.1300/J202v06n02_04

Masten, A., \& Curtis, W. (2000). Integrating competence and psychopathology: Pathways toward a comprehensive science of adaptation in development. Development and Psychopathology, 12(3), 529-550. doi:

10.1017/S095457940000314X 
Matas, L., Arend, R. A., \& Sroufe, L. (1978). Continuity of adaptation in the second year: The relationship between quality of attachment and later competence. Child Development, 49(3), 547-556. doi:10.1111/1467-8624.ep10424617

McElwain, N., Cox, M., Burchinal, M., \& Macfie, J. (2003). Differentiating among insecure mother - infant attachment classifications: A focus on child - friend interaction and exploration during solitary play at 36 months. Attachment \& Human Development, 5(2), 136-164. doi: 10.1080/1461673031000108513

McElwain, N. L., Wu, X., \& Booth-LaForce, C. L. (2011). Infant-mother attachment and children’s friendship quality: Maternal mental-state talk as an intervening mechanism. Developmental Psychology, 47(5), 1295-1311. doi:

10.1037/a0024094

Mendez, R. L. (2001). Multiple Partners in the Age of AIDS: Self-consciousness Theory and HIV Risk Behavior. Current Psychology, 20(4), 349-362. doi: $10.1007 / \mathrm{s} 12144-001-1017-0$

Meredith, W., \& Tisak, J. (1990). Latent curve analysis. Psychometrika, 55(1), 107-22. doi: 10.1007/BF02294746

Mertens, J., Flisher, A., Fleming, M., \& Weisner, C. (2007). Medical conditions of adolescents in alcohol and drug treatment: comparison with matched controls. The Journal of Adolescent Health: Official Publication of the Society for Adolescent Medicine, 40(2), 173-179. doi: 10.1016/j.jadohealth.2006.09.021

Meyers, L.S., Gamst, G., \& Guarino, A. (2006). Applied multivariate research: Design and interpretation. Thousand Oaks, CA: Sage Publishers.

Mijuskovic, B. (1988). Loneliness and adolescent alcoholism. Adolescence, 23(91), 503- 
16.

Miller, P. H. (2002). Theories of Developmental Psychology. (4 ${ }^{\text {th }}$ ed.). New York: Worth Publishers.

Moore, D., \& Schultz, N. R. (1983). Loneliness at adolescence: Correlates, attributions, and coping. Journal of Youth and Adolescence, 12(2), 95-100.

doi:10.1007/BF02088307

Munson, J., McMahon, R., \& Spieker, S. (2001). Structure and variability in the developmental trajectory of children's externalizing problems: Impact of infant attachment, maternal depressive symptomatology, and child sex. Development and Psychopathology, 13(2), 277-296. doi: 10.1017/S095457940100205X

NICHD Early Child Care Research Network. (1996). Characteristics of infant child care: Factors contributing to positive caregiving. Early Childhood Research Quarterly, 11 (3), 269-306.

NICHD Early Child Care Research Network. (1997). The effects of infant child care on infant-mother attachment security: Results of the NICHD Study of Early Child Care. Child Development, 68 (5), 860-879.

NICHD Early Child Care Research Network. (1998). Relations between family predictors and child outcomes: Are they weaker for children in child care? Developmental Psychology, 34 (5), 1119-1128.

NICHD Early Child Care Research Network. (1999). Child care and mother-child interaction in the first three years of life. Developmental Psychology, 35 (6), 1399-1413.

NICHD Early Child Care Research Network. (2000). Factors associated with fathers' 
caregiving activities and sensitivity with young children. Journal of Family Psychology, 14 (2), 200-219.

NICHD Early Child Care Research Network. (2001). Child-care and family predictors of preschool attachment and stability from infancy. Developmental Psychology, 37(6), 847-862. doi:10.1037/0012-1649.37.6.847

NICHD Early Child Care Research Network. (2003). Does quality of child care affect child outcomes at age 4 1⁄2? Developmental Psychology, 39, 451-469. doi: 10.1037/0012-1649.39.3.451

NICHD Early Child Care Research Network. (2006). Infant-mother attachment classification: Risk and protection in relation to changing maternal caregiving quality. Developmental Psychology, 42(1), 38-58. doi:10.1037/0012-1649.42.1.38

O’Donnell, L., O’Donnell, C. R., \& Stueve, A. (2001). Early sexual initiation and subsequent sex-related risks among urban minority youth: The reach for health study. Family Planning Perspectives, 33(6), 268-275. doi: 10.2307/3030194

Orvaschel, H., Lewinsohn, P. M., \& Seeley, J. R. (1995). Continuity of psychopathology in a community sample of adolescents. Journal of the American Academy of Child and Adolescent Psychiatry, 34(11), 1525-1535. doi: 10.1097/00004583199511000-00020

Page, R. M., \& Cole, G. E, (1991). Loneliness and alcoholism risk in late adolescence: A comparative study of adults and adolescents. Adolescence, 26(104), 925-930.

Parker, J. G., and Asher, S. R. (1987). Peer relations and later personal adjustment: Are low-accepted children at risk? Psychological Bulletin, 102, 357-389. doi: 10.1037/0033-2909.102.3.357 
Parker, J. S., \& Benson, M. J. (2004). Parent-adolescent relations and adolescent functioning: Self-esteem, substance abuse, and delinquency. Adolescence, 39(155), 519-530.

Pasco Fearon, R. M., \& Belsky, J. (2011). Infant-mother attachment and the growth of externalizing problems across the primary-school years. Journal of Child Psychology and Psychiatry, 52(7), 782-791. doi: 10.1111/j.14697610.2010.02350.x

Pastor, D. L. (1981). The quality of mother-infant attachment and its relationship to toddlers' initial sociability with peers. Developmental Psychology, 17(3), 326-335. doi:10.1037/0012-1649.17.3.326

Peplau, L. A., \& Perlman, D. (1982). Perspectives on loneliness. In L. A. Peplau \& D. Perlman (Eds.), Loneliness: A sourcebook of current theory, research, and therapy (pp. 1-20). New York: John Wiley \& Sons, Inc.

Pinderhughes, E. E., Coie, J. D., Lochman, J. E., Bierman, K. L., Dodge, K., Greenberg, M. T., and McMahon, R., J. (2010). The Fast Track project: Preventing severe conduct problems in school-age youth. In R. C. Murrihy, A. D. Kidman, \& T. H. Ollendick, (Eds.), Clinical handbook of assessing and treating conduct problems in youth (pp. 407-433). New York, NY: Springer Science + Business Media.

Pine, D. S., Cohen, E., Cohen, P., \& Brook, J. (1999). Adolescent depressive symptoms as predictors of adult depression: Moodiness or mood disorder? American Journal of Psychiatry, 156(1), 133-135.

Podsakoff, P., MacKenzie, S., Lee, J., \& Podsakoff, N. (2003). Common method biases 
in behavioral research: a critical review of the literature and recommended remedies. The Journal of Applied Psychology, 88(5), 879-903. doi: 10.1037/00219010.88.5.879

Pollard, J. A., \& Austin, G. A. (1990). Substance abuse among juvenile delinquents and gang members. Prevention Research Update Number Six, Spring 1990. Retrieved from ERIC database. (ED319149)

Qualter, P., \& Munn, P. (2002). The separateness of social and emotional loneliness in childhood. Journal of Child Psychology \& Psychiatry \& Allied Disciplines, 43(2), 233-244. doi: 10.1111/1469-7610.00016

Qualter, P., Brown, S., Munn, P., \& Rotenberg, K. (2010). Childhood loneliness as a predictor of adolescent depressive symptoms: an 8-year longitudinal study. European Child \& Adolescent Psychiatry, 19(6), 493-501. doi:10.1007/s00787009-0059-y

Raikes, H., \& Thompson, R. A. (2008). Attachment security and parenting quality predict children's problem-solving, attributions, and loneliness with peers. Attachment \& Human Development, 10(3), 319-344. doi:10.1080/14616730802113620

Rao, C. (1958). Some statistical methods for comparison of growth curves. Biometrics, 14, 1-17. doi:10.2307/2527726

Raykov, T., \& Marcoulides, G. A. (2006). On multilevel model reliability estimation from the perspective of structural equation modeling. Structural Equation Modeling, 13(1), 130-141. doi:10.1207/s15328007sem1301_7

Reyna, V. F., \& Farley, F. (2006). Risk and rationality in adolescent decision making: 
Implications for theory, practice, and public policy. Psychological Science in the Public Interest, 7(1), 1-44. doi:10.1111/j.1529-1006.2006.00026.x

Robins, L. (1991). Conduct disorder. Journal of Child Psychology and Psychiatry, and Allied Disciplines, 32(1), 193-212. doi: 10.1111/j.1469-7610.1991.tb00008.x

Rokach, A. (1989). Antecedents of loneliness: A factorial analysis. Journal of Psychology, 123(4), 369-384. doi: 10.1080/00223980.1989.10542992

Rokach, A. (2004). Loneliness then and now: Reflections on social and emotional alienation in everyday life. Current Psychology, 23(1), 24-40. doi: $10.1007 / s 12144-004-1006-1$

Rokach, A. (2011). From loneliness to belonging: A review. Psychology Journal, 8(2), 70-81.

Rokach, A., \& Orzeck, T. (2003). Coping with loneliness and drug use in young adults. Social Indicators Research, 61(3), 259-283. doi:10.1023/A:1021977731756

Rose, R. (1998). A developmental behavior-genetic perspective on alcoholism risk. Alcohol Health and Research World, 22(2), 131-143.

Rubenstein, C., \& Shaver, P. (1982). The experience of loneliness. In L. A. Peplau \& D. Perlman (Eds.), Loneliness: A sourcebook of current theory, research, and therapy (pp. 206-223). New York: John Wiley \& Sons, Inc..

Rubin, K. H., Hymel, S., Mills, R. S. L., \& Rose-Krasnor, L. (1991). Conceptualizing different developmental pathways to and from social isolation in childhood. In D. Cicchetti and S. Toth (Eds.), Rochester Symposium on Developmental Psychopathology, Vol. 2. (pp.91-122). Hillsdale, NJ: Erlbaum.

Rudasill, K. M., Reio, T. G., Stipanovic, N., \& Taylor, J. E. (2010). A longitudinal study 
of student-teacher relationship quality, difficult temperament, and risky behavior from childhood to early adolescence. Journal of School Psychology, 48, 389-412. doi: 10.1016/j.jsp.2010.05.001

Russell, D., Peplau, L. A., and Cutrona, C. E. (1980). The revised UCLA Loneliness Scale: Concurrent and discriminant validity evidence. Journal of Personality and Social Psychology, 39, 472-480. doi: 10.1037/0022-3514.39.3.472

Rutter, M. (1979). Maternal deprivation, 1972-1978: New findings, new concepts, new approaches. Child Development, 50(2), 283-305. doi:10.1111/14678624.ep12421470

Rutter, M., \& Sroufe, L. (2000). Developmental psychopathology: Concepts and challenges. Development and Psychopathology, 12(3), 265-296. doi: $10.1017 / \mathrm{S} 0954579400003023$

Schofield, H., Bierman, K., Heinrichs, B., Nix, R., \& Conduct Problems Prevention Research Group. (2008). Predicting early sexual activity with behavior problems exhibited at school entry and in early adolescence. Journal of Abnormal Child Psychology, 36(8), 1175-1188. doi:10.1007/s10802-008-9252-6

Shapiro, R. (1998). Risk-taking patterns of female adolescents: What they do and why. Journal of Adolescence, 21(2), 143-159. doi: 10.1006/jado.1997.0138

Shaw, S. K., \& Dallos, R. (2005). Attachment and adolescent depression: The impact of early attachment experiences. Attachment \& Human Development, 7(4), 409-424. doi:10.1080/14616730500365902

Shaw, D. S., Owens, E. B., Vondra, J. I., \& Keenan, K. (1996). Early risk factors and 
pathways in the development of early disruptive behavior problems. Development and Psychopathology, 8(4), 679-699. doi:10.1017/S0954579400007367

Shrier, L., Harris, S., Sternberg, M., \& Beardslee, W. (2001). Associations of depression, self-esteem, and substance use with sexual risk among adolescents. Preventive Medicine, 33(3), 179-189. doi: 10.1006/pmed.2001.0869

Shulman, S., Elicker, J., \& Sroufe, L. (1994). Stages of friendship growth in preadolescence as related to attachment history. Journal of Social and Personal Relationships, 11(3), 341-361. doi:10.1177/0265407594113002

Somers, C. L., \& Gizzi, T. J. (2001). Predicting adolescents' risky behaviors: The influence of future orientation, school involvement, and school attachment. Adolescent \& Family Health, 2(1), 3-11.

Soper, A., Wolchik, S., Tein, J., \& Sandler, I. (2010). Mediation of a preventive intervention's 6-year effects on health risk behaviors. Psychology of Addictive Behaviors: Journal of the Society of Psychologists in Addictive Behaviors, 24(2), 300-310. doi:10.1037/a0019014

Sroufe, L. (1997). Psychopathology as an outcome of development. Development and Psychopathology, 9(2), 251-268. doi: 10.1017/S0954579497002046

Sroufe, L. (2005). Attachment and development: A prospective, longitudinal study from birth to adulthood. Attachment \& Human Development, 7(4), 349-367. doi:10.1080/14616730500365928

Sroufe, L. A., Carlson, E. A., Levy, A. K., \& Egeland, B. (1999). Implications of attachment theory for developmental psychopathology. Development and Psychopathology, 11, 1-13. doi: 10.1017/S0954579499001923 
Sroufe, L. A., Egeland, B., Carlson, E. A., and Collins, W. A. (2005a). The development of the person: The Minnesota study of risk and adaptation from birth to adulthood. New York: Guilford Press.

Sroufe, L. A., Egeland, B., Carlson, E. A., and Collins, W. A. (2005b). Placing early attachment experiences in developmental context. In K. E. Grossman, K. Grossman, \& E. Waters, Attachment from infancy to adulthood: The major longitudinal studies (pp. 48-70). New York: Guilford Press.

Sroufe, L., Egeland, B., \& Kreutzer, T. (1990). The fate of early experience following developmental change: Longitudinal approaches to individual adaptation in childhood. Child Development, 61(5), 1363-1373. doi: 10.1111/j.14678624.1990.tb02867.x

Steiger, J. H. (2000). Point estimation, hypothesis testing, and interval estimation using the RMSEA: Some comments and a reply to Hayduk and Glaser. Structural Equation Modeling, 7(2), 149-162. doi: 10.1207/S15328007SEM0702_1

Steinberg, L., \& Avenevoli, S. (2000). The role of context in the development of psychopathology: A conceptual framework and some speculative propositions. Child Development, 71(1), 66-74. doi: 10.1111/1467-8624.00119

Stupica, B., Sherman, L. J., \& Cassidy, J. (2011). Newborn irritability moderates the association between infant attachment security and toddler exploration and sociability. Child Development, 82(5), 1381-1389. doi: 10.1111/j.14678624.2011.01638.x

Thompson, R. A. (2000). The legacy of early attachments. Child Development, 71(1), 145. doi: $10.1111 / 1467-8624.00128$ 
Thompson, R. (2008a). Measure twice, cut once: Attachment theory and the NICHD study of early child care and youth development. Attachment \& Human Development, 10(3), 287-297. doi:10.1080/14616730802113604

Thompson, R. A. (2008b). Early attachment and later development: Familiar questions, new answers. In J. Cassidy \& P. R. Shaver (Eds.), Handbook of attachment: Theory, research, and clinical applications (2nd ed.) (pp. 348-365). New York, NY US: Guilford Press.

Thompson, R., Jiyoung Kim, T., Litrownik, A. J., Briggs, E. C., Hussey, J. M., English, D. J., \& Dubowitz, H. (2011). Early adolescent risk behavior outcomes of childhood externalizing behavioral trajectories. Journal of Early Adolescence, 31(2), 234-257. doi:10.1177/0272431609361203

Trzesniewski, K. H., Donnellan, M., \& Lucas, R. E. (2011). Secondary data analysis: An introduction for psychologists. Washington, DC US: American Psychological Association. doi:10.1037/12350-000

Tucker, L. R. (1958). Determination of parameters of a functional relation by factor analysis. Psychometrika, 23, 19-23. doi:10.1007/BF02288975

Turner, P. (1991). Relations between attachment, gender, and behavior with peers in preschool. Child Development, 62(6), 1475-1488. doi: 10.1111/j.14678624.1991.tb01619.x

United States Department of Health and Human Services. National Institutes of Health. Eunice Kennedy Shriver National Institute of Child Health and Human Development. NICHD Study of Early Child Care and Youth Development: Phase I, 1991-1995 [Computer file]. ICPSR21940-v1. Ann Arbor, MI: Inter-university 
Consortium for Political and Social Research [distributor], 2010-01-08. doi:10.3886/ICPSR21940.v1

United States Department of Health and Human Services. National Institutes of Health.

Eunice Kennedy Shriver National Institute of Child Health and Human Development. NICHD Study of Early Child Care and Youth Development: Phase III, 2000-2004 [Computer file]. ICPSR21942-v1. Ann Arbor, MI: Inter-university Consortium for Political and Social Research [distributor], 2010-01-08. doi:10.3886/ICPSR21942.v1

United States Department of Health and Human Services. National Institutes of Health. Eunice Kennedy Shriver National Institute of Child Health and Human Development. (2008). NICHD Study of Early Child Care and Youth Development: Phase IV, 2005-2008 [Computer file]. ICPSR22361-v1. Ann Arbor, MI: Inter-university Consortium for Political and Social Research [distributor], 2010-01-26. doi:10.3886/ICPSR22361.v1

Van Ryzin, M., Carlson, E., \& Sroufe, L. (2011). Attachment discontinuity in a high-risk sample. Attachment \& Human Development, 13(4), 381-401. doi:10.1080/14616734.2011.584403

Vaughn, B., Egeland, B., Sroufe, L., \& Waters, E. (1979). Individual differences in infant-mother attachment at twelve and eighteen months: Stability and change in families under stress. Child Development, 50(4), 971-975. doi: 10.1111/j.14678624.1979.tb02456.x

Warren, S. L., Huston, L., Egeland, B., \& Sroufe, L. (1997). Child and adolescent anxiety 
disorders and early attachment. Journal of the American Academy of Child \& Adolescent Psychiatry, 36(5), 637-644. doi:10.1097/00004583-199705000-00014

Waters, E., \& Deane, K. E. (1985). Defining and assessing individual differences in attachment relationships: Q-methodology and the organization of behavior in infancy and early childhood. Monographs of the Society for Research in Child Development, 50(1-2), 41-65. doi:10.2307/3333826

Waters, E., Merrick, S., Treboux, D., Crowell, J., \& Albersheim, L. (2000). Attachment security in infancy and early adulthood: A twenty-year longitudinal study. Child Development, 71(3), 684-689. doi: 10.1111/1467-8624.00176

Waters, E., Posada, G., Crowell, J., \& Keng-ling, L. (1993). Is attachment theory ready to contribute to our understanding of disruptive behavior problems? Development and Psychopathology, 5(1-2), 215-224. doi:10.1017/S0954579400004351

Waters, E., Wippman, J., \& Sroufe, L. (1979). Attachment, positive affect, and competence in the peer group: Two studies in construct validation. Child Development, 50(3), 821-829. doi: 10.1111/j.1467-8624.1979.tb02431.x

Weinfield, N. S., Ogawa, J. R., \& Sroufe, L. (1997). Early attachment as a pathway to adolescent peer competence. Journal of Research on Adolescence, 7(3), 241-265. doi:10.1111/1532-7795.ep11339778

Weinfield, N., Sroufe, L., \& Egeland, B. (2000). Attachment from infancy to early adulthood in a high-risk sample: Continuity, discontinuity, and their correlates. Child Development, 71(3), 695-702. doi: 10.1111/1467-8624.00178

Weiss, R. S. (1973). Loneliness: The experience of emotional and social isolation. Cambridge, MA: MIT Press. 
Willett, J. B., \& Sayer, A. G. (1994). Using covariance structure analysis to detect correlates and predictors of individual change over time. Psychological Bulletin, 116(2), 363-381. doi:10.1037/0033-2909.116.2.363

Wiseman, H., Mayseless, O., \& Sharabany, R. (2006). Why are they lonely? Perceived quality of early relationships with parents, attachment, personality predispositions and loneliness in first-year university students. Personality \& Individual Differences, 40(2), 237-248. doi:10.1016/j.paid.2005.05.015

Witvliet, M., Brendgen, M., van Lier, P. A. C., Koot, H. M., \& Vitaro, F. (2010). Early adolescent depressive symptoms: Prediction from clique Isolation, loneliness, and perceived social acceptance. Journal of Abnormal Child Psychology, 38,10451056. doi: 10.1007/s10802-010-9426-X

Wood, J. J., Emmerson, N. A., \& Cowan, P. A. (2004). Is early attachment security carried forward into relationships with preschool peers? British Journal of Developmental Psychology, 22(2), 245-253. doi: 10.1348/026151004323044591

Zahn-Waxler, C., Klimes-Dougan, B., \& Slattery, M. J. (2000). Internalizing problems of childhood and adolescence: Prospects, pitfalls, and progress in understanding the development of anxiety and depression. Development and Psychopathology, 12(3), 443-466. doi:10.1017/S0954579400003102

Zapata, L., Forthofer, M., Eaton, D., Brown, K., Bryant, C., Reynolds, S., \& McDermott, R. (2004). Cigarette use in 6th through 10th grade: The Sarasota County Demonstration Project. American Journal of Health Behavior, 28(2), 151-165. 
Table 1

Item Parceling Summary for Risky Behavior Indicators in CFA Model

\begin{tabular}{|c|c|}
\hline Risky Behavior Indicators & $\begin{array}{l}\text { Items from Risky Behavior Questionnaire } \\
\text { included }\end{array}$ \\
\hline Sexual Risk & $\begin{array}{l}\text { 52: had oral sex } \\
\text { 53: had sexual intercourse } \\
\text { 54: got pregnant or got a girl pregnant } \\
\text { 55: told by Dr. or nurse that you have an STD }\end{array}$ \\
\hline Noncompliance/Conduct problems & $\begin{array}{l}\text { 5: done something dangerous or as a dare } \\
\text { 9: sold drugs } \\
\text { 26: been on probation } \\
\text { 27: been in juvenile detention } \\
\text { 31:been suspended from school } \\
\text { 33: vandalized property } \\
\text { 34: stolen something without use of weapons } \\
\text { 39: ever been arrested } \\
\text { 40: skipped school without permission } \\
\text { 46: taken something worth a lot } \\
\text { 47: taken something worth a little } \\
\text { 48: gotten in a place without paying } \\
\text { 49: ran away from home } \\
\text { 50: broke into a building and stole } \\
\text { 51: purposely damaged property }\end{array}$ \\
\hline Substance Use & $\begin{array}{l}\text { 43: smoked cigarettes/tobacco } \\
\text { 44: had alcohol } \\
\text { 45: used/smoked marijuana }\end{array}$ \\
\hline Violence & $\begin{array}{l}\text { 6: threaten to beat up someone } \\
\text { 7: taken part in a gang fight } \\
\text { 8: been a gang member } \\
\text { 24: fired a gun } \\
\text { 25: attacked someone and hurt them } \\
\text { 29: been a fight with other kids } \\
\text { 30: used a weapon to threaten another } \\
\text { 32: carried a hidden weapon } \\
\text { 35: stolen something with a weapon } \\
\text { 36: threatened to attack with a weapon } \\
\text { 37: beat up someone without a weapon } \\
\text { 38: beat up someone with a weapon } \\
\text { 41: purposely set a fire } \\
\text { 42: hurt an animal on purpose }\end{array}$ \\
\hline
\end{tabular}


Table 2

Descriptive Statistics of Variables for Participants

\begin{tabular}{|c|c|c|c|c|c|c|c|c|}
\hline \multirow[b]{2}{*}{ Variable } & \multicolumn{2}{|c|}{$\begin{array}{c}\text { Participants with } \\
\text { completed data } \\
\text { N = 825 }\end{array}$} & \multicolumn{2}{|c|}{$\begin{array}{c}\text { Males with } \\
\text { completed data } \\
\mathrm{N}=403\end{array}$} & \multicolumn{2}{|c|}{$\begin{array}{c}\text { Females with } \\
\text { completed data } \\
\mathrm{N}=422\end{array}$} & \multicolumn{2}{|c|}{$\begin{array}{l}\text { All participants } \\
\quad \mathrm{N}=1364\end{array}$} \\
\hline & Mean & $\begin{array}{l}\text { Std. } \\
\text { Dev. }\end{array}$ & Mean & $\begin{array}{l}\text { Std. } \\
\text { Dev. }\end{array}$ & Mean & $\begin{array}{l}\text { Std. } \\
\text { Dev. }\end{array}$ & Mean & $\begin{array}{l}\text { Std. } \\
\text { Dev. }\end{array}$ \\
\hline $\begin{array}{l}\text { Attachment } \\
\text { security rating }\end{array}$ & 5.08 & 1.68 & 5.18 & 1.70 & 4.98 & 1.65 & 5.02 & 1.73 \\
\hline $\begin{array}{l}\text { Loneliness at } \\
\text { G3 }\end{array}$ & 28.34 & 9.38 & 26.34 & 8.76 & 28.43 & 9.65 & 28.44 & 9.59 \\
\hline $\begin{array}{l}\text { Loneliness at } \\
\text { G5 }\end{array}$ & 25.68 & 8.98 & 28.23 & 9.09 & 25.05 & 9.14 & 25.71 & 9.02 \\
\hline $\begin{array}{l}\text { Loneliness at } \\
\text { age } 15\end{array}$ & 26.28 & 8.79 & 26.64 & 8.85 & 25.94 & 8.73 & 26.41 & 8.70 \\
\hline Sexual risk & .32 & .90 & .32 & .89 & .32 & .91 & .32 & .90 \\
\hline $\begin{array}{l}\text { Noncompliance/ } \\
\text { Conduct } \\
\text { Problems }\end{array}$ & 1.79 & 2.62 & 2.17 & 3.01 & 1.42 & 2.12 & 1.79 & 2.62 \\
\hline Violence & .99 & 2.07 & 1.54 & 2.67 & .47 & 1.03 & .99 & 2.07 \\
\hline Substance Use & .61 & 1.30 & .56 & 1.23 & .66 & 1.37 & .62 & 1.30 \\
\hline
\end{tabular}


Table 3

Correlations of Observed Variables

\begin{tabular}{|c|c|c|c|c|c|c|c|c|c|}
\hline Observed Variables & 1 & 2 & 3 & 4 & 5 & 6 & 7 & 8 & 9 \\
\hline $\begin{array}{l}\text { 1. Attachment } \\
\text { Security Rating }\end{array}$ & 1.0 & & & & & & & & \\
\hline $\begin{array}{l}\text { 2. Loneliness at } \\
\text { G3 }\end{array}$ & -.022 & 1.0 & & & & & & & \\
\hline $\begin{array}{l}\text { 3. Loneliness at } \\
\text { G5 }\end{array}$ & -.036 & $.431 * *$ & 1.0 & & & & & & \\
\hline 4. Loneliness at 15 & -.054 & $.202^{* *}$ & $.362 * *$ & 1.0 & & & & & \\
\hline 5. Sexual Risk & -.054 & -.034 & .005 & .058 & 1.0 & & & & \\
\hline $\begin{array}{l}\text { 6. Noncompliance/ } \\
\text { Conduct } \\
\text { Problems }\end{array}$ & -.059 & .035 & .059 & $.127^{* *}$ & $.528^{* *}$ & 1.0 & & & \\
\hline 7. Violence & -.019 & .035 & .051 & $.130^{* *}$ & $.422 * *$ & $.642 * *$ & 1.0 & & \\
\hline 8. Substance Use & -.054 & -.009 & .034 & $.098^{* *}$ & $.469 * *$ & $.534 * *$ & $.302 * *$ & 1.0 & \\
\hline 9. Child Gender & -.060 & .011 & $-.072^{*}$ & -.039 & .003 & $-.145^{* *}$ & $-.257^{* *}$ & .038 & 1.0 \\
\hline
\end{tabular}

Note: ** Correlation is significant at the .01 level

* Correlation is significant at the .05 level Subgroup Used for Analyses: N=825 
Table 4

Number of Estimated Parameters for Each Model

\begin{tabular}{lc}
\hline \multicolumn{1}{c}{ Model } & $\begin{array}{c}\text { Number of } \\
\text { estimated } \\
\text { parameters }\end{array}$ \\
\hline LGC model of loneliness & 8 \\
$\begin{array}{l}\text { LGC model of loneliness } \\
\text { with gender }\end{array}$ & 12 \\
$\begin{array}{l}\text { CFA model of risky } \\
\text { behavior }\end{array}$ & 11 \\
$\begin{array}{l}\text { CFA model of risky } \\
\text { behavior with gender }\end{array}$ & 14 \\
Full model & 26 \\
Full model with gender & 32 \\
\hline
\end{tabular}


Table 5

Sample Sizes, Means, and Standard Deviations for Group with Complete Data and Group with Missing Data

\begin{tabular}{|c|c|c|c|c|}
\hline Observed Variables & Grouping & $\mathrm{N}$ & Mean & $\begin{array}{l}\text { Standard } \\
\text { Deviation }\end{array}$ \\
\hline Attachment Security & Complete & 825 & 5.08 & 1.68 \\
\hline Rating & Missing & 315 & 4.88 & 1.84 \\
\hline \multirow[t]{2}{*}{ Loneliness at G3 } & Complete & 825 & 28.34 & 9.38 \\
\hline & Missing & 206 & 28.86 & 10.42 \\
\hline \multirow[t]{2}{*}{ Loneliness at G5 } & Complete & 825 & 25.68 & 8.98 \\
\hline & Missing & 199 & 25.84 & 9.23 \\
\hline \multirow[t]{2}{*}{ Loneliness at 15} & Complete & 825 & 26.28 & 8.79 \\
\hline & Missing & 131 & 27.22 & 8.05 \\
\hline \multirow[t]{2}{*}{ Sexual Risk } & Complete & 825 & .32 & .90 \\
\hline & Missing & 128 & .31 & .83 \\
\hline Noncompliance/Conduct & Complete & 825 & 1.79 & 2.62 \\
\hline Problems & Missing & 128 & 2.33 & 3.62 \\
\hline \multirow[t]{2}{*}{ Violence } & Complete & 825 & .99 & 2.07 \\
\hline & Missing & 128 & 1.28 & 2.11 \\
\hline \multirow[t]{2}{*}{ Substance Use } & Complete & 825 & .61 & 1.30 \\
\hline & Missing & 128 & .80 & 1.48 \\
\hline
\end{tabular}

Note: Subgroup total with Missing Data: $\quad \mathrm{N}=539$

Subgroup total with Complete Data: $\mathrm{N}=825$ 
Table 6

Data Analysis for Effects of Attrition: Comparison of Group with Complete Data and Group with Missing Data

\begin{tabular}{lccc}
\hline \multicolumn{1}{c}{ Observed Variables } & \multicolumn{1}{c}{ t test $\chi^{2}$} & $p$ & $\mathrm{~d}$ \\
\hline Attachment Security Rating & $\mathrm{t}(1138)=1.694$ & .090 & .12 \\
Loneliness at G3 & $\mathrm{t}(1029)=-.709$ & .479 & -.05 \\
Loneliness at G5 & $\mathrm{t}(1022)=-.230$ & .818 & -.02 \\
Loneliness at 15 & $\mathrm{t}(954)=-1.150$ & .250 & -.11 \\
Sexual Risk & $\mathrm{t}(951)=.060$ & .952 & .01 \\
$\begin{array}{l}\text { Noncompliance/Conduct } \\
\text { Problems }\end{array}$ & $\mathrm{t}(951)=-2.056$ & .040 & -.19 \\
Violence & $\mathrm{t}(951)=-1.469$ & .142 & -.14 \\
Substance Use & $\mathrm{t}(951)=-1.454$ & .146 & -.14 \\
Child Gender & $\chi^{2}(1)=6.389$ & .011 & $\mathrm{n} / \mathrm{a}$
\end{tabular}

Note: Subgroup total with Missing Data: $\mathrm{N}=539$

Subgroup total with Complete Data: $\mathrm{N}=825$ 
Table 7

Means, Variances, and Covariance for LGC Model of Loneliness without Gender

\begin{tabular}{lc}
\hline & Estimate \\
\cline { 2 - 2 } Mean of Initial Loneliness & $27.529 *$ \\
Mean of Loneliness Change per & $-.248^{*}$ \\
Year & \\
Variance of Initial Loneliness & $44.296^{*}$ \\
Variance of Annual Change in & $1.718^{*}$ \\
Loneliness & \\
Covariance between initial & $-4.585^{*}$ \\
loneliness and changes in \\
loneliness
\end{tabular}

Note: ${ }^{*} p<.001$ 
Table 8

Means, Variances, and Covariance for LGC Model of Loneliness with Gender

\begin{tabular}{lc}
\hline & Estimate \\
\cline { 2 - 2 } Mean of Initial Loneliness & $27.676^{* *}$ \\
Mean of Loneliness Change per & $-.202^{*}$ \\
Year & $44.212^{* *}$ \\
Variance of Initial Loneliness & \\
Variance of Annual Change in \\
Loneliness \\
$\begin{array}{l}\text { Covariance between initial } \\
\text { loneliness and changes in } \\
\text { loneliness }\end{array}$ \\
\hline $\begin{array}{l}\text { Note: }{ }^{*} p<.05 ; * * p<.001 \\
\end{array}$
\end{tabular}


Table 9

Modification Indices for Initial CFA Model for Risky Behaviors

\begin{tabular}{lcc}
\hline & M.I. & Par Change \\
\cline { 2 - 3 } E7 <--> E9 & 22.323 & -.287 \\
E6 <--> E9 & 34.223 & .168 \\
E6 <--> E8 & 7.322 & -.117 \\
\hline
\end{tabular}


Table 10

Standardized and Unstandardized Coefficients for CFA Model of Risky Behaviors without Gender

\begin{tabular}{lccc}
\hline Observed Variable & B & $\beta$ & S. E. \\
\hline Sexual Risk Taking & 1.0 & .550 & .254 \\
$\begin{array}{l}\text { Noncompliance/ Conduct } \\
\text { Problems }\end{array}$ & $4.961^{*}$ & .919 & .158 \\
Violence & $2.904^{*}$ & .690 & .087 \\
Substance Use & $1.620^{*}$ & .597 & \\
\hline
\end{tabular}

Note: ${ }^{*} p<.01$ 
Table 11

Standardized and Unstandardized Coefficients for CFA Model of Risky Behaviors with Gender

\begin{tabular}{lccc}
\hline \multicolumn{1}{c}{ Observed Variable } & B & $\beta$ & S. E. \\
\hline Sexual Risk Taking & 1.0 & .549 & .253 \\
$\begin{array}{l}\text { Noncompliance/ Conduct } \\
\text { Problems }\end{array}$ & $4.962^{*}$ & .916 & .160 \\
Violence & $2.927^{*}$ & .695 & .087 \\
Substance Use & $1.620^{*}$ & .595 & .036 \\
Gender & $-.159 *$ & -.164 & \\
\hline Note: ${ }^{*} p<.01$ & & &
\end{tabular}


Table 12

Standardized and Unstandardized Coefficients for the Structural Paths of the Full Model without the Covariate Gender

\begin{tabular}{lccc}
\hline \multicolumn{1}{c}{ Regression Weights } & $\mathrm{B}$ & $\beta$ & S. E. \\
\hline Attachment $\rightarrow$ Slope & -.026 & -.033 & .039 \\
Attachment $\rightarrow$ Intercept & -.130 & -.033 & .182 \\
Attachment $\rightarrow$ Risk Behaviors & -.015 & -.051 & .011 \\
Slope $\rightarrow$ Risk Behaviors & $.075 *$ & .203 & .025 \\
Intercept $\rightarrow$ Risk Behaviors & $.011^{*}$ & .145 & .004 \\
\hline Note: $* p<.01$ & & &
\end{tabular}


Table 13

Standardized and Unstandardized Coefficients for the Structural Paths of the Full Model with the Covariate Gender

\begin{tabular}{lccc}
\hline \multicolumn{1}{c}{ Regression Weights } & B & $\beta$ & S. E. \\
\hline Attachment $\rightarrow$ Slope & -.026 & -.033 & .039 \\
Attachment $\rightarrow$ Intercept & -.130 & -.033 & .182 \\
Attachment $\rightarrow$ Risk & -.018 & -.061 & .011 \\
Behaviors & & & .024 \\
Slope $\rightarrow$ Risk Behaviors & $.071^{* *}$ & .192 & .004 \\
Intercept $\rightarrow$ Risk Behaviors & $.010^{*}$ & .135 & .117 \\
Gender $\rightarrow$ Attachment & -.202 & -.060 & .036 \\
Gender $\rightarrow$ Risk Behaviors & $-.157^{* *}$ & -.162 & \\
\hline Note: $* p<.05$, * $p<.01$ & & &
\end{tabular}


Table 14

Summary of Fit Indices for Models

\begin{tabular}{|c|c|c|c|}
\hline Model & $\chi^{2}(\mathrm{df}), p$ & CFI & $\begin{array}{l}\text { RMSEA with } 90 \% \\
\text { CI }\end{array}$ \\
\hline $\begin{array}{c}\text { CFA for risky } \\
\text { behavior (without } \\
\text { gender) }\end{array}$ & $8.3(3), .041$ & .995 & $\begin{array}{c}.046 \\
90 \% \text { CI [.008,.085] }\end{array}$ \\
\hline $\begin{array}{l}\text { CFA for risky } \\
\text { behavior (with } \\
\text { gender) }\end{array}$ & 66.62 (6), .000 & .946 & $\begin{array}{c}.111 \\
90 \% \text { CI }[.088, .135]\end{array}$ \\
\hline $\begin{array}{l}\text { LGC for loneliness } \\
\text { (without gender) }\end{array}$ & 45.66 (1), .000 & .843 & $\begin{array}{c}.233 \\
90 \% \text { CI }[.178, .293]\end{array}$ \\
\hline $\begin{array}{l}\text { LGC for loneliness } \\
\text { (with gender) }\end{array}$ & 49.97 (2), .000 & .833 & $\begin{array}{c}.171 \\
90 \% \text { CI }[.132, .213]\end{array}$ \\
\hline $\begin{array}{l}\text { Full model (without } \\
\text { gender) }\end{array}$ & 62.92 (18), .000 & .967 & $\begin{array}{c}.055 \\
90 \% \text { CI }[.041, .070]\end{array}$ \\
\hline $\begin{array}{l}\text { Full model (with } \\
\text { gender) }\end{array}$ & 127.92 (24), .000 & .927 & $\begin{array}{c}.072 \\
90 \% \text { CI }[.060, .085]\end{array}$ \\
\hline
\end{tabular}




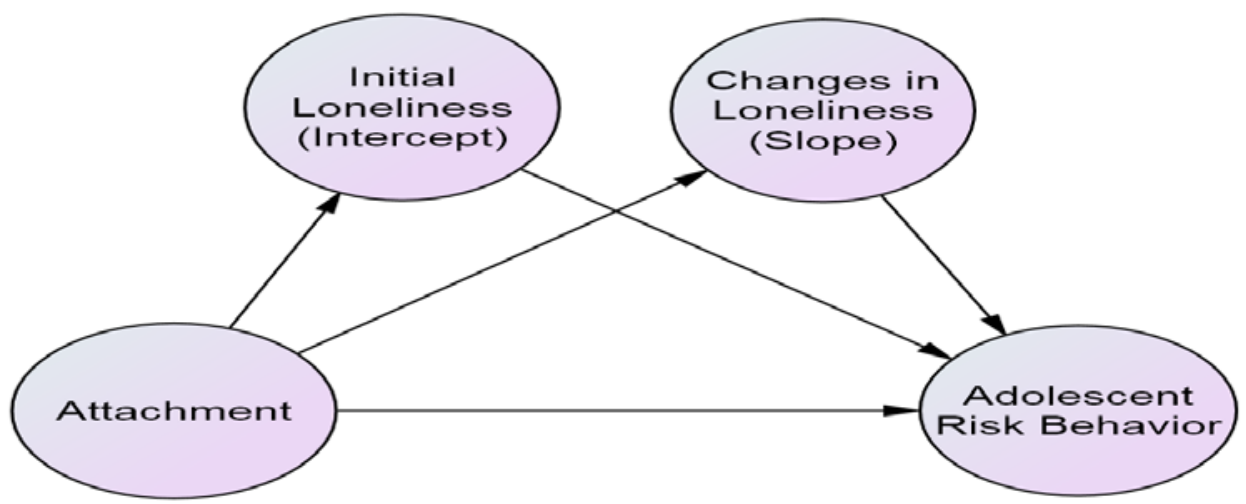

Figure 1. Proposed structural model 


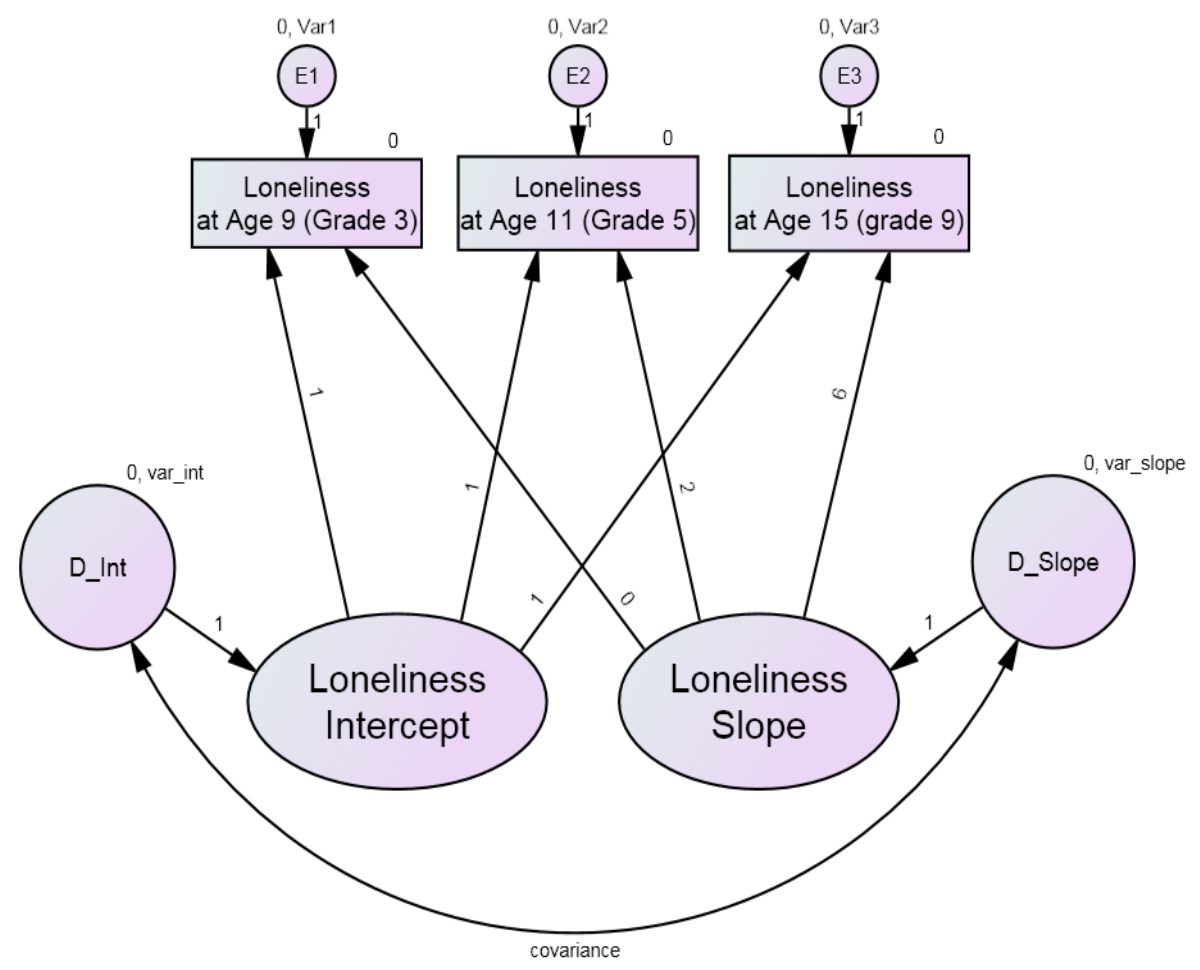

Figure 2. Hypothesized Latent Growth Curve (LGC) model for loneliness over three time points 


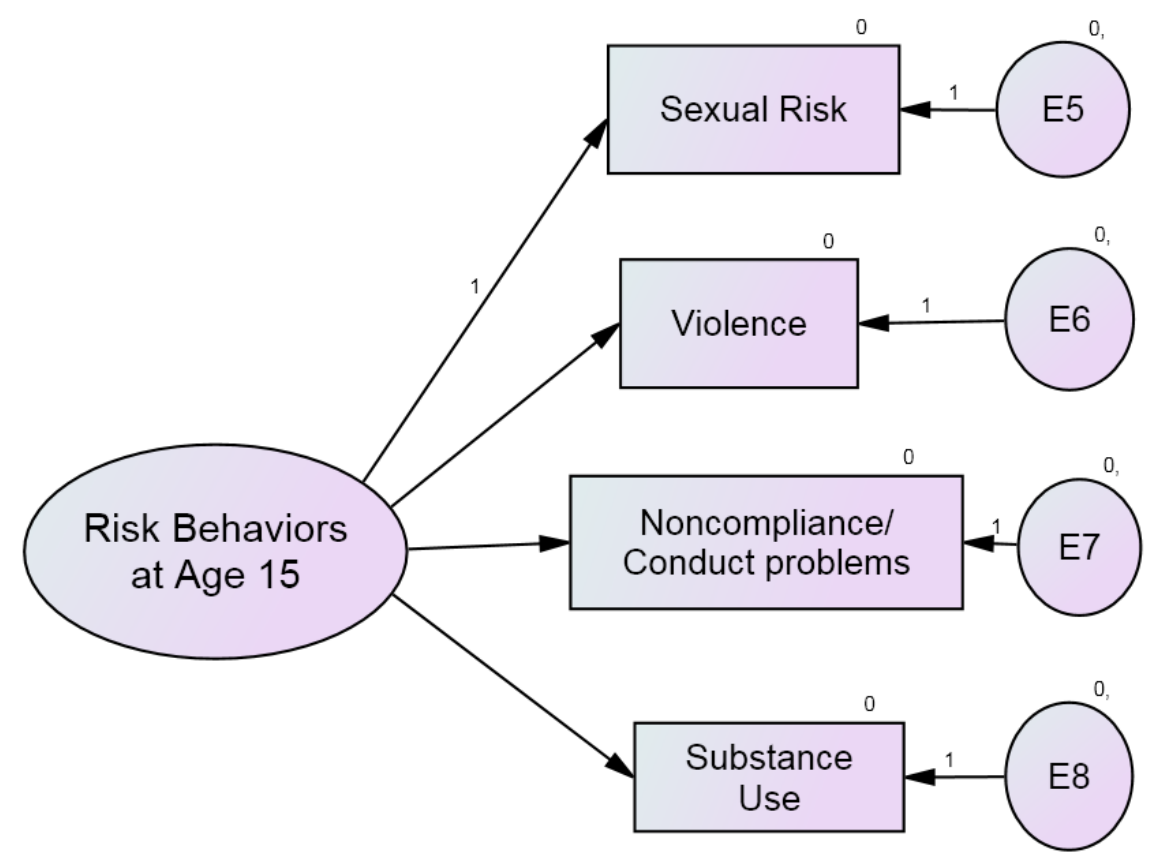

Figure 3. Hypothesized Confirmatory Factor Analysis (CFA) measurement model for adolescent risky behavior 


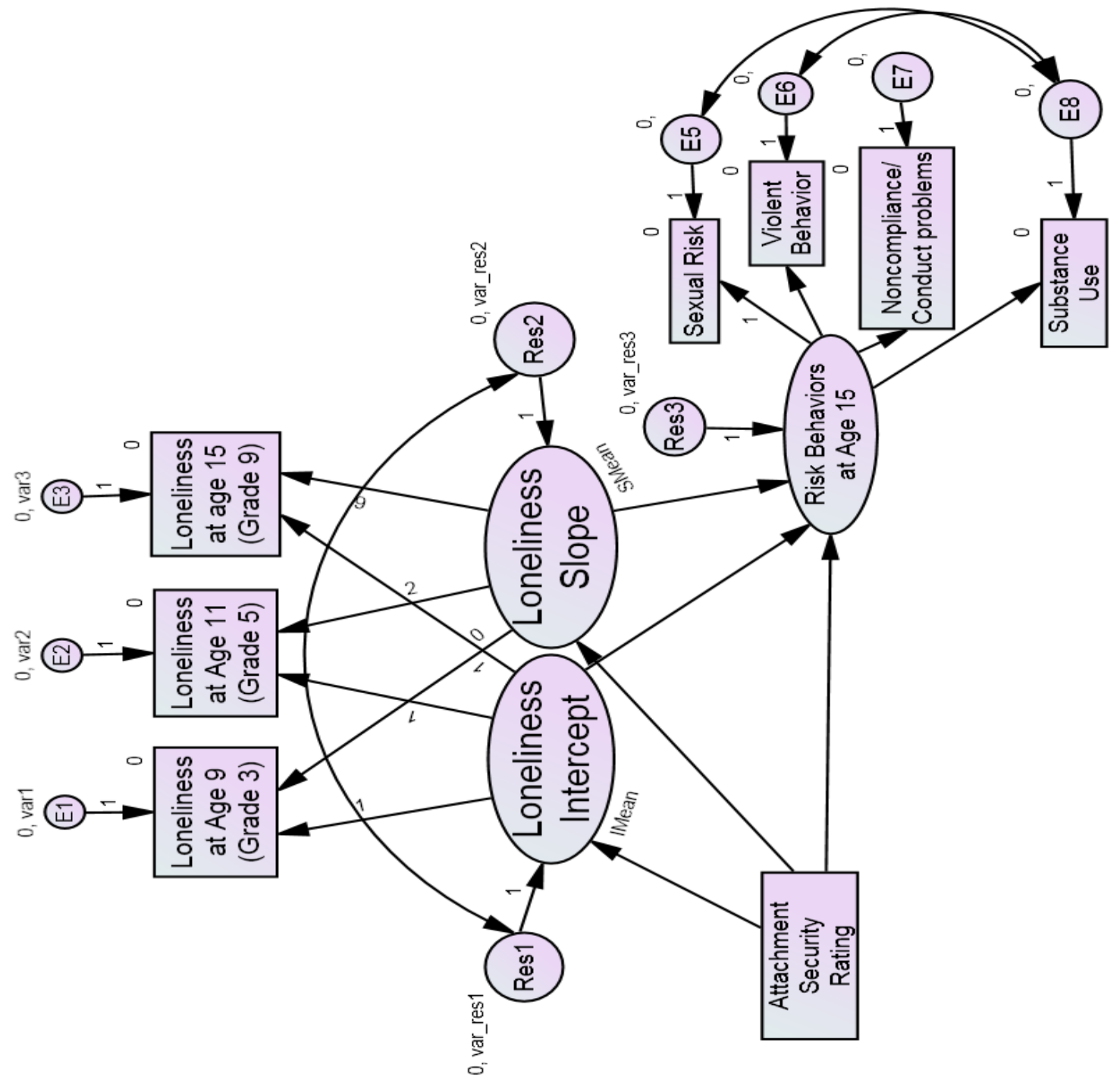

Figure 4. Hypothesized full structural model 


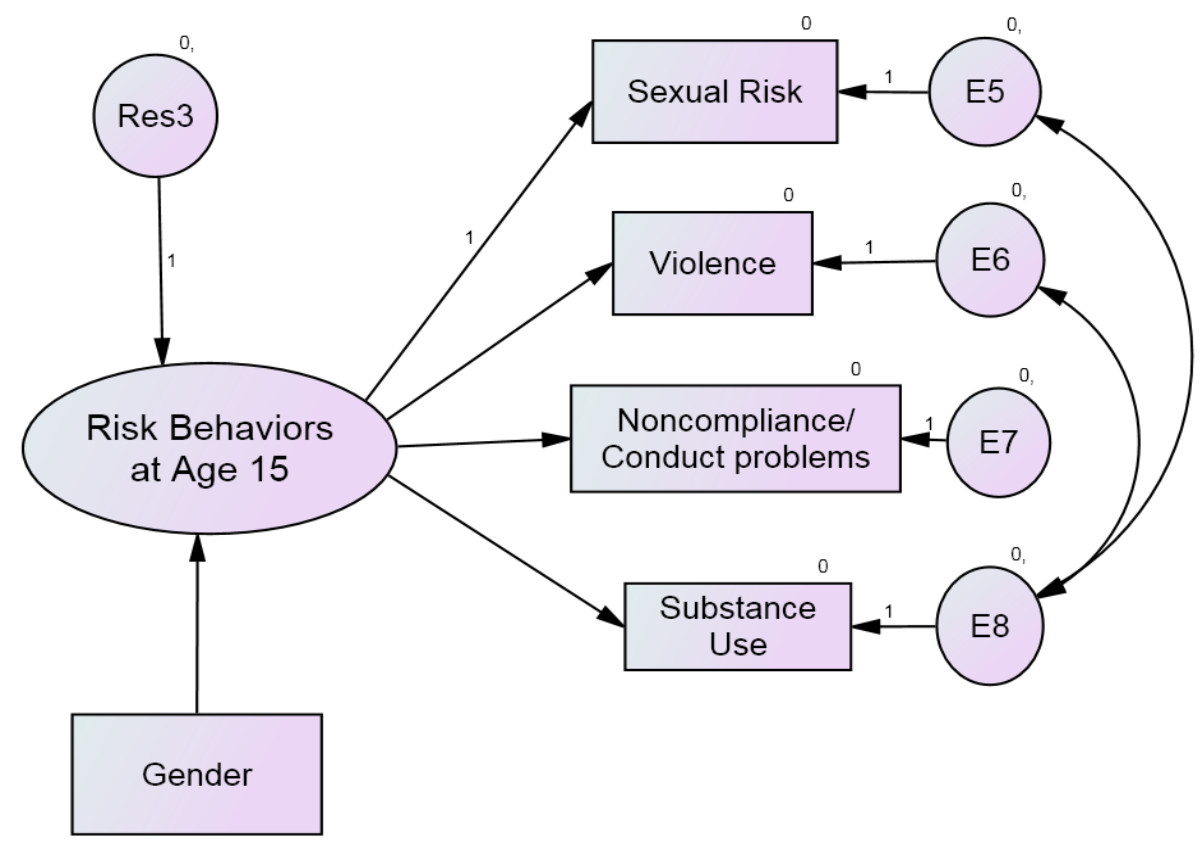

Figure 5. CFA measurement model for adolescent risky behavior with gender as time-invariant covariate 


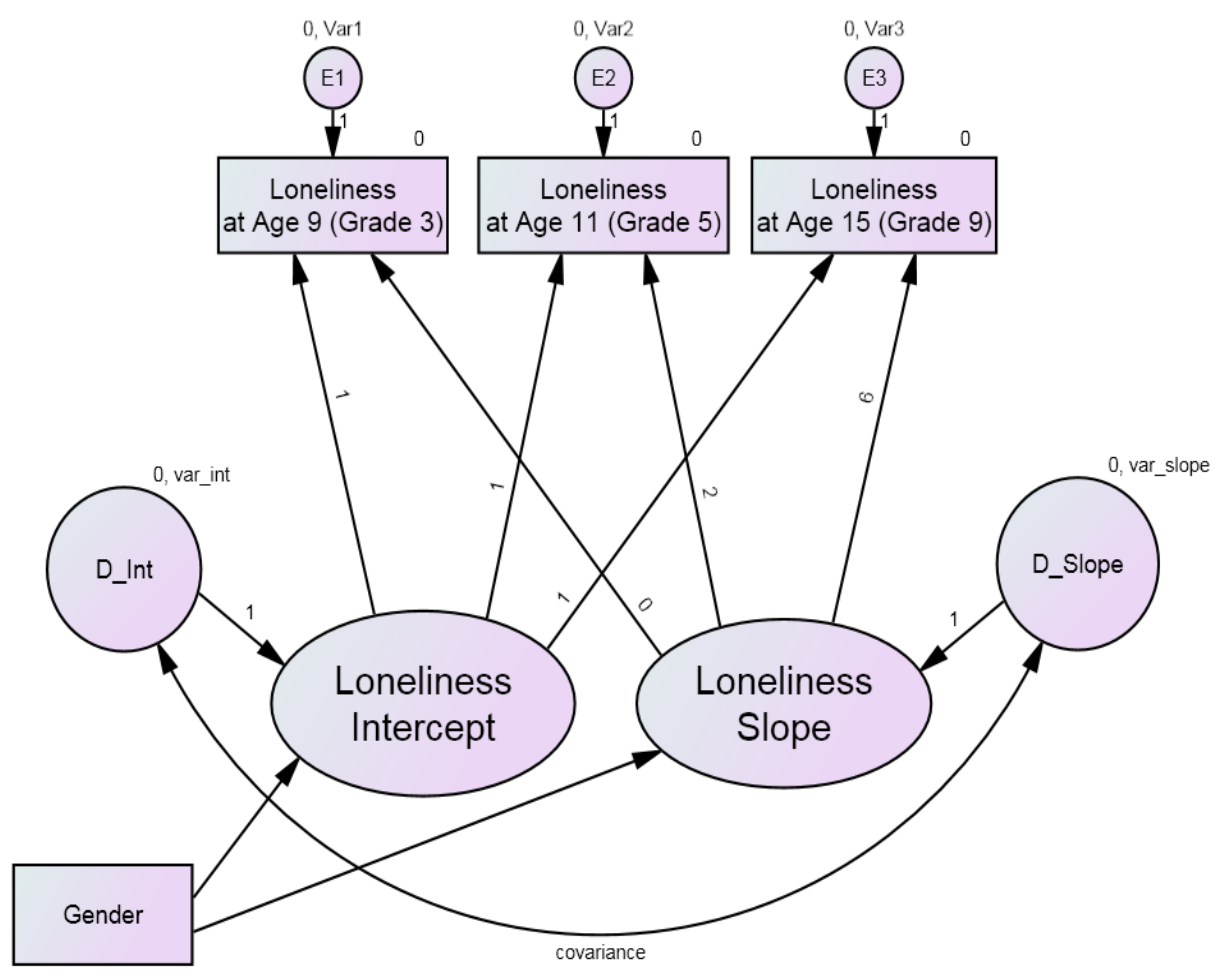

Figure 6. LGC model with child gender as a time-invariant covariate 


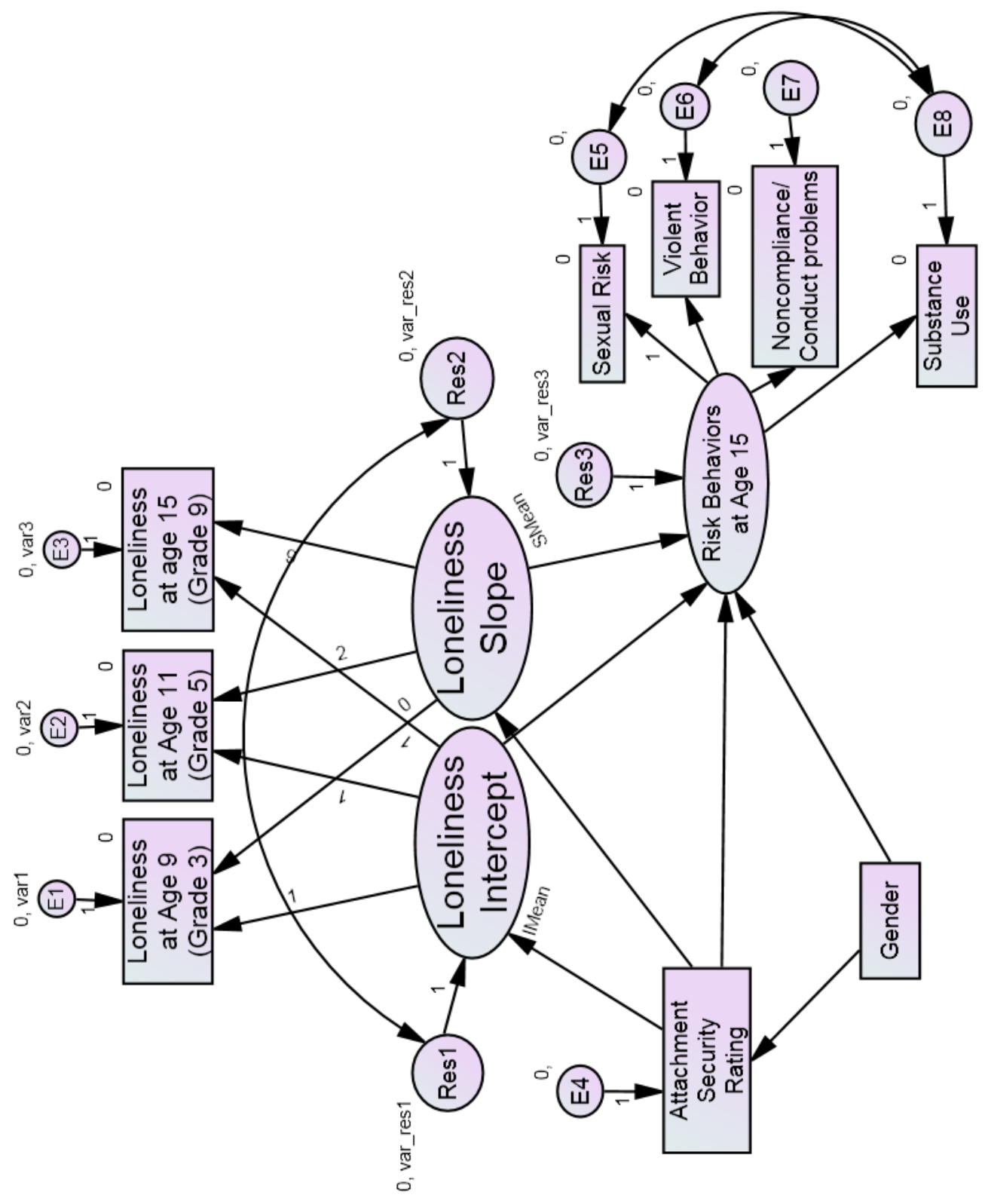

Figure 7. Full model with gender as a time-invariant covariate 


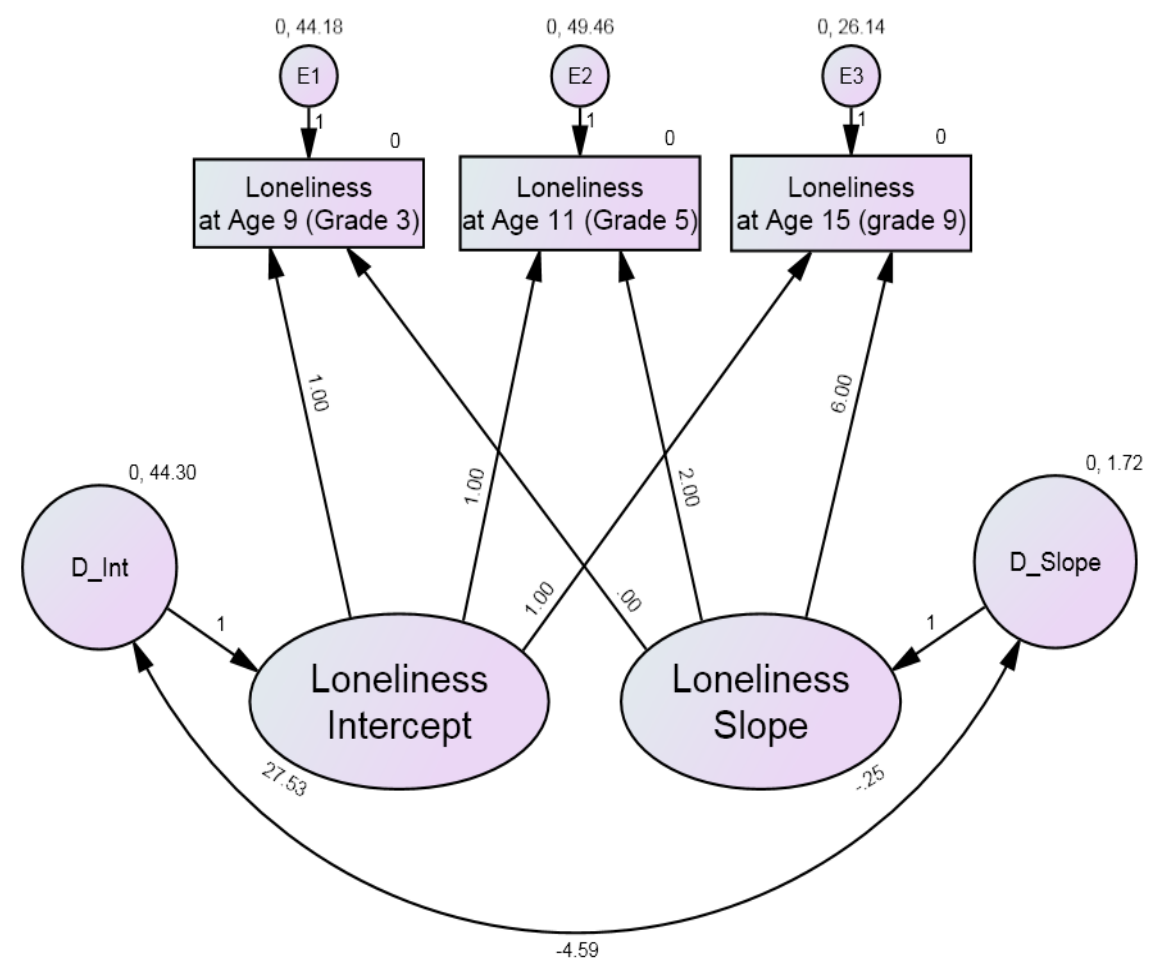

Figure 8. LGC model of loneliness with means, variances, and covariance 


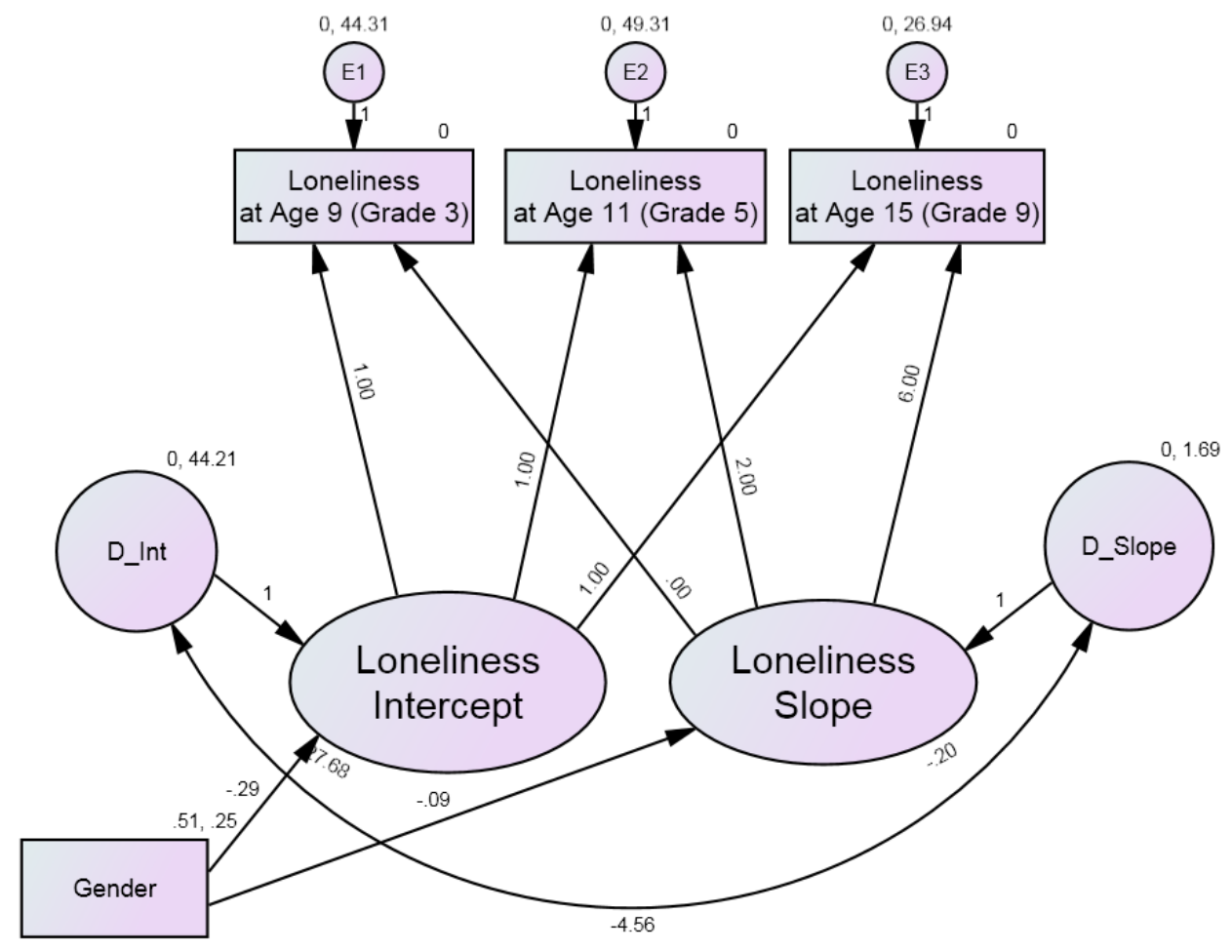

Figure 9. LGC model of loneliness with gender as a covariate with factor loadings, means, variances, and covariance 


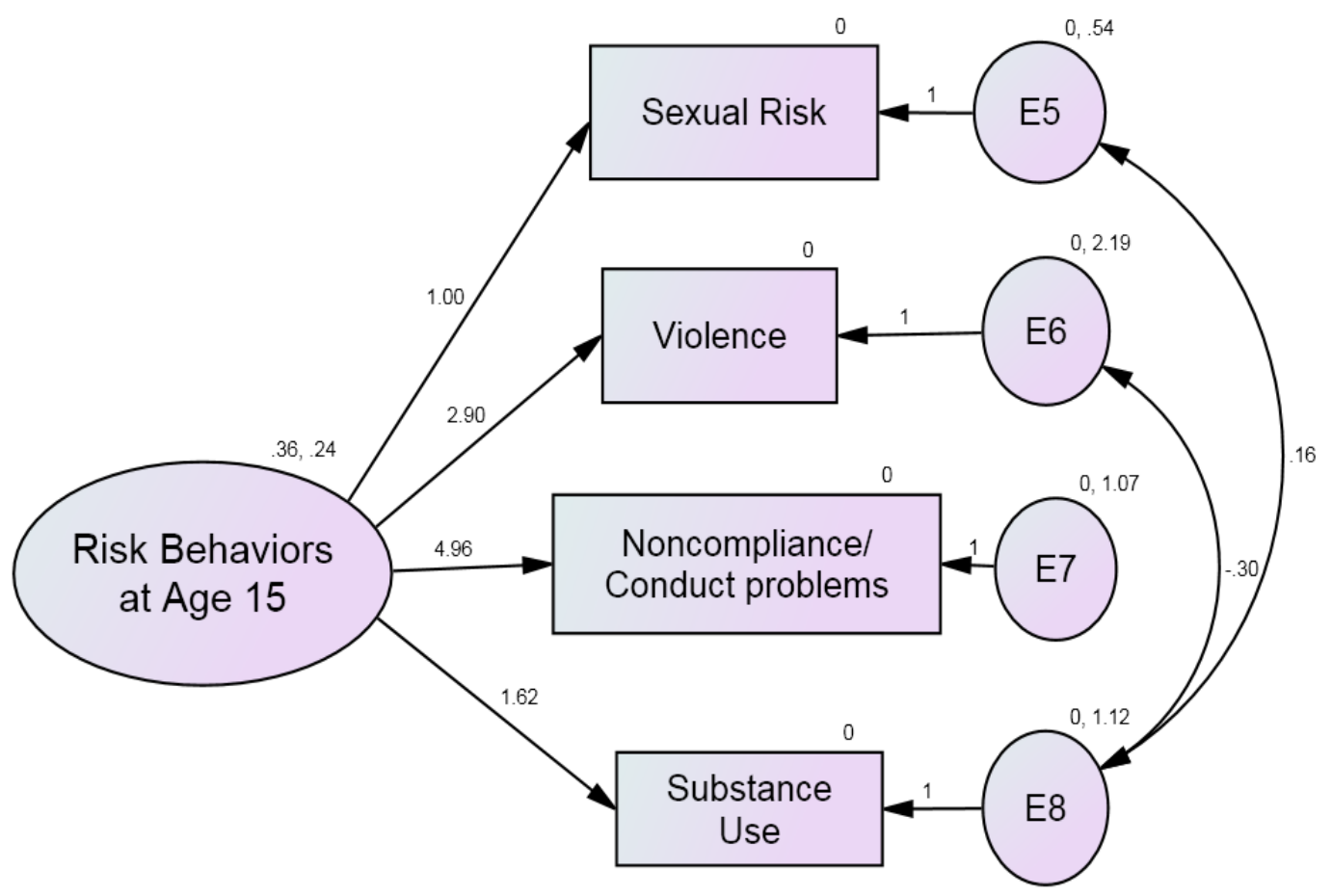

Figure 10. Final CFA measurement model of risky behavior with factor loadings and error covariances between E5-E8 and E6-E8 freely estimated 


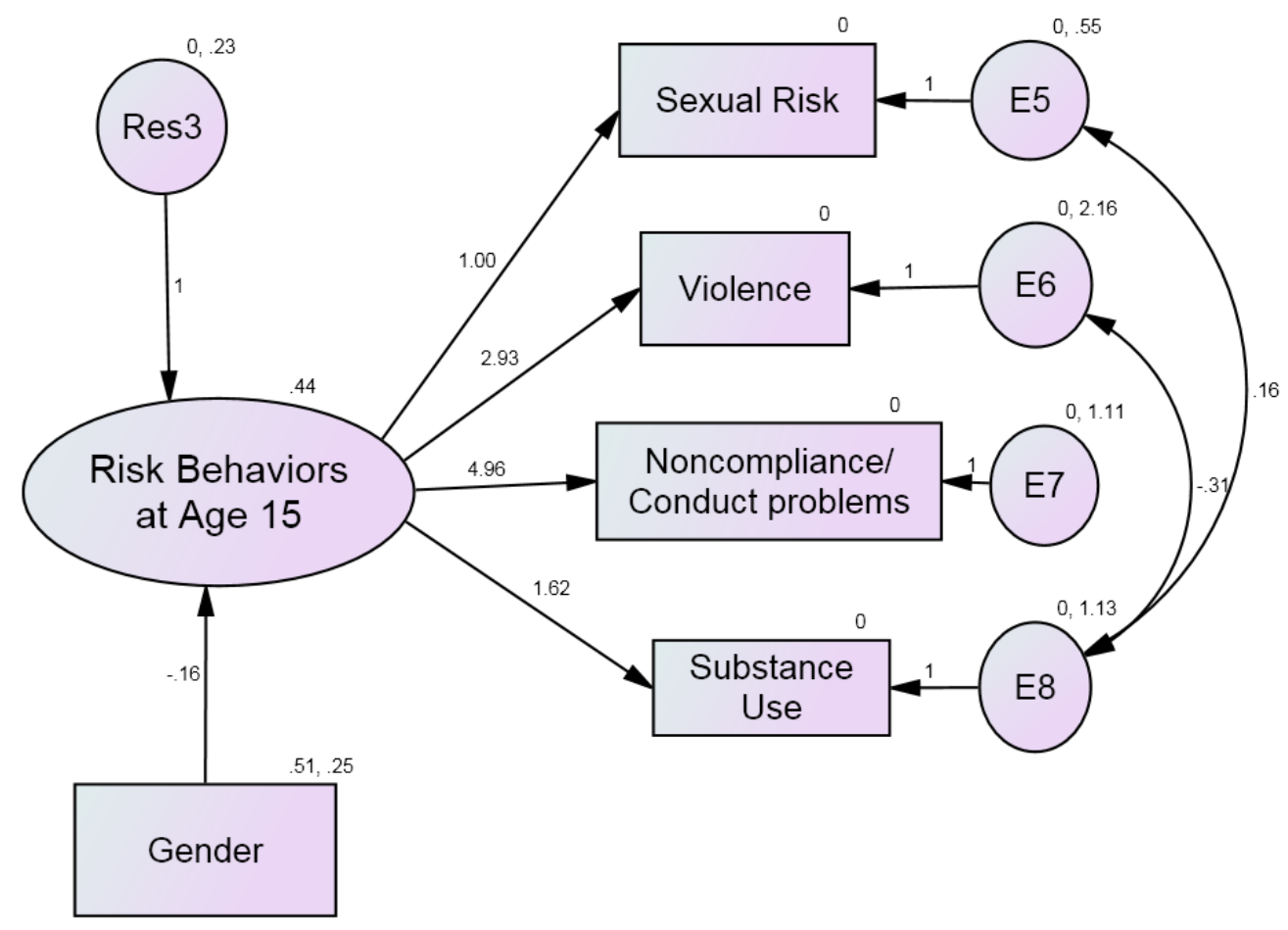

Figure 11. CFA model of risky behavior with gender as a covariate and factor loadings, variances, and covariances 


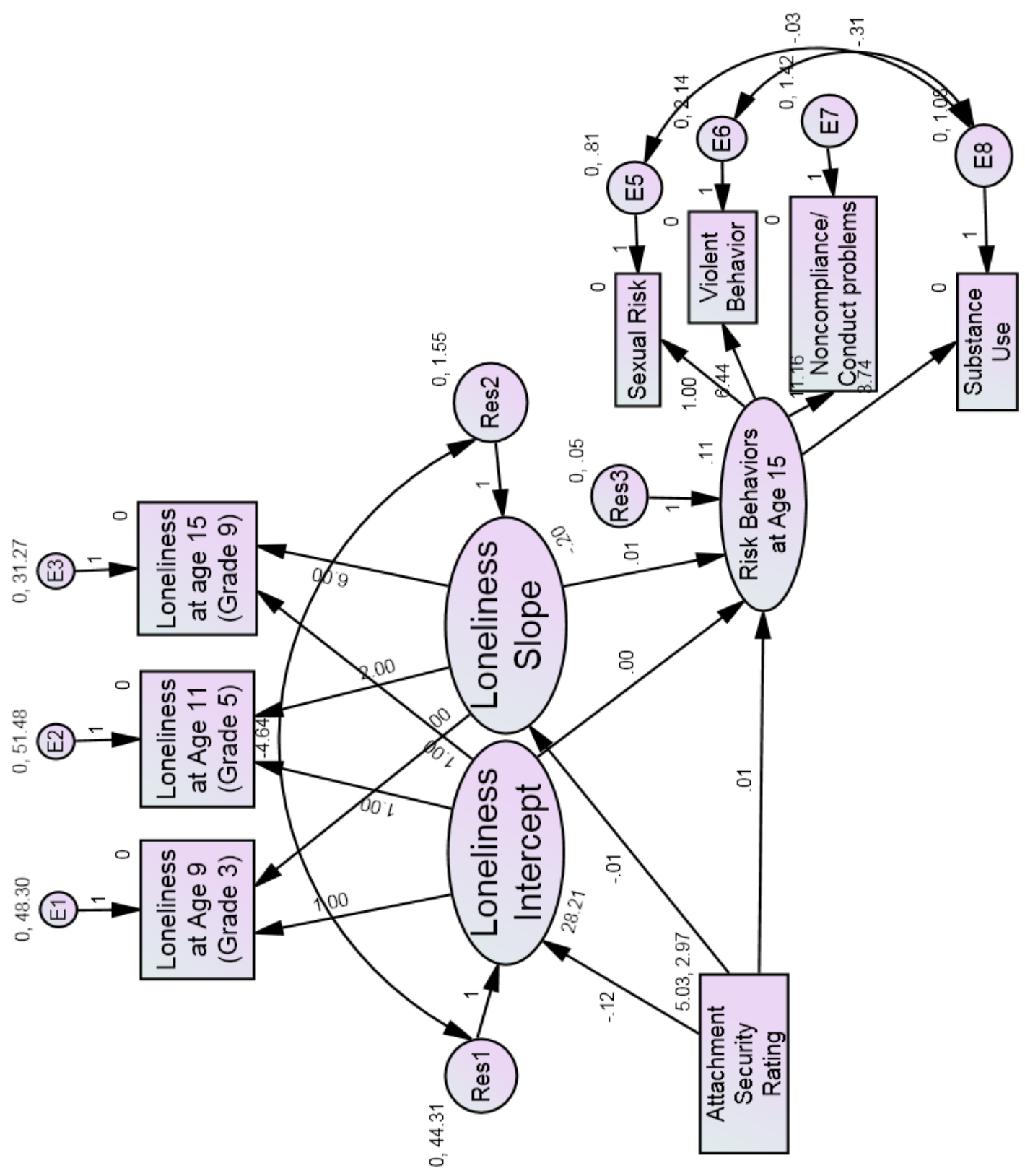

Figure 12. Full model with factor loadings, means, variances, and covariances 


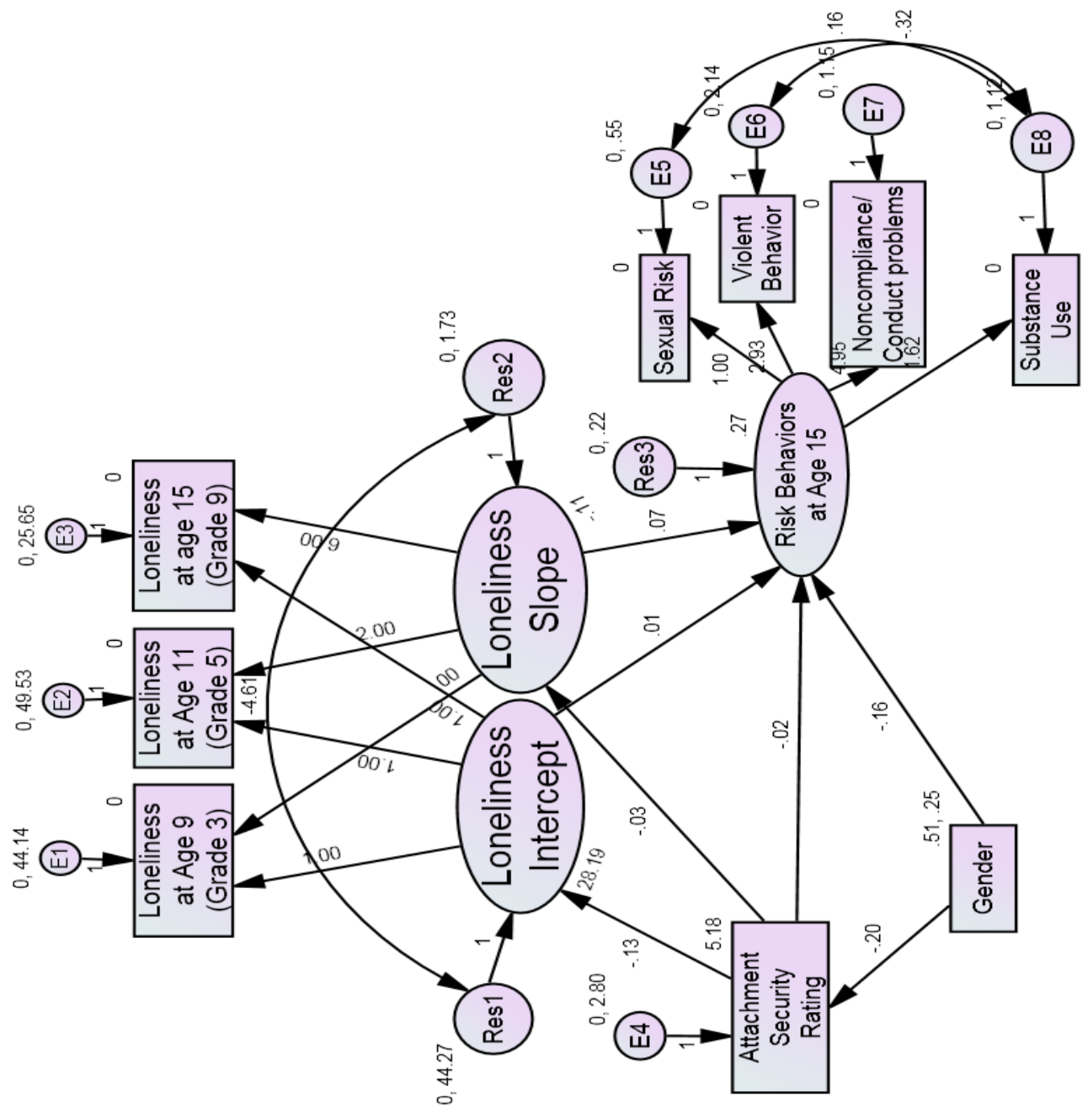

Figure 13: Full model with gender as a covariate and factor loadings, variances, and error covariances 


\title{
CURRICULUM VITAE
}

\author{
Sze Sze Tong \\ 10321 Matador Dr. \\ McKinney, TX 75070 \\ Phone: (214) 856-5512 \\ E-mail: szesze_tong@hotmail.com
}

\section{EDUCATION:}

$\begin{array}{ll}\underline{\text { Current }} & \begin{array}{l}\text { University of Louisville - Louisville, KY } \\ \text { PhD in Counseling Psychology } \\ \text { Anticipated graduation: May 2013 }\end{array} \\ \underline{\text { December 2002 }} & \begin{array}{l}\text { Texas Woman's University - Denton, TX } \\ \text { Master of Arts in Counseling Psychology }\end{array} \\ \underline{\text { August 1997 }} & \begin{array}{l}\text { University of Texas at Austin - Austin, TX } \\ \text { Bachelor of Arts in Psychology }\end{array} \\ & \begin{array}{l}\text { Baylor University - Waco, TX } \\ \text { Bachelor of Arts in Biology and Asian Studies }\end{array}\end{array}$

\section{GRADUATE PSYCHOLOGY COURSES:}

\author{
Clinical Courses \\ Theory and Practice of Counseling and Psychotherapy \\ Theory and Practice of Family Psychology \\ Psychological Appraisal \\ Clinical Therapeutic Group Processes \\ Psychotherapy for Children \\ Seminar in Professional Issues (Vocational Assessment) \\ Ethics in Psychology \\ Diagnosis and Treatment of Sexual Dysfunction \\ Advanced Psychopathology \\ Lifespan Human Development \\ Psychology of Women \\ Advanced Psychological Statistics \\ Psychopathology of Children and Adolescents \\ Cross Cultural Psychology \\ Research Techniques \\ Development and Family Theory \\ Parent Education \\ Evaluation \& Measurement in Education \\ Consultation \\ Supervised Research in Counseling Psychology \\ Biological Bases of Behavior
}


Learning Systems - Theory \& Practice

Applied Multiple Regression

Survey Research and Attitude Measurement

Advanced Social Psychology

Counselor Supervision

Psychology of Career Development

Prevention of Mental Disorders

Multivariate Statistics

Qualitative Field Research Methods

Grief and Medical Counseling in Art Therapy

Applied Behavior Analysis

Structural Equation Modeling

Assessment Courses

Intellectual Assessment/Prepracticum in Applied Psychology

Vocational Assessment

Preschool Assessment

Personality Assessment

Professional Paper

Trauma, acculturation, and parent-child attachment relationships in Southeast Asian

Americans: Literature integration and implications

Dissertation

The relationship between early attachment and adolescent risky behaviors with changes

in loneliness in a mediating role

\section{SCHOLARSHIPS/AWARDS:}

August 2009 to

May 2010

August 2007 to

May 2008
GRADUATE SERVICE ASSISTANTSHIP

University of Louisville

Resources for Educational Achievement (REACH), Gen 105 Instructor, Undergraduate Affairs

- Worked for 20 hours per week

- Responsible for teaching 2 sections of Gen 105 - supplemental reading skills class for entering freshman

- Responsible for posting assignments on Blackboard, grading assignments, and mid-term meetings with students

- Responsible for teaching GRE prep seminars

- Responsible for curriculum development for Gen 105 and GRE prep seminars

- Responsible for individual and small group tutoring for undergraduates

GRADUATE SERVICE ASSISTANTSHIP

University of Louisville

Resources for Educational Achievement (REACH), Learning Resource

Center, Undergraduate Affairs

- Worked for 20 hours per week

- Responsible for individual and small group tutoring for undergraduates

- Responsible for development and teaching of GRE prep seminars

- Responsible for teaching student success seminars for topics related to promoting effective study skills

- Management and scheduling of work study student workers

- Management of daily activities of the Learning Resource Center 
Auqust 2005 to

May 2006

CLINICAL EXPERIENCE:

July 19, 2010 to July 19, 2011

August 2009 to May 2010

May 2009 to

August 2009

May 2008 to

May 2009

September 2007 to May 2008
PROFESSIONAL YEAR TEACHER SCHOLARSHIP

University of Louisville

College of Education and Human Development Honors and

Scholarship Committee
PREDOCTORAL PSYCHOLOGY INTERN

Veterans Administration North Texas Health Care System, Dallas, TX

- Worked 40 hours per week

- Responsible for providing individual therapy services for veterans

o Training in Evidenced Based Psychotherapy (Prolonged Exposure, Cognitive Processing Therapy, Cognitive Behavioral Therapy, and Acceptance and Commitment Therapy)

- Co-facilitator of group therapy offered through various clinics

o Psychoeducation groups for substance abuse, general mental health issues, and trauma survivors

o Process groups for trauma survivors and substance abuse

- Responsible for electronic documentation for services provided

- Responsible for 4 group presentations

- Co-author for group research project to be presented as a poster

DOCTORAL PRACTICUM THERAPIST

Bellarmine University Counseling Center, Louisville, KY

- Worked 20 hours per week

- Responsible for providing individual therapy services for college students

- Co-facilitator of Coping Skills Group

- Responsible for outreach services provided through the counseling center

DOCTORAL PRACTICUM THERAPIST

Kentucky State Reformatory, Correctional Psychiatric Treatment Unit LaGrange, KY

- Worked 8 hours per week

- Responsible for administering assessment and providing interpretation of results for treatment planning

- Interaction with inmates with various psychological disorders

DOCTORAL PRACTICUM THERAPIST

Archdiocese of Louisville Family Counseling Center, Louisville, KY

- Worked 10-12 hours per week

- $\quad$ Responsible for providing individual, family, and couples counseling services for adults, adolescents, and children

DOCTORAL PRACTICUM THERAPIST

Weisskopf Child Evaluation Center, Louisville, KY

- Worked 20 hours per week

- Responsible for providing psychological assessment of children

- Responsible for treatment of children with autism spectrum disorders 
September 2006 to

December 2006

August 2001 to

May 2002

August 2000 to

June 2001
- Responsible for participating in case conferencing and program planning

\section{DOCTORAL PRACTICUM THERAPIST}

Veterans Administration Dupont Mental Health Clinic, Louisville, KY

- Worked 15-20 hours per week

- Responsible for providing psychological and neuropsychological assessment for veterans

MASTER'S PRACTICUM COUNSELOR

Denton County Mental Health and Mental Retardation, Denton, TX

- Worked 30 hours per week

- Provide individual and family counseling for adults, children and adolescents with an Axis I diagnosis

MASTER'S PRACTICUM COUNSELOR

Collin County Children's Advocacy Center, Plano, TX

- Worked 20-25 hours per week

- Provide play, individual, and family counseling for abused/neglected children, adolescents, and their families

- Conduct intake interviews

- Co-facilitate teen art therapy group for sexual abuse victims

\section{RELEVANT EXPERIENCE:}

Auqust 2011 to

Current

April 2003 to

July 2004

June 1998 to

May 1999

\section{RESEARCH ASSISTANT I}

University of Texas at Dallas, Richardson, TX

- Worked 24-30 hours per week

- Testing of participants using established protocol

- Recruitment of participants from community

- Data entry

- Administrative duties including supply orders, preparing testing protocol packets, general organization duties

\section{SOCIAL SERVICES SPECIALIST}

Medical Center of Louisiana at New Orleans, New Orleans, LA

- Worked 40 hours per week

- Provide supportive services to patients who have complaints/grievances regarding the medical services of a large, multidimensional health care facility

- Act as an intermediary between hospital staff, hospital services, and patients and/or family members

- Conduct rounds through various inpatient units (psychiatry, medical detox, intensive care units) throughout the health care facility, ensuring that patient care is adequate on behalf of the patient

\section{ADOLESCENT COUNSELOR}

YMCA CASA Shelter, Dallas, TX

- Worked 29 hours per week

- Supervise adolescents between the ages of 10 to 17 years

- Crisis calls: setting up intakes, provide referrals to other agencies

- Documentation of activities and/or incidents involving in-house adolescents

- Dispensing medication 
February 1997 to

May 1997
CRISIS SHELTER VOLUNTEER

Center for Battered Women, Austin, TX

- Volunteered for 2 days a week

- Completed 40+ hour volunteer training program

- Worked with children of various age groups, ranging from infants to 9 years of age

- Worked in small groups for the children from 3 to 9 years old, divided according to age on a specific task, usually involving drawing a picture related to a given topic; these groups were usually followed with a brief discussion with the child about his or her drawing

- $\quad$ Monitored small groups of infants and toddlers (up to the age of 2 to 3 years old) in the nursery

- Group meetings with the children's program supervisors, before and after the groups with the children

\section{PRESENTATIONS}

- $\quad$ Ardasheva, Y., Tong, S., \& Tretter, T. R. (2012, April). Measuring Language Learning Motivational Orientations among Precollege English Language Learners: An Instrument Validation Study. Paper presented at the American Educational Research Association (AERA) Annual Meeting, Vancouver, BC, Canada.

- Suris, A., Phillips, C. C., Raymond, N. C., Shook, C. B., Smart-Perille, H. R., Tong, S., and Wilson, J. (2011). The effects of social support on post-traumatic stress disorder symptoms in veterans with a history of sexual trauma. Poster presented at Research Week for the VA North Texas Health Care System.

- Valentine, J. C., Burnett, J. B., Nichols, A., Gonshak, A. B., Tong, S., Whitten, M., and Pickering, M. (2009). Validity characteristics of randomized and quasi-experiments in studies of school-based prevention programs. Poster presented at the annual meeting of the American Psychological Association, Toronto.

\section{MANUSCRIPTS IN PROGRESS}

- Valentine, J. C., Burnett, J. B., Nichols, A., Gonshak, A. B., Tong, S., Whitten, M., and Pickering, M. (2009). Validity characteristics of randomized and quasi-experiments in studies of school-based prevention programs.

\section{PUBLICATIONS}

- $\quad$ Ardasheva, Y., Tong, S., and Tretter, T. R. (2012). Validating the English Language Learner Motivation Scale (ELLMS): Pre-College to Measure Language Learning Motivational Orientations Among Young ELLs. Learning and Individual Differences, 22, 473-483.

\section{CERTIFICATION}

- College Reading and Learning Association (CRLA) Level II (Advanced) Tutor Awarded on April 22, 2008

\section{PROFESSIONAL AFFILIATIONS:}

- American Psychological Association for Graduate Students

- Texas Psychological Association for Graduate Students

\section{COMPUTER SKILLS:}

- Windows 95/98/2000/XP/Vista/7 
- MS Word

- MS Excel

- MS PowerPoint

- MS Publisher

- SPSS

- AMOS

\section{REFERENCES:}

Cindy de Frias, $\mathrm{PhD}$

Assistant Professor

School of Behavioral and Brain Sciences

University of Texas at Dallas

800 W. Campbell Rd.

Richardson, TX 75080

972-883-4108

cdefrias@utdallas.edu

Jody Rubenstein, $\mathrm{PhD}$

Clinical Psychologist/Neuropsychologist

Predoctoral Training Director, VA North Texas Health Care System

Postdoctoral Fellowship Training Director, VA North Texas Health Care System

Medical Psychology Team, Mental Health Service, VA North Texas Health Care System

Spinal Cord Injury Unit

Assistant Professor, Department of Psychiatry, University of Texas Southwestern Medical Center

Dallas, TX

214-857-0857

Jody.Rubenstein@va.gov

Teresa J. Hale, PhD

Clinical Psychologist

Medical/Surgical Unit

Medical Psychology Team, Mental Health Service, VA North Texas Health Care System

Dallas, TX

214-857-530

Teresa.Hale@va.gov

Mark Woolwine

Coordinator, Gen 105

Strickler Hall, Room 329

REACH, Department of Undergraduate Affairs

Office of the Provost

University of Louisville

Louisville, KY 40292

502-852-2320

mawool01@louisville.edu

Julie Webb Hohmann

Coordinator , Learning Resource Center (LRC)

Strickler Hall, Room 107A

REACH, Department of Undergraduate Affairs

Office of the Provost

University of Louisville

Louisville, KY 40292

502-852-7516 
jmwebb02@louisville.edu

Kathleen Kirby, Ed. D., Ph. D., Licensed Psychologist

Louisville, KY 40292

502-295-5420

Patrick Hardesty, Ph.D.

Associate Professor of Counseling Psychology

Department of Counseling Psychology

College of Education and Human Development

University of Louisville

Louisville, KY 40292

502-852-6887

Patrick.hardesty@louisville.edu

Eva Markham, Ed.D

Associate Professor

Department of Pediatrics

Weisskopf Child Evaluation Center

University of Louisville

Louisville, KY 40292

502-852-7528

Emark01@louisville.edu

Jeanne Bennett, PsyD.

Louisville VAMC

800 Zorn Ave.

Louisville, KY 40206

502-287-6153

Jeanne.Bennett@va.gov

Sally D. Stabb, Ph.D.

Associate Professor of Psychology

Director of PhD Program in Counseling Psychology

Department of Psychology \& Philosophy

College of Arts and Sciences

Texas Woman's University

P.O. Box 425470

Denton, TX 76204-5470

(940) 898-2149

Further references available upon request. 